\title{
Factors Affecting Orthodontic Treatment Outcomes in Southern West Virginia
}

\author{
Tyler Crowe
}

Follow this and additional works at: https://researchrepository.wvu.edu/etd

\section{Recommended Citation}

Crowe, Tyler, "Factors Affecting Orthodontic Treatment Outcomes in Southern West Virginia" (2018). Graduate Theses, Dissertations, and Problem Reports. 5413.

https://researchrepository.wvu.edu/etd/5413

This Thesis is protected by copyright and/or related rights. It has been brought to you by the The Research Repository @ WVU with permission from the rights-holder(s). You are free to use this Thesis in any way that is permitted by the copyright and related rights legislation that applies to your use. For other uses you must obtain permission from the rights-holder(s) directly, unless additional rights are indicated by a Creative Commons license in the record and/ or on the work itself. This Thesis has been accepted for inclusion in WVU Graduate Theses, Dissertations, and Problem Reports collection by an authorized administrator of The Research Repository @ WVU. For more information, please contact researchrepository@mail.wvu.edu. 


\title{
FACTORS AFFECTING ORTHODONTIC TREATMENT OUTCOMES IN SOUTHERN WEST VIRGINIA
}

\author{
Tyler Crowe, D.D.S.
}

\author{
Thesis submitted \\ to the School of Dentistry \\ at West Virginia University \\ in partial fulfillment of the requirements for the degree of
}

Master of Science in

Orthodontics

\author{
Peter Ngan, D.M.D. \\ Chris A. Martin, D.D.S. \\ Daniel W. McNeil, Ph.D. \\ Susan K. Morgan, D.D.S. \\ Department of Orthodontics \\ Morgantown, West Virginia \\ 2018
}

Keywords: patient compliance, treatment outcomes, oral hygiene, Medicaid Copyright 2018 Tyler Crowe, D.D.S. 


\section{ABSTRACT \\ FACTORS AFFECTING ORTHODONTIC TREATMENT OUTCOMES IN SOUTHERN WEST VIRGINIA \\ Tyler Crowe, D.D.S.}

Background and Objectives: It is well known that a multitude of factors have an influence in the field of orthodontics from both the provider and the patient perspective. Patient compliance and oral hygiene both play a pivotal role in keeping an orthodontic treatment plan on track to become a successful treatment outcome. One question that is not completely understood, however, is how does each of these factors specifically affect the treatment outcome? Furthermore, patients come from different backgrounds and socioeconomic situations. Access to care and appointment keeping behavior are thought to vary between private pay, insurance subsidy, and Medicaid/CHIP patients. Therefore, it is imperative to look at these factors and identify to what extent, if any, they affect the overall success of the treatment outcome.

Experimental Design and Methods: A sample of 91 patients aged 8-20 from the private practice of Dr. Daniel Foley was used for this study. IRB-approval was obtained. Pre- and post-treatment photographs were taken according to the record specifications set by the American Board of Orthodontists (ABO). Pretreatment records were scored using the ABO Discrepancy Index form. A retrospective chart analysis was completed to obtain payment type, distance traveled, oral hygiene, broken appointments, and treatment length. Post-treatment scans were taken using an iTero Element intraoral scanner and subsequent models were printed by an orthodontic lab. Post-treatment models were graded using the ABO Model Grading System to determine the success of the treatment outcome. The data was examined using a combination of one-way ANOVA, Chi-square, Wilcoxon Rank Sum, Kruskal Wallis, and logistic regression tests.

Results: There is no significant difference between any payment type and treatment outcome, however, private pay patients showed a significantly higher average oral hygiene scores than Medicaid/CHIP patients $(\mathrm{p}<0.05)$. Private pay patients traveled a significantly longer distance to obtain orthodontic treatment than Medicaid/CHIP patients $(\mathrm{p}<0.05)$. The actual length of active orthodontic treatment for Medicaid/CHIP was significantly longer than either private pay or insurance patients $(p<0.05)$.

Conversely, no significant difference was found in the appointment keeping behavior between payment types.

Conclusions: There is no difference in the ability of private pay, insurance, or Medicaid/CHIP patients to attain a successful treatment outcome, nor is there a difference in their appointment keeping behavior. On average, private pay patients have significantly better oral hygiene and travel a significantly longer distance for orthodontic treatment than Medicaid/CHIP patients. Medicaid/CHIP patients are in active orthodontic treatment significantly longer than private pay and insurance patients. More research needs to be conducted to determine the specific impact of oral hygiene on the ability to obtain a successful treatment outcome. Also, it would be beneficial to replicate this study on a larger sample size to eliminate any limitations due to a small number of subjects. 


\section{DEDICATIONS}

To my wife, Courtney. Thank you for your unwavering love and support through my entire educational journey. I am so grateful for your willingness to allow me to chase my dreams and for encouraging me each step of the way. I have been blessed with such a selfless wife. I love you. You are truly the unsung hero of this story.

To our daughter, Harper. You are such a joy in our lives and a gift from God. Long before I knew your name, you were the driving force behind what I wake up to do each day. I hope to make you the most proud.

To my parents, Steve and Cindy. I could not have accomplished so much in my life if it were not for the foundation you set me on. Your support and sacrifice for my success is immeasurable. Thank you for inspiring me and giving me the drive to persevere. I love both of you beyond words.

To my sister, Stephanie. You are a great example to me in so many ways and have been such a kind source of encouragement during this season of my life. I am forever grateful to not only have you as a sister, but a friend.

To my family and friends, your care and prayers have meant the world to me. I hope to pay it forward and be the support system for others that you have been for me. Thank you. 


\section{ACKNOWLEDGEMENTS}

I would like to take the opportunity to thank the following individuals who have played pivotal roles in my specialty training:

Dr. Peter Ngan, for giving me the opportunity to pursue this career. You are so dedicated to this program and to each of your residents. Thank you for devoting so much of your time for the betterment of others. It is noticed and appreciated.

Dr. Chris Martin, for your guidance in clinic and on my thesis. Thank you for allowing me to make mistakes so that I may learn. Your patience and commitment are so impressive, and I'm grateful for the positive impact you've had on me.

Dr. Daniel McNeil, for the time and effort given towards my thesis. Thank you for carving time out of your schedule to guide and support my endeavors.

Dr. Susan Morgan, for being a continual and constant presence during dental school and my orthodontic education. Your wisdom is not to be overlooked, and I will take many of your words with me as I move forward in my career and life. Thank you.

Dr. Daniel Foley, for graciously allowing access to your patient database. Thank you for your support of this project and for your dedication to those in the profession.

Ms. Jun Xiang, for your tireless effort in completing the statistical analyses. You have gone above and beyond, and it is much appreciated.

Dr. MacKenzie Boyles-Horan and Dr. Amer Shammaa, my classmates and friends, for so many wonderful memories. God knew what He was doing when He put us together, as we balance one another out so well. I look forward to watching both of you succeed and only wish it would not have to be from afar.

Ghaddy, Carl, Niki, Sarah, Mohamad, and Joanna, my fellow residents, for a fun learning environment and support. I know each of you will accomplish wonderful achievements in your careers and will greatly miss traveling alongside you. Thank you. 


\section{TABLE OF CONTENTS}

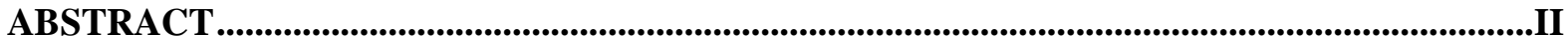

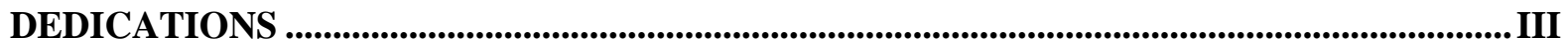

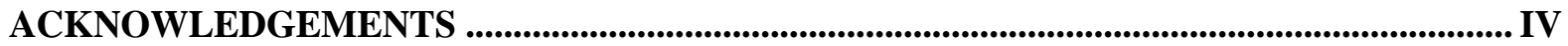

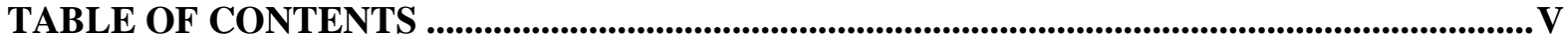

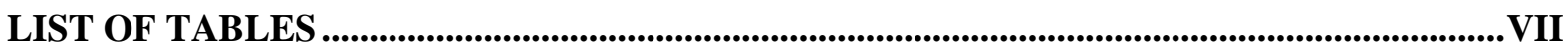

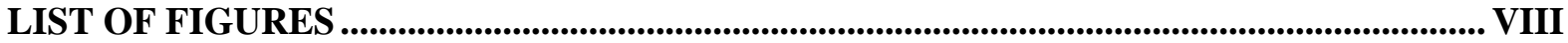

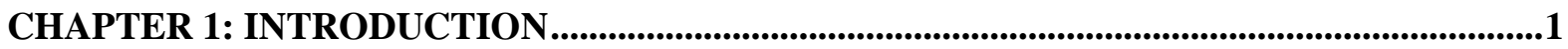

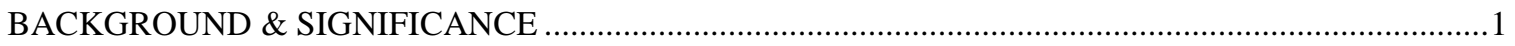

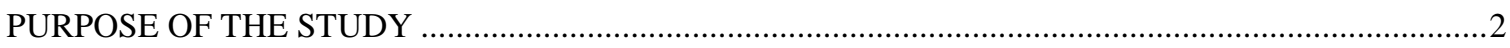

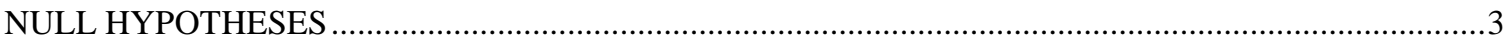

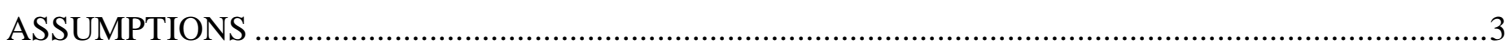

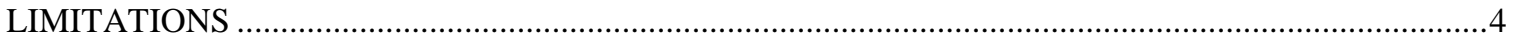

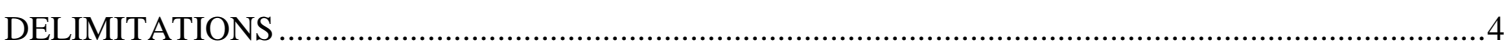

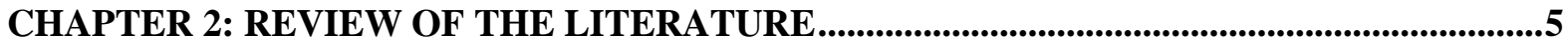

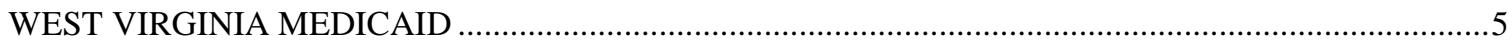

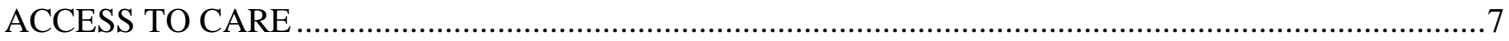

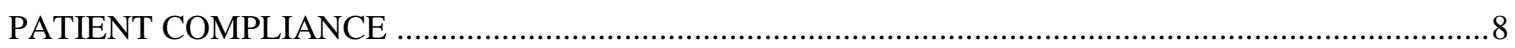

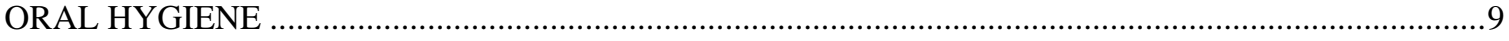

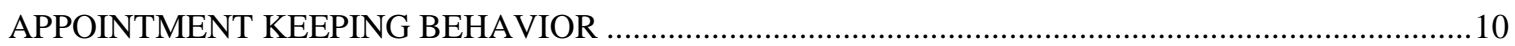

CHAPTER 3: RESEARCH DESIGN \& METHODOLOGY .........................................................12

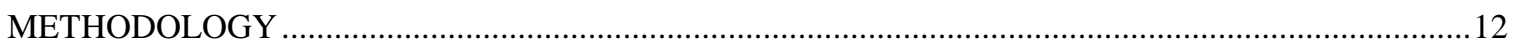

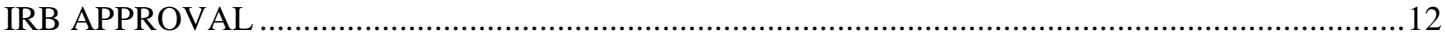

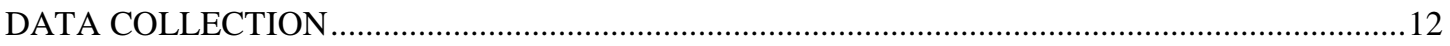

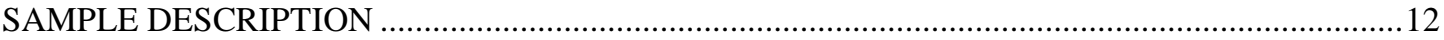

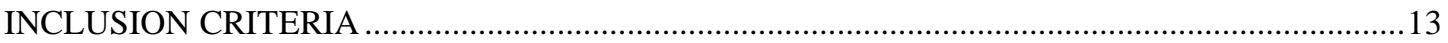

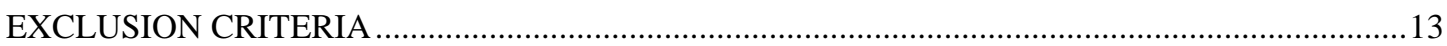

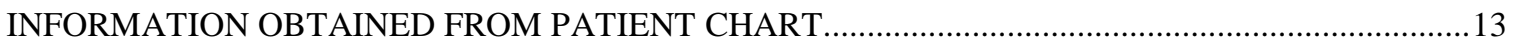

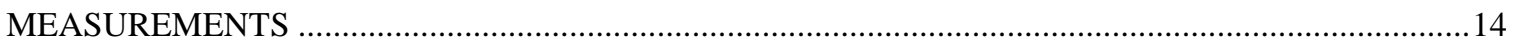




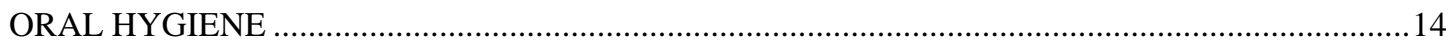

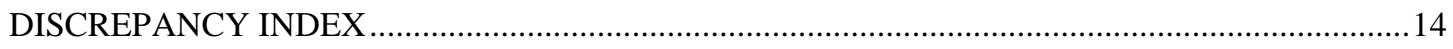

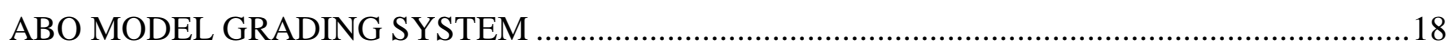

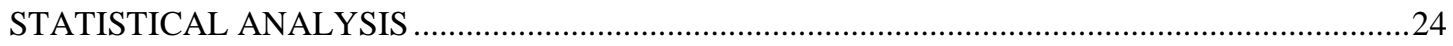

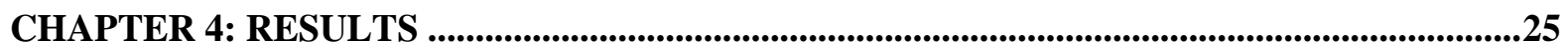

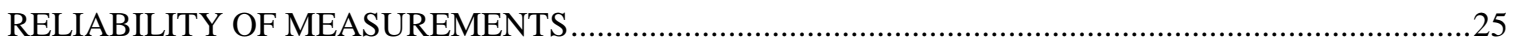

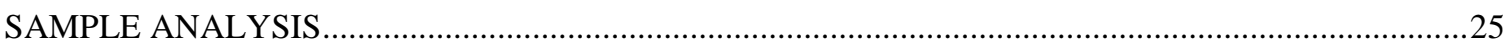

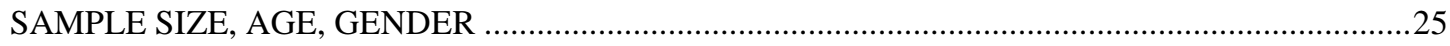

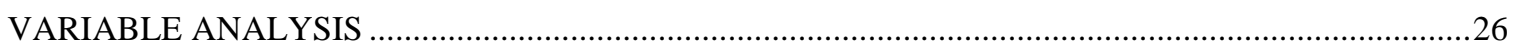

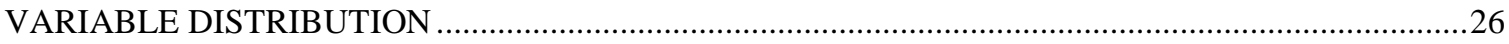

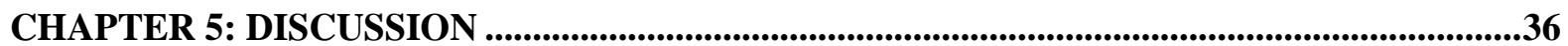

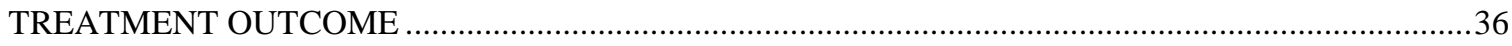

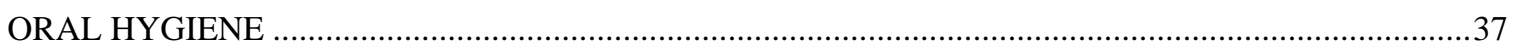

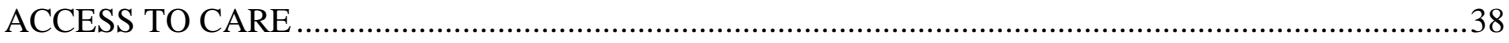

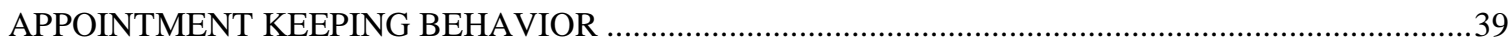

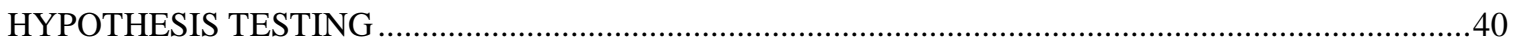

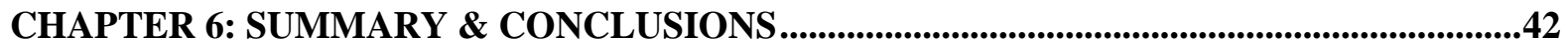

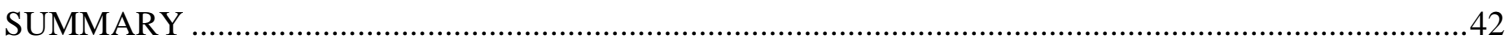

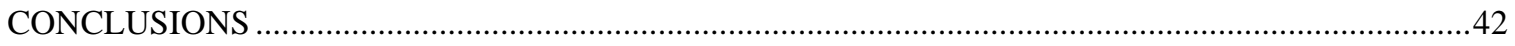

CHAPTER 7: RECOMMENDATIONS FOR FUTURE REASEARCH ....................................44

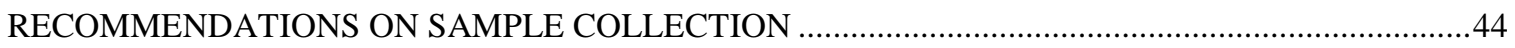

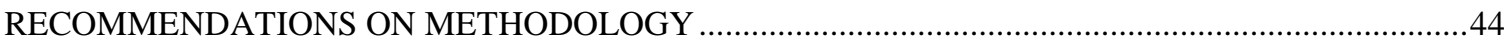

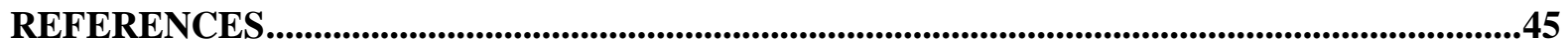

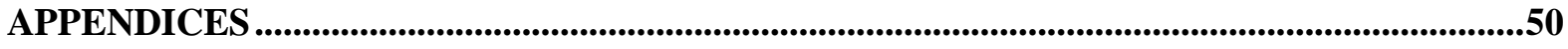

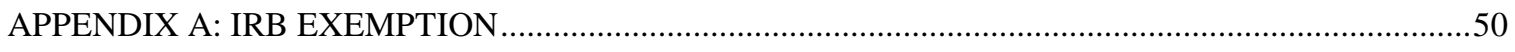

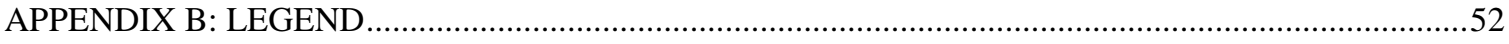

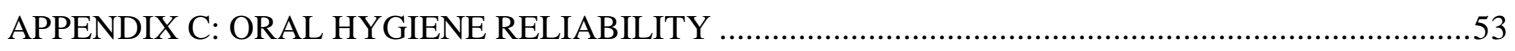

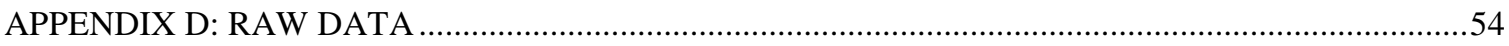




\section{LIST OF TABLES}

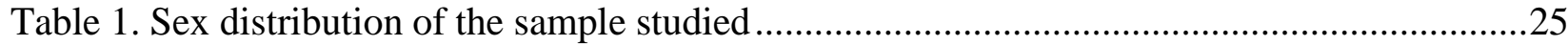

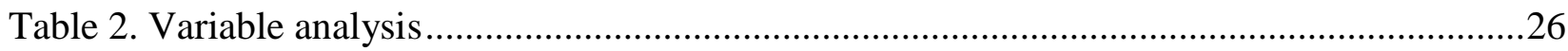

Table 3. Outcome distribution of the sample studied ......................................................2

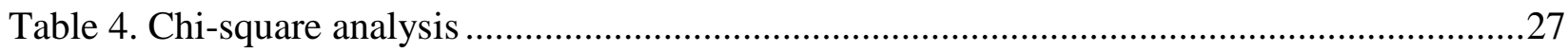

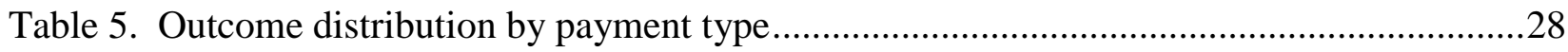

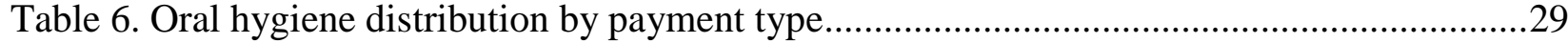

Table 7. Tukey's Studentized Range Test for oral hygiene......................................................29

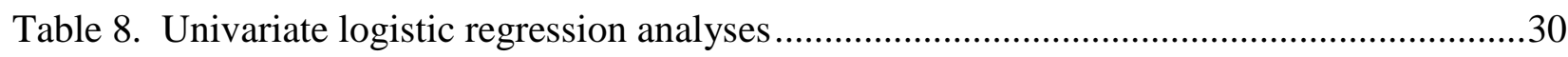

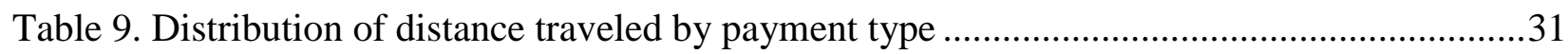

Table 10. Tukey's Studentized Range Test for distance traveled.............................................32

Table 11. Pearson correlation test for association between variables......................................32

Table 12. Distribution of treatment length by payment type .................................................33

Table 13. Comparison of treatment length between payment types .............................................33

Table 14. Tukey's Studentized Range Test for treatment length..............................................33

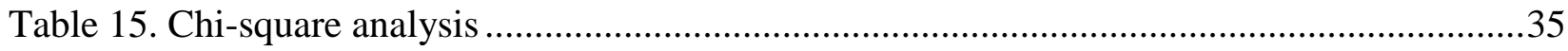




\section{LIST OF FIGURES}

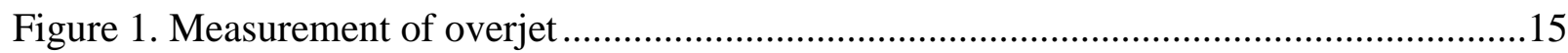

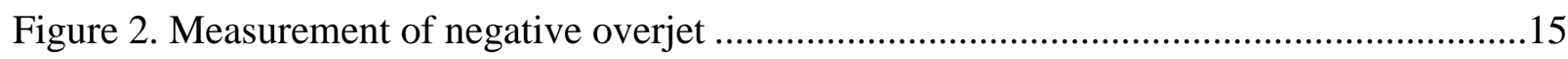

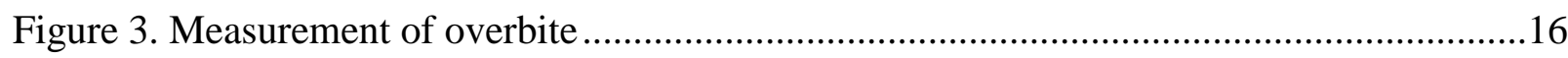

Figure 4. Measurement of anterior edge-to-edge or open bite................................................16

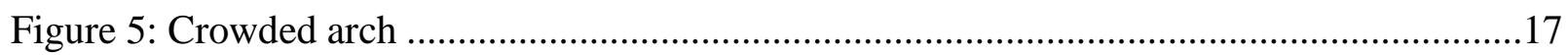

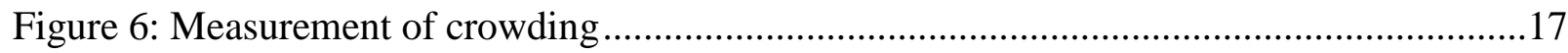

Figure 7. Measurement of posterior crossbite......................................................................18

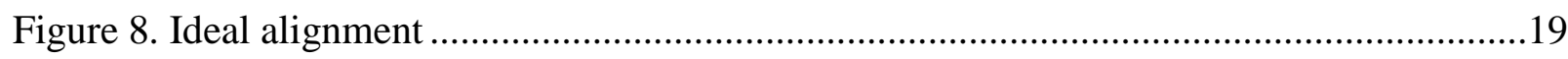

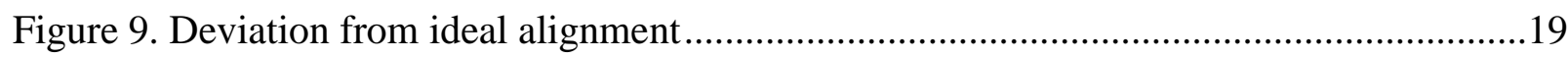

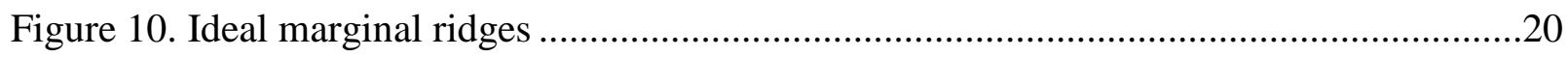

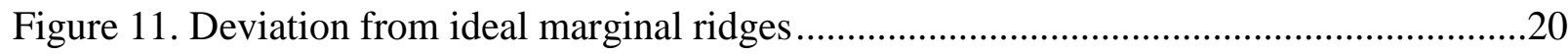

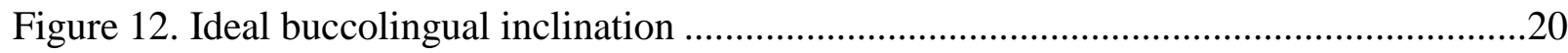

Figure 13. Deviation from ideal buccolingual inclination .......................................................20

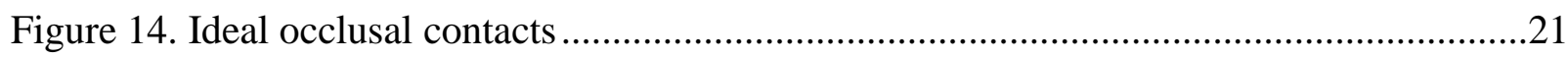

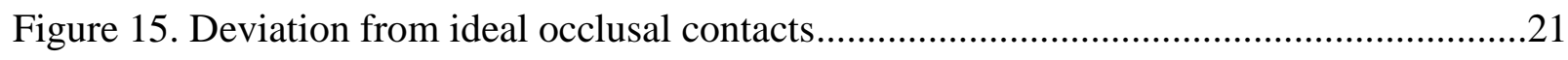

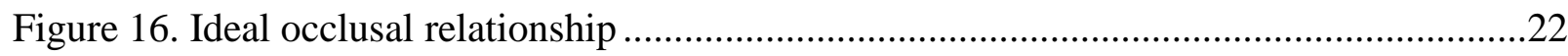

Figure 17. Deviation from ideal occlusal relationship..............................................................22

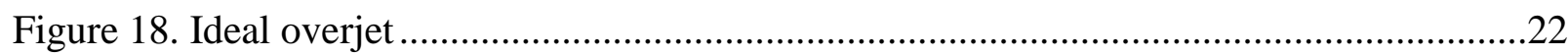

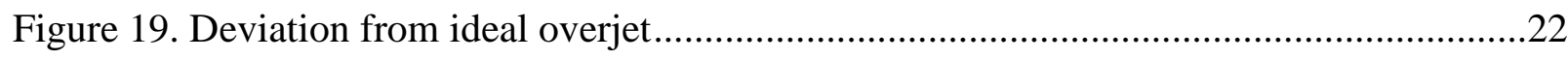

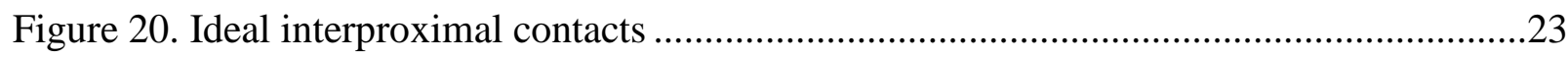

Figure 21. Deviation from ideal interproximal contacts ..........................................................23

Figure 22. Number of subjects by payment type ……….......................................................26

Figure 23. Outcome distribution by payment type ……….......................................................27

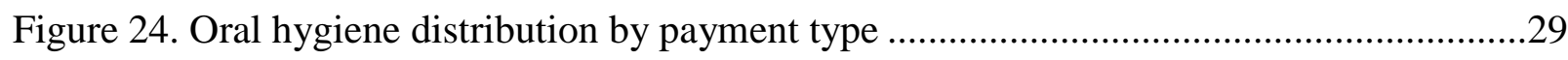

Figure 25. Distribution of distance traveled by payment type ……............................................ 31

Figure 26. Difference in actual treatment length between payment types...................................34 


\section{CHAPTER 1: INTRODUCTION}

\section{BACKGROUND \& SIGNIFICANCE}

One out of every three children in the United States is covered by Medicaid and CHIP, with over 35 million children covered as of June $2016 .{ }^{1}$ Within this population are children who meet the eligibility standard and qualify for Medicaid-covered orthodontic treatment. ${ }^{1}$ However, there is apprehension among providers to accept Medicaid patients within their practices and a resultantly low number of orthodontic practices providing care to Medicaid patients. ${ }^{2}$ A study from the University of North Carolina found that perceptions of Medicaid patients seem to have a negative effect on provider participation. ${ }^{3}$ This reluctance stems from the perception that Medicaid patients are non-compliant with treatment instructions, oral hygiene, and have frequent broken appointments, among other reasons. ${ }^{3}$ Research has been conducted to analyze the validity of these claims. One study looked at the appointment keeping behavior of Medicaid vs. nonMedicaid orthodontic patients and determined there to be a significant difference in the number of failed appointments between the two groups. ${ }^{4}$ The Medicaid patients had a failure rate of $15.4 \%$, whereas the non-Medicaid patients failed $8.3 \%$ of appointments. ${ }^{4}$

An ongoing battle in the field of orthodontics is patient motivation and adherence to treatment instructions. Patient compliance is a very important factor in the overall orthodontic treatment outcome. ${ }^{5}$ Studies have found that non-compliance in oral hygiene and broken appointments result in the occurrence of hyperplastic gingivitis, progression towards carious lesions, and periodontal problems. ${ }^{6-8}$ If a patient properly administers basic practices of oral hygiene, such as brushing and flossing during treatment, plaque accumulation and periodontal disease will not be induced. $^{9}$ 
In general, the experienced orthodontist can provide an estimated length of treatment to the patient prior to the induction of treatment. Fink and Smith evaluated variables for connections to treatment length and found a significant association between treatment time and number of broken appointments. ${ }^{10}$ Some other variables that can significantly increase the amount of time a patient is in treatment include poor oral hygiene, bracket breakages, and poor elastic wear. ${ }^{11}$ Missing orthodontic appointments and varying degrees of noncompliance decrease the likelihood that treatment will be successfully completed. Several studies have analyzed noncompliance in both oral hygiene and appointment keeping behaviors of Medicaid and non-Medicaid patients. However, there is a lack of evidence showing that these factors have a detrimental effect on the orthodontic treatment outcome. A study of this magnitude could affect the perception of Medicaid patients within the orthodontic community and change the access to care for these individuals.

\section{PURPOSE OF THE STUDY}

1. To determine what factors have an effect on the overall success of an orthodontic treatment outcome, and the degree to which each has an effect.

2. To improve our understanding of how compliance in various areas of treatment can affect the ability to obtain a successful treatment outcome and what practitioners can implement in their practices to produce successful treatment outcomes. 


\section{NULL HYPOTHESES}

1. There is no significant difference in successful treatment outcome among various payment types.

2. There is no significant difference in oral hygiene ratings among various payment types.

3. There is no significant relation between oral hygiene ratings and successful treatment outcome.

4. There is no significant difference in one-way distance travelled among various payment types.

5. There is no significant relation between oral hygiene ratings and actual length of orthodontic treatment.

6. There is no significant difference in actual treatment length between various payment types.

7. There is no significant difference in broken appointments between various payment types.

\section{ASSUMPTIONS}

1. The digital model scans are of sufficient quality with no patient movement or operator error contributing to the introduction of artifacts.

2. The operator in this study has a working knowledge of computer technology and grading systems 
3. Landmarks can be accurately identified according to the ABO Discrepancy Index form and Grading System.

4. Pre-treatment scans on subjects were taken prior to initiation of any type of orthodontic or orthopedic treatment.

\section{LIMITATIONS}

1. There will be gender, weight, ethnicity, medical history, and socioeconomic status differences among the subjects.

2. Scans may contain artifacts depending on patient movement, operator error, and machine calibration.

3. The study is limited to the subjects in the database of pre- and post-treatment scans in the private practice of the study consultant.

4. The number of patients will be limited to those that have an ABO Discrepancy Index form completed.

5. Oral hygiene grading is completed by multiple assistants.

\section{DELIMITATIONS}

1. Ages of the patients comprising the sample will be adolescent and young adults, under the age of 21 .

2. All assistants collecting oral hygiene data will have complete a form, which assesses their reliability.

3. One researcher will make all measurements on pre-treatment photos and posttreatment models. This researcher will have reliability in grading assessed by one board certified orthodontist. 


\section{CHAPTER 2: REVIEW OF THE LITERATURE}

\section{WEST VIRGINIA MEDICAID}

Medicaid is defined as "an entitlement program financed by state and federal governments and is administered by the state." In West Virginia, this program is administered by the Bureau for Medical Services within Department of Health and Human Resources. ${ }^{12}$ According to the Kaiser Family Foundation, Medicaid and the Children's Health Insurance Program (CHIP) provide health and long-term care coverage to $29 \%$ of people in West Virginia. ${ }^{13}$ There was an increase of 218,634 people covered by Medicaid/CHIP from fall of 2013 to June $2016 .{ }^{14}$ As of June 2016, 573,178 people were covered by Medicaid in West Virginia. There was a $56 \%$ reduction in the uninsured rate as a result of the Medicaid expansion from 2013 to $2015 .^{14}$

Title XIX of the Social Security Act of 1965 was signed by President Lyndon Johnson in an effort to provide medical care coverage to those in need. Listed within this Act were services that could be covered, including orthodontics. ${ }^{15}$ A conference was held prior to the American Association of Orthodontists (AAO) annual session in April 1966 with the goal of defining the criteria that recognizes a handicapping occlusion. A malocclusion must have "a definite handicap to the health and function of the dentition" and "deleterious effect on facial esthetics" to be accepted and paid for by public funds. ${ }^{15}$ In 1985 , the decision to use an index or classification system to define orthodontic treatment need by the AAO was withdrawn. ${ }^{16}$ The AAO currently defines medically necessary orthodontic care as "the treatment of a malocclusion (including craniofacial abnormalities/anomalies) that compromises the patient's physical, emotional, or dental health."17 
The Bureau for Medical Services Provider Manual explains that orthodontic services are covered in the case of medical necessity for children up to 21 years of age. ${ }^{18}$ This approval requires prior authorization on the basis of a treatment plan of care including findings, diagnosis, prognosis, length of treatment, phases of treatment, and specific codes requested, as well as radiographic and photographic information. One comprehensive orthodontic treatment is covered per covered entity in their lifetime, with the exception of a case involving orthognathic surgery. Treatments involving orthognathic surgery will be covered even if that patient exceeds the 21 years of age restriction and it was previously noted in the original treatment plan. ${ }^{18,19}$ In order for comprehensive treatment to be approved in West Virginia at least one of the following criteria must be met: overjet in excess of $7 \mathrm{~mm}$, severe malocclusion associated with dento-facial deformity, true anterior open bite, full cusp classification from normal (Class II or Class III), palatal impingement of lower incisors into the palatal tissue causing tissue trauma, cleft palate, congenital or developmental disorders, anterior crossbite ( 2 or more teeth and in cases where gingival stripping from the crossbite is demonstrated and not correctable by limited orthodontic treatment), unilateral posterior crossbite with deviation or bilateral posterior crossbite involving multiple teeth including at least one molar, true posterior open bite (not involving partially erupted teeth or one or two teeth slightly out of occlusion and not correctable by habit therapy), impacted teeth (excluding third molars) including cuspids and laterals only. ${ }^{19}$

The federal government has established guidelines for services that states can include in their Medicaid health plans which allow for customization on a state-by-state basis. Therefore, each state's allocation of resources can be similar, but different. ${ }^{15}$ In West Virginia, no index rating classification or coding system is used to determine case complexity, unlike other states that may use the Salzmann index, handicapping labiolingual deviation (HLD) index, or other classification 
system. A trend is apparent in states that utilize an index system with receiving a higher reimbursement rate than those states that do not. West Virginia has one of the lowest fee reimbursement rates with an average reimbursement of $\$ 2630 .{ }^{20}$

\section{ACCESS TO CARE}

Access to care for children in low socioeconomic groups is a challenge due to a lack of participation by providers. ${ }^{2}$ Low reimbursement rates have been reported by providers as a major factor in choosing to not participate with Medicaid. ${ }^{2}$ This, along with factors such as excessive paperwork, broken appointments, and non-compliance has resulted in poor provider participation. $^{3,21}$ Additionally, providers who choose to participate with Medicaid may have to increase their staff to meet the demands of paperwork and record submission, which results in an increase in overhead. ${ }^{22}$ Some providers have excluded participation with Medicaid because the reimbursement did not come close to meeting the usual and customary fees, and the cost of providing these services have increased. ${ }^{23}$ Over the span of time from 2006 to 2015 , reimbursement rates for orthodontic services generally decreased by a range of $115-283 \% .^{22}$ As a result of these negatively-perceived changes, a disproportion exists in the access to orthodontic care for private versus publically insured youth in the United States. ${ }^{24}$

In some states, the poor distribution of providers is emphasized by the fact that only a few orthodontists provide over $80 \%$ of the orthodontic treatment to patients covered by Medicaid. ${ }^{25}$ Research indicates that there are no obvious demographic or practice pattern differences between providers who accept Medicaid and providers who do not accept Medicaid. ${ }^{3}$ Regardless, there are geographic barriers which limit access to specialty care such as orthodontics, and as a result, many patients are required to travel long distances to be treated. ${ }^{22}$ These barriers to care prevent 
patients that fall into a low socioeconomic status from receiving orthodontic treatment and experiencing the psychosocial and oral health advantages from improved appearance and oral function. ${ }^{26}$ Conversely, data collected in Tennessee revealed that driving distances were significantly longer for private pay patients as they are more willing to travel to receive treatment at a reduced cost. ${ }^{27}$ Medicaid patients tend to seek treatment by the closest provider; and if one is not available, they will forego treatment, leading to a disparity. ${ }^{28}$

\section{PATIENT COMPLIANCE}

One conversation that is conducted prior to the initiation of orthodontic treatment is the expectation to follow the recommended regimens suggested by the orthodontist. ${ }^{29}$ Compliance in orthodontics entails taking steps necessary to prevent broken fixed appliances, consistently wearing removable appliances, and maintaining proper oral hygiene throughout treatment. ${ }^{11}$ Non-compliance in orthodontics can result in many complications including destruction of the teeth and periodontium, a longer treatment time, unnecessary changes to the proposed treatment plan, and frustration for the patient and/or parents. ${ }^{6}$ Specifically, compliance in regards to maintaining oral hygiene is particularly important as the lack thereof can result in increased plaque retention, decalcification, dental caries, gingivitis, and even periodontitis. ${ }^{7}$

There is conflicting evidence concerning the predictability of the level of compliance for each patient. Data has suggested that patients who are cooperative at the beginning of treatment continue to be cooperative throughout. ${ }^{30}$ However, it has been shown that patient compliance tends to decrease as treatment progresses, regardless of the level of compliance demonstrated early on in treatment. ${ }^{31,32}$ A study conducted to illustrate what personality variables have an effect on compliance and a patient's ability to adapt found there is a strong correlation between a 
patient's attitude and the ability to accommodate to orthodontic discomfort with the resulting overall compliance during treatment. ${ }^{33}$

Studies have been completed to evaluate compliance by state-subsidized (or Medicaid) and selfpay orthodontic patients. Existing data on this subject cite Medicaid patients having poorer compliance than orthodontic patients whose treatment was not publically funded. ${ }^{34}$ One study suggests that there is a noteworthy compliance issue within the Medicaid population resulting in a considerable decrease of patients completing treatment due to lack of cooperation. ${ }^{27}$ Within this study, approximately $35 \%$ of patients discontinued treatment due to poor oral hygiene. The completion rate of self-pay patients was $86.2 \%$, compared to a $43.8 \%$ completion rate of Medicaid/CHIP patients. ${ }^{35}$ However, these findings differ from other orthodontic literature that reported no difference in orthodontic treatment and compliance between Medicaid and self-pay patients. ${ }^{36}$

\section{ORAL HYGIENE}

As previously stated, compliance in regards to oral hygiene is of particular importance as the lack thereof can have detrimental effects on the health of the oral cavity. ${ }^{7}$ Decalcification of the enamel surface is caused by ineffective oral hygiene and retention of bacterial plaque for an extended period of time. ${ }^{37}$ Calcium and phosphate are the mineral elements that are broken down upon decalcification. ${ }^{9}$ When this occurs, the mineral content of the enamel is decreased and the early stages of a carious lesion are initiated. ${ }^{9}$ The process leading up to the initiation of a carious lesion can be reversed, however, with proper oral hygiene. Effective brushing with a manual or electric toothbrush is the best way to remove plaque on a daily basis and therefore prevent demineralization of the enamel surface. ${ }^{38}$ 
Patient cooperation with regards to oral hygiene has been cited as one factor that accounts for wide variations between expected and actual treatment times. ${ }^{39}$ One study determined poor oral hygiene, as well as pool elastic wear and bracket breakages, to significantly increase treatment duration. ${ }^{40}$ Likewise, evidence has been shown that the rate of orthodontic tooth movement is decreased when gingival inflammation is present. ${ }^{39}$ Poor oral hygiene has a direct relationship with treatment duration as some data indicates each oral hygiene entry into a patient's chart that is less than "good" is associated with an additional two thirds of a month in treatment time. ${ }^{41}$

\section{APPOINTMENT KEEPING BEHAVIOR}

The skilled orthodontist is able to make an accurate prediction of the number of treatment visits based on the severity of the malocclusion; however, it is the responsibility of both the provider and the patient to ensure this timeline is upheld. Success within an orthodontic practice is directly related to the accurate prediction of treatment duration as patients who complete treatment within the estimated time frame may be more satisfied. ${ }^{42}$ Various patient compliance factors have been identified as potentially having an influence on the length of orthodontic treatment including missed appointments, the sum of replaced brackets and bands, and oral hygiene. ${ }^{39}$ An extensive study was conducted to analyze the impact of certain factors on treatment duration and concluded a statistically significant association between number of broken appointments and length of treatment. ${ }^{10}$ These findings concur with an investigation that discovered the primary causes for extended treatment times in a private practice to be poor patient cooperation, broken appointments, and appliance breakage. ${ }^{42}$

It can be inferred that attendance has an effect on treatment success by observing the appointment failure rate of patients who completed orthodontic treatment versus those whose 
braces were removed early due to lack of compliance in appointment keeping behavior. ${ }^{43}$ Patients who successfully completed their orthodontic treatment exhibited an appointment failure rate of $10.3 \%$ and patients who discontinued treatment showed a failure rate of $21.4 \% .{ }^{43}$ Other studies have found the broken orthodontic appointment rates to range from $13.6 \%$ to $23.3 \%$. $^{4,45}$

A dental facility within a children's hospital compared the appointment keeping behavior of Medicaid and private pay patients found that $73 \%$ of Medicaid patients were likely to miss appointments compared with $30 \%$ of private pay patients. ${ }^{46}$ A study conducted within both general dentistry and orthodontic private practices revealed the Medicaid patients had poorer appointment keeping behavior than private pay patients. ${ }^{47}$ While limited information is currently available on the significance of pay status and how it relates specifically to orthodontic appointment keeping behavior, the findings of one study support that Medicaid patients have a higher rate of broken appointments than non-Medicaid patients. ${ }^{48}$ Research conducted from data within electronic charts of active orthodontic patients in a university setting found a statistically significant difference in the number of appointment failures between Medicaid and nonMedicaid groups. Medicaid patients had a significantly higher failure rate (15.4\%) than did nonMedicaid patients $(8.3 \%){ }^{4}$ 


\section{CHAPTER 3: RESEARCH DESIGN AND METHODOLOGY}

\section{METHODOLOGY}

\section{$\underline{\text { IRB APPROVAL }}$}

IRB exemption was obtained from West Virginia University Institutional Review Board prior to the start of this study (see Appendix A).

\section{DATA COLLECTION}

A sample of 107 orthodontic patients from the private practice of Dr. Daniel Foley in Beckley, West Virginia was collected for this study. These patients were evaluated according to the inclusion criteria and 91 patients met all the necessary standards to be included in the study. Pretreatment and post-treatment photographs were taken on each patient according to the photographic record specifications set by the American Board of Orthodontics. Post-treatment scans were taken using an iTero Element intraoral scanner. This scan was utilized to have 3D printed models fabricated of each patient's upper and lower arches. The subjects ranged in age

from 8 to 20 years. All pre- and post- treatment records were de-identified before analysis and assigned a subject number from 01 to 91 .

\section{$\underline{\text { SAMPLE DESCRIPTION }}$}

The subjects ranged in age from 8 to 20 years as a result of the limitations placed by the state in which state subsidized treatment is only covered through the age of 21 . The goal of this limitation is to maintain consistency between the various payment statuses. There were 32 males and 59 females included in the study. 


\section{INCLUSION CRITERIA}

Subjects were included by the following criteria:

1. Complete and adequate pre-treatment and post-treatment photos available

2. Complete and adequate post-treatment scan available

3. Patients under the age of 21 at the start of treatment

4. Patients who have completed comprehensive orthodontic treatment

5. A record of oral hygiene at each visit

\section{EXCLUSION CRITERIA}

Subjects were excluded by the following criteria:

1. Incomplete or poor quality pre-treatment or post-treatment photos

2. Inadequate post-treatment scan with missing anatomy

3. Inadequate reporting of patient oral hygiene at each appointment

4. Patients over the age of 21 at the start of treatment

5. History of prior orthodontic treatment

6. Presence of primary dentition

7. Any severe craniofacial or developmental deformity

\section{INFORMATION OBTAINED FROM PATIENT CHART}

1. Payment status of the patient (Private Pay/Insurance/Medicaid/CHIP)

2. Gender

3. Age at the beginning of treatment

4. Distance traveled from home to orthodontic office (one-way) 
5. Estimated treatment length

6. Oral hygiene at each appointment

7. Treatment provided at each appointment

8. Cancelled and broken appointments

9. Actual treatment length

This information was coded within the raw data spreadsheet according to the legend found in Appendix B.

\section{MEASUREMENTS}

\section{ORAL HYGIENE}

Oral hygiene was measured on each patient at the beginning of each of their appointments during active treatment. A scale of 1 to 5 was utilized to measure oral hygiene according to the following scale: $1=$ poor, 2 = fair, $3=$ good, $4=$ great, $5=$ excellent. A test was given to the oral hygiene evaluators to test their reliability and to determine if any evaluators needed to be removed from the data due to interrater variability (Appendix $C$ ). No evaluators were removed from the study.

\section{DISCREPANCY INDEX}

Each patient's pre-treatment photos were scored by the study investigator using a standardized measure of case complexity, which was developed by the American Board of Orthodontics, known as the Discrepancy Index. There are specific target disorders that are taken into account, and a point value is assigned for each of these discrepancies. A higher Discrepancy Index score indicates that a case is more complex to treat. Typically, radiographic analysis is included within 
the Discrepancy Index score; however, it was excluded from this study due to the lack of lateral cephalometric radiographs for all subjects. All of the following criteria originated from the American Board of Orthodontics Discrepancy Index Scoring System:

Overjet is measured between upper and lower anterior teeth to determine the horizontal overlap relationship between the two anterior teeth comprising the greatest distance. It is measured from the facial surface of the most lingual mandibular tooth to the middle of the incisal edge of the more facially positioned maxillary tooth. In the event of a case with negative overjet, in which the mandibular teeth protrude more than the maxillary teeth, a measurement from the facial surface of the maxillary tooth to the middle of the incisal edge of the mandibular tooth is taken. In terms of quantifying this discrepancy, the following point values are given: $\geq 1$ to $\leq 3 \mathrm{~mm}=0$ points; $\geq 0$ to $<1 \mathrm{~mm}=1$ point; $>3$ to $\leq 5 \mathrm{~mm}=2$ points $>5$ to $\leq 7=3$ points; $>7$ to $\leq 9 \mathrm{~mm}=4$ points, $>9 \mathrm{~mm}=5$ points.

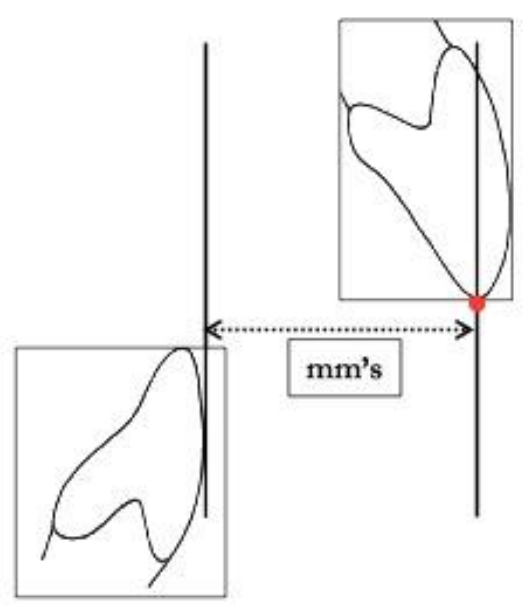

Figure 1. Measurement of overjet (American Board of Orthodontics, 2016)

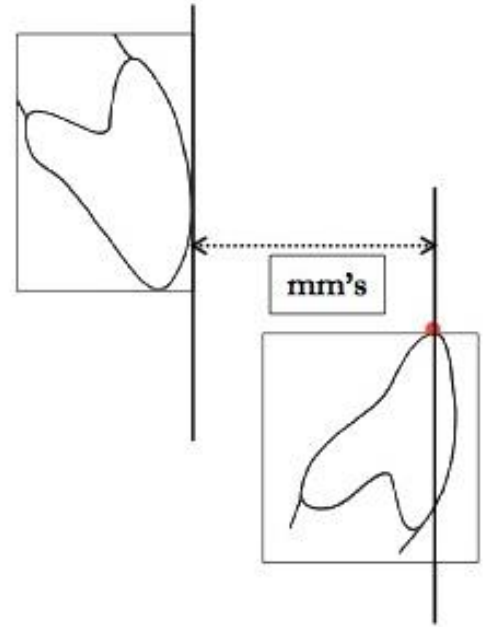

Figure 2. Measurement of negative overjet (American Board of Orthodontics, 2016)

Overbite is another measurement between an upper and lower incisor, but in this case to determine the vertical overlap relationship between the teeth. The point value increases as the overlap of the teeth increases according to the following scale: $>0$ to $<3 \mathrm{~mm}=0$ points; $>3$ to 
$<5 \mathrm{~mm}=2$ points; $>5$ to $<7 \mathrm{~mm}=3$ points. In a case where the lower incisal edges are impinging on the palatal tissues or there is a complete overlap of the lower incisors, a score of 5 points is given. Some patients exhibit an anterior open bite relationship in which the anterior teeth are in an edge to edge relationship or not overlapping at all. For each anterior tooth in an edge to edge relationship, a score of 1 point per tooth is given. Additional points are given for each tooth in open bite $>1 \mathrm{~mm}$ and any fractional remainder is rounded to the next full millimeter.

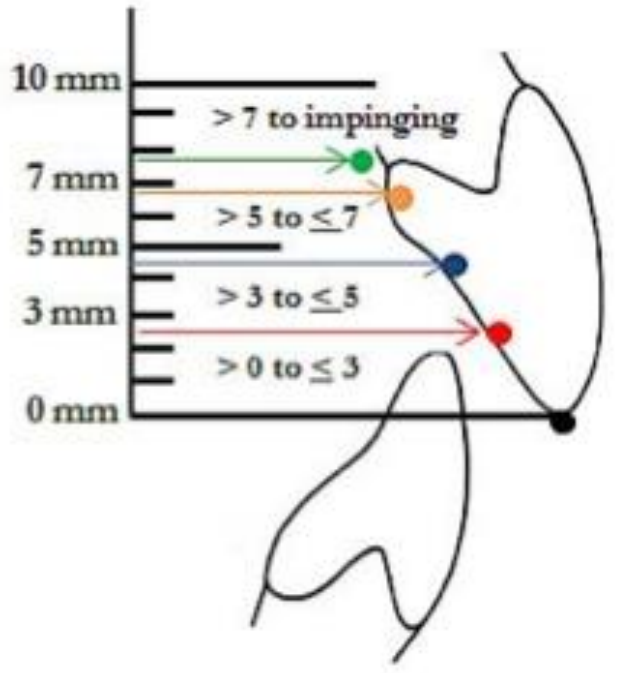

Figure 3. Measurement of overbite (American Board of Orthodontics, 2016)

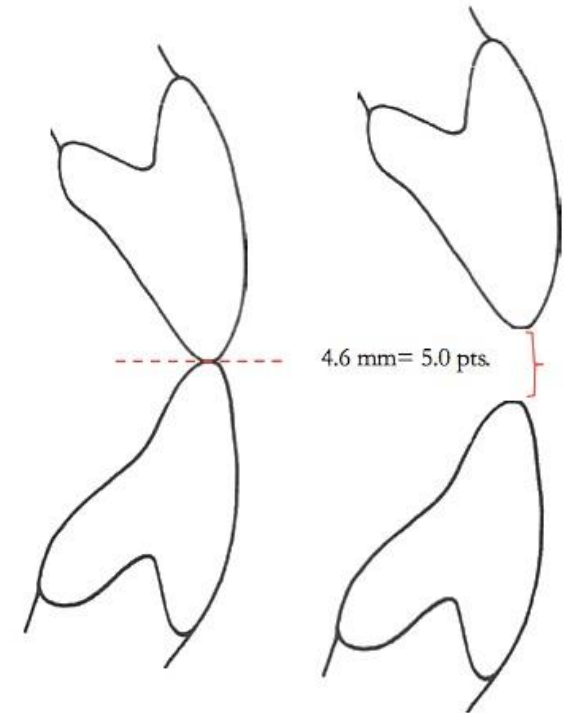

Figure 4. Measurement of anterior edge-toedge or open bite (American Board of Orthodontics, 2016)

Some patients present with a lateral open bite prior to orthodontic treatment. In this instance, points are given for each maxillary posterior tooth, ranging from the first premolar to the second molar, that is in an open bite relationship $\geq 0.5 \mathrm{~mm}$ from its opposing tooth. 2 points are scored for each millimeter of open bite per tooth. 
Crowding is measured from the mesial contact point of the right first molar to the mesial contact point of the left first molar in only one arch. It is typically the most crowded arch that is taken into account for the Discrepancy Index.

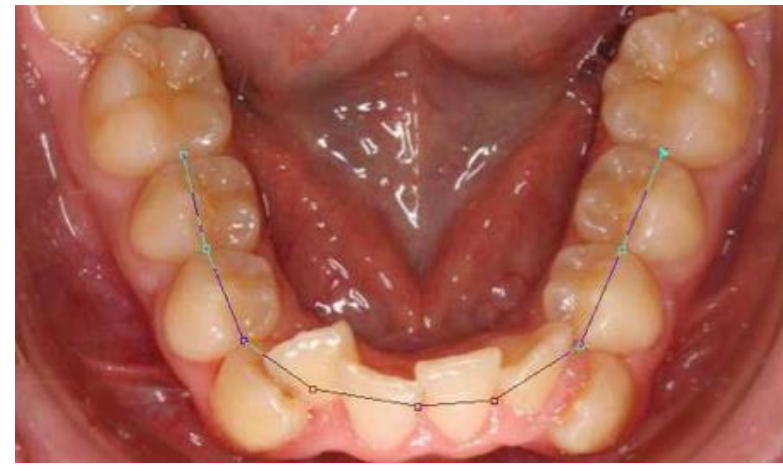

Figure 5. Crowded arch (American Board of Orthodontics, 2016)

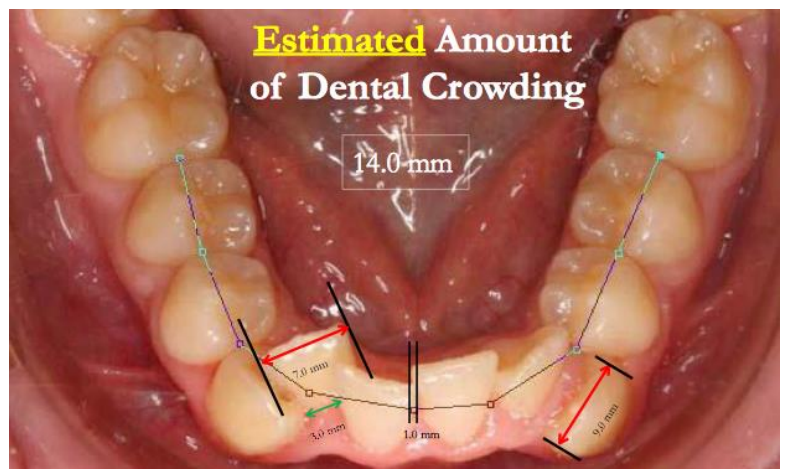

Figure 6. Measurement of crowding (American Board of Orthodontics, 2016)

To measure a patient's occlusal relationship, the Angle molar classification system is used.

Molar classification is determined for each side of the arch and is estimated for the purposes of a Discrepancy Index score. If the occlusal relationship is classified as a Class I relationship, 0 points are given. An End to End Class II or Class III relationship is valued at 2 points per side. If the patient exhibits a full cusp Class II or Class III relationship, 4 points are given per side. One additional point is given per millimeter per side if the occlusal relationship goes beyond a full cusp relationship.

A posterior crossbite can be directed to either the buccal or the lingual. In the event of a lingual posterior crossbite, each maxillary posterior tooth where the maxillary buccal cusp is lingual to the buccal cusp tip of the opposing mandibular tooth is given a score of 1 point. A buccal posterior crossbite occurs when the maxillary palatal cusp is buccal to the buccal cusp of the opposing tooth. In this instance, 2 points are scored per tooth in buccal crossbite. 


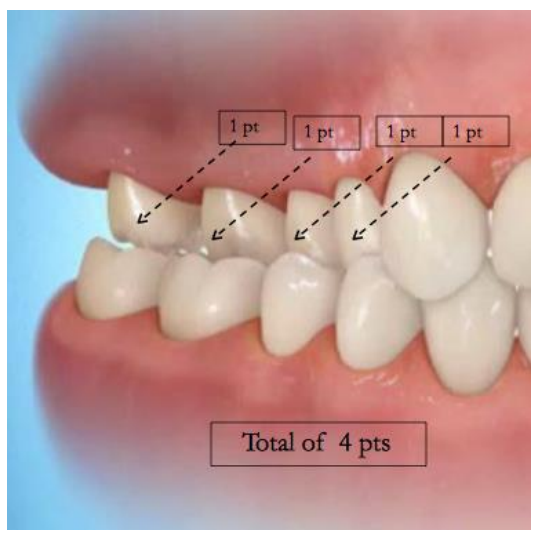

Figure 7. Measurement of posterior crossbite (American Board of Orthodontics, 2016)

A miscellaneous category is added to the Discrepancy Index as it is not possible to include every clinical entity within the index. This permits the scoring of non-standard conditions that may contribute to treatment complexity including: supernumerary teeth, anomalous morphology of tooth size and shape, impaction of teeth, missing teeth (except third molars), midline discrepancy, and spacing.

\section{$\underline{\text { ABO MODEL GRADING SYSTEM }}$}

The American Board of Orthodontics established the Model Grading System which has specific criteria that must be met in order to consider the completed treatment to be successful. The Cast Evaluation portion of the Model Grading System was utilized to measure alignment, marginal ridges, buccolingual inclination, occlusal relationships, occlusal contacts, overjet, and interproximal contacts on all post-treatment models. Typically, radiographic analysis is included within the Model Grading System score as well; however, it was excluded from this study due to the lack of radiographs for all subjects. 
A successful orthodontic treatment outcome must contain properly aligned teeth. In the anterior region, the incisal edges and lingual surfaces of the maxillary teeth and the incisal edges and labial surfaces of the mandibular teeth are evaluated to determine proper alignment. The mesiodistal central groove of the premolars and molars is used to assess alignment in the maxillary posterior, while the buccal cusp tips of the premolars and molars are used in the mandibular posterior region. Teeth are considered to be in proper alignment if there is no discrepancy up to $0.5 \mathrm{~mm}$. If any interproximal contact point is $\geq 0.5 \mathrm{~mm}$ to $1 \mathrm{~mm}$ deviated from ideal alignment, 1 point is scored for the tooth that is out of alignment. If the deviation from aligned is greater than $1 \mathrm{~mm}$, then 2 points are scored for that tooth; however, there is a limit of 2 points for any tooth.

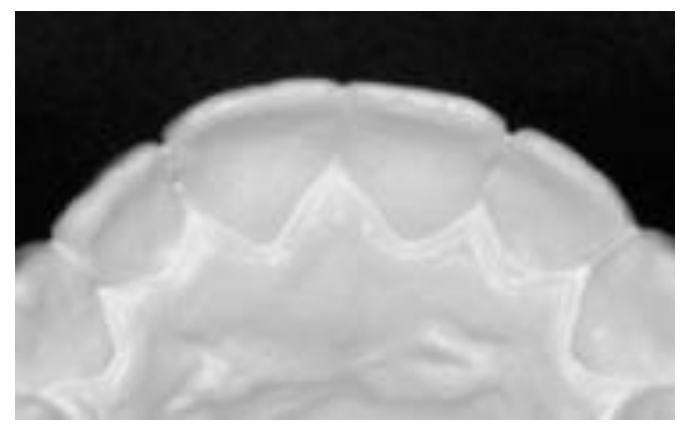

Figure 8. Ideal alignment (American Board of Orthodontics, 2012)

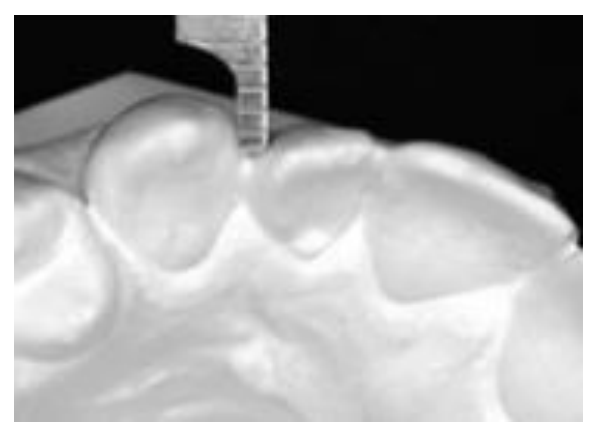

Figure 9. Deviation from ideal alignment (American Board of Orthodontics, 2012)

The proper vertical positioning of the posterior teeth is evaluated by analyzing the marginal ridges. This is important from an occlusal standpoint, but also from a periodontal aspect as level marginal ridges will result in level cementoenamel junctions, which in turn results in alveolar bone levels that are even between adjacent teeth. In order to receive no points scored for this criterion, marginal ridges must be at the same level, or within $0.5 \mathrm{~mm}$ of the same level. If the marginal ridges are $\geq 0.5 \mathrm{~mm}$ to $1 \mathrm{~mm}, 1$ point is scored for that interproximal contact. Two 
points are scored for any discrepancy greater than $1 \mathrm{~mm}$, with a limit of 2 points for any interproximal contact point.

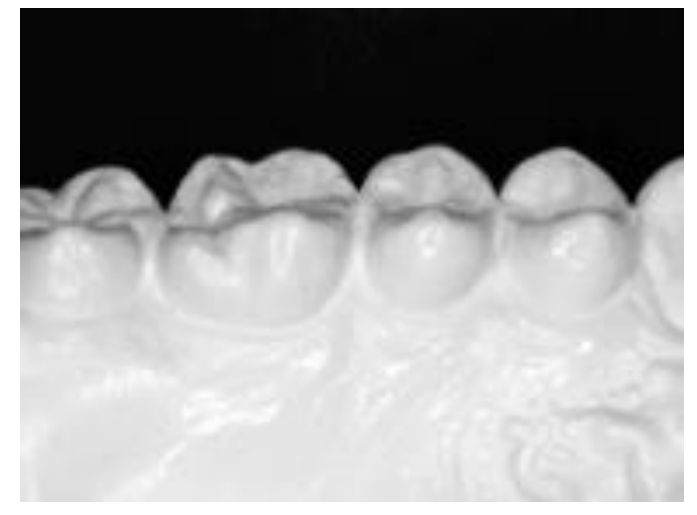

Figure 10. Ideal marginal ridges (American Board of Orthodontics, 2012)

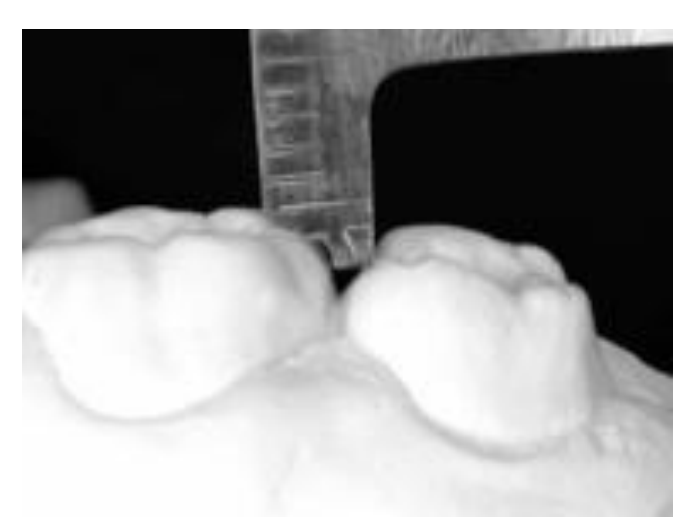

Figure 11. Deviation from ideal marginal ridge (American Board of Orthodontics, 2012)

Posterior teeth should be upright in order to properly occlude with the opposing arch. The evaluation of proper buccolingual angulation is referred to as the buccolingual inclination and it takes into account any height differences that are exhibited between the buccal and lingual cusps of the maxillary and mandibular premolars and molars. A specific gauge is utilized by positioning a straight edge along the cusp tips of the posterior teeth. In the maxillary arch, the straight edge will contact the lingual cusp tips, and the buccal cusp tips should be within $1 \mathrm{~mm}$ from the surface of the straight edge. The mandibular arch is the exact opposite with the buccal cusp tips contacting the straight edge and the lingual cusp tips within $1 \mathrm{~mm}$. If the maxillary buccal cusp tips are $>1 \mathrm{~mm}$ but $<2 \mathrm{~mm}, 1$ point is scored for that tooth. If there is a discrepancy $>2 \mathrm{~mm}$, then 2 points are scored with a limit of 2 points per tooth. 


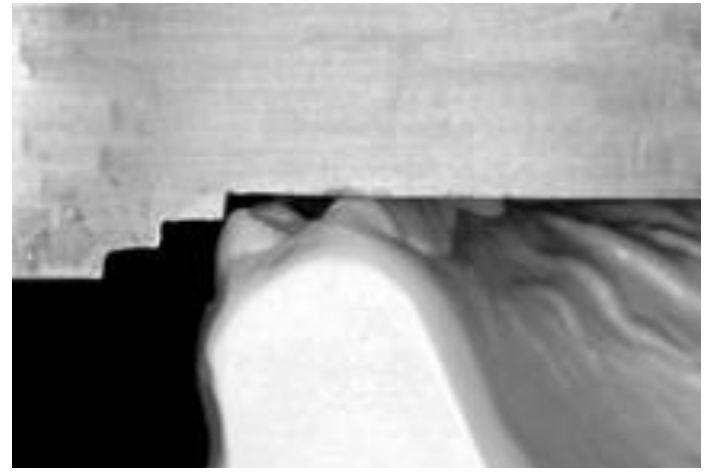

Figure 12. Ideal buccolingual inclination (American Board of Orthodontics, 2012)

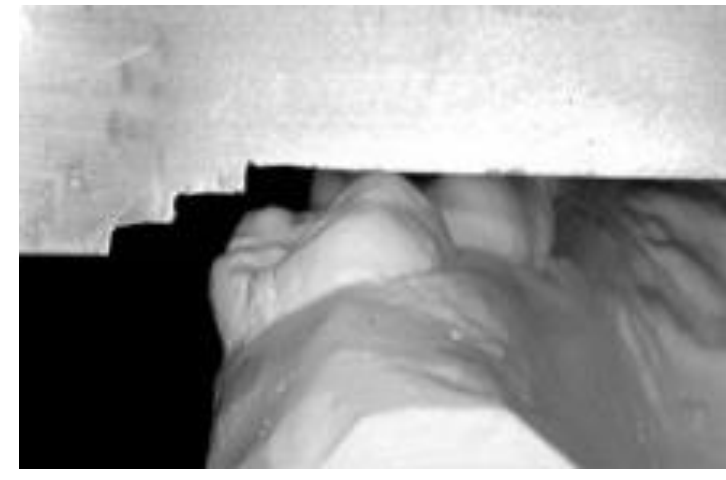

Figure 13. Deviation from ideal buccolingual inclination (American Board of Orthodontics, 2012)

Another important aspect of a proper occlusion is establishing maximum intercuspation of the opposing teeth. To measure the adequacy of this, occlusal contacts are measured to ensure all functioning cusps are in contact with their counterparts. The functioning cusps of the teeth are the lingual cusps of the maxillary premolars and molars, as well as the buccal cusps of the mandibular premolars and molars. Cusps that are in contact with the opposing arch receive no points; however, if a cusp is out of contact with the opposing arch $\leq 1 \mathrm{~mm}, 1$ point is scores. Any tooth out of contact at a distance of $>1 \mathrm{~mm}$ receives a score of 2 points.

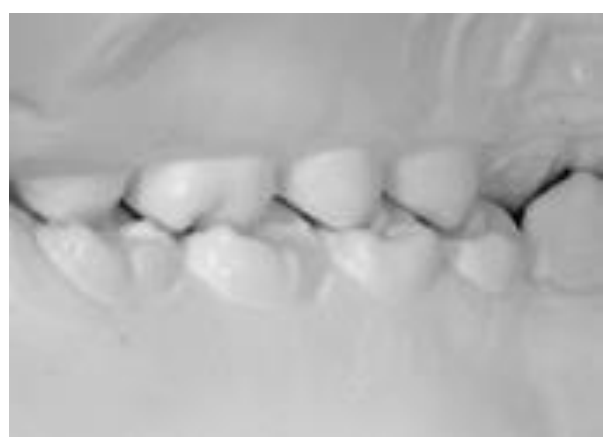

Figure 14. Ideal occlusal contacts (American Board of Orthodontics, 2012)

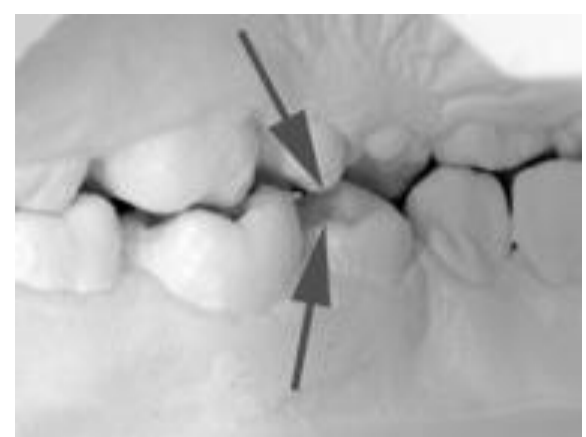

Figure 15. Deviation from ideal occlusal contact (American Board of Orthodontics, 2012) 
Just as in the Discrepancy Index score, the Angle classification system is used to measure the occlusal relationship and anteroposterior position of the maxillary and mandibular posterior teeth. In an ideal occlusion, the buccal cusps of the maxillary canines, premolars, and molars must align within $1 \mathrm{~mm}$ of the interproximal embrasures of the mandibular posterior teeth. Likewise, the mesiobuccal cusp of the maxillary first molar must align within $1 \mathrm{~mm}$ of the buccal groove of the mandibular first molar. If the cusp tips deviate $\geq 1 \mathrm{~mm}$ to $\leq 2 \mathrm{~mm}$ from these positions, 1 point is scored for the tooth. If the deviation is $>2 \mathrm{~mm}$, two points are scored with a limit of two points per tooth.

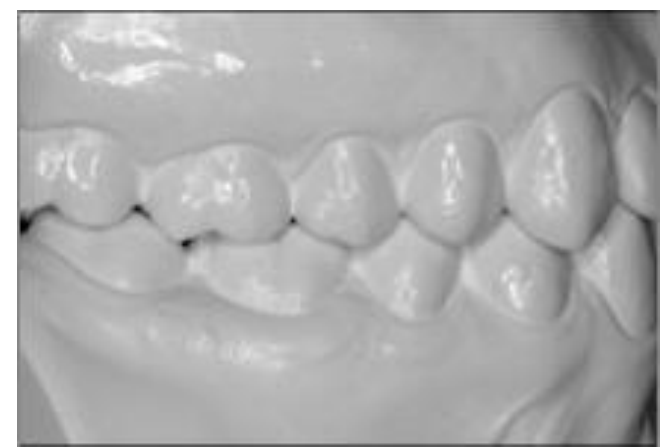

Figure 16. Ideal occlusal relationship (American Board of Orthodontics, 2012)

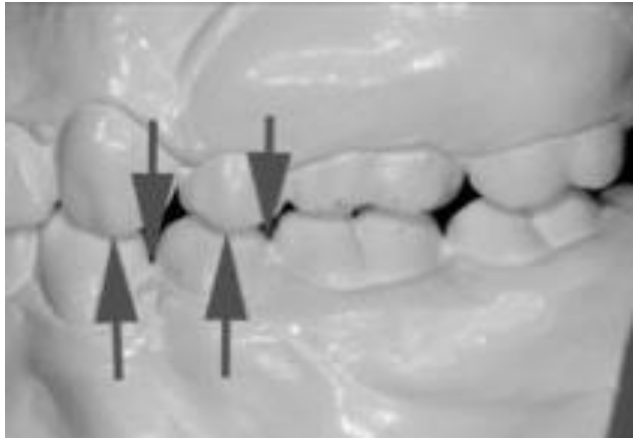

Figure 17. Deviation from ideal occlusal relationship (American Board of Orthodontics, 2012)

The transverse relationship of the posterior teeth and the anteroposterior relationship of the anterior teeth is evaluated by the criterion overjet. The maxillary lingual cusps and mandibular buccal cusps, which have previously been defined as the functioning cusps, should interpose nicely within the fossae of the opposing arch. Anteriorly, the mandibular incisal edges should come in contact with the lingual surfaces of the maxillary anterior teeth. No points are scored when the teeth meet these specifications. If the cusp tips deviate from the central fossa of the opposing tooth $\leq 1 \mathrm{~mm}, 1$ point is scored for that tooth. Two points are scored for any tooth that deviates $>1 \mathrm{~mm}$ with a limit of two points per tooth. Any mandibular incisal edges that are not 
in contact with the maxillary lingual surfaces at a distance of $\leq 1 \mathrm{~mm}$ are given a score of 1 point. If the discrepancy is $>1 \mathrm{~mm}$, then 2 points are scored for each tooth.

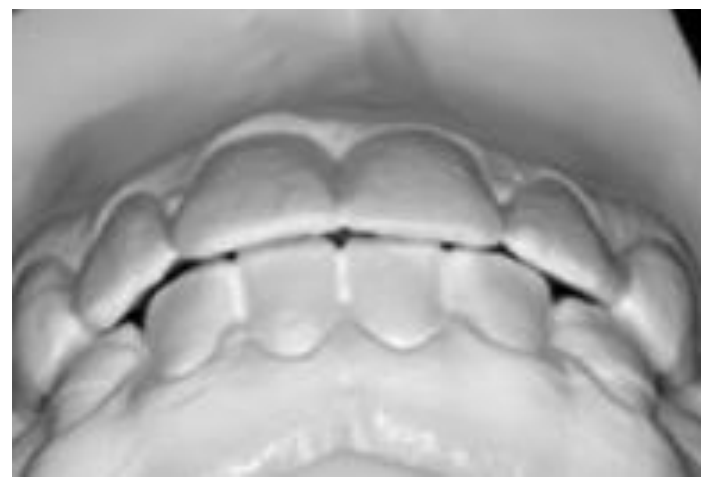

Figure 18. Ideal overjet (American Board of Orthodontics, 2012)

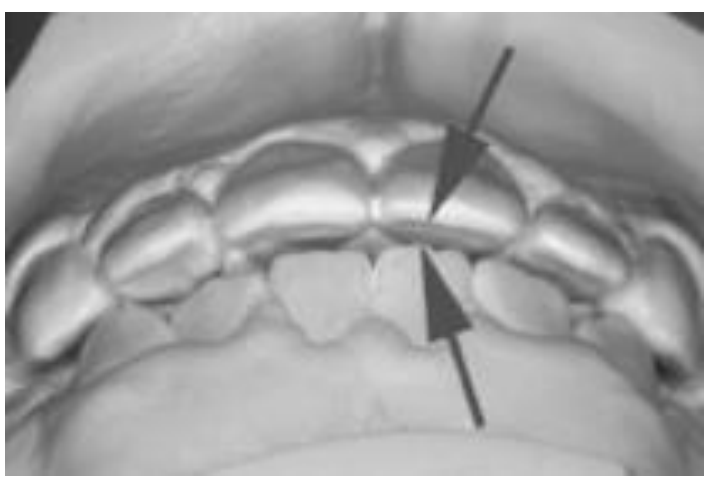

Figure 19. Deviation from ideal overjet (American Board of Orthodontics, 2012)

All teeth within an arch should be in contact, with no space between two teeth mesiodistally.

Occasionally an orthodontic band will temporarily cause a space between two teeth; however a space of $\leq 0.5 \mathrm{~mm}$ results in no points scored in any case. An interproximal space of $>0.5 \mathrm{~mm}$ to $\leq 1 \mathrm{~mm}$ will result in a score of 1 point per interproximal space. If $>1 \mathrm{~mm}$ space exists between two teeth, 2 points are scored with a limit of 2 points per interproximal space.

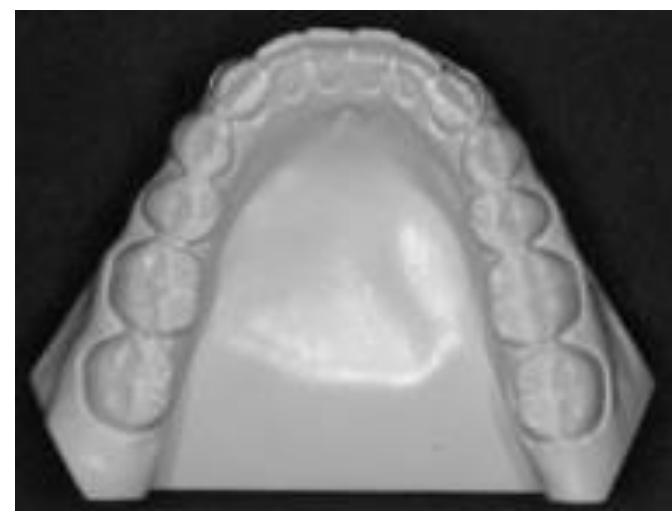

Figure 20. Ideal interproximal contacts (American Board of Orthodontics, 2012)

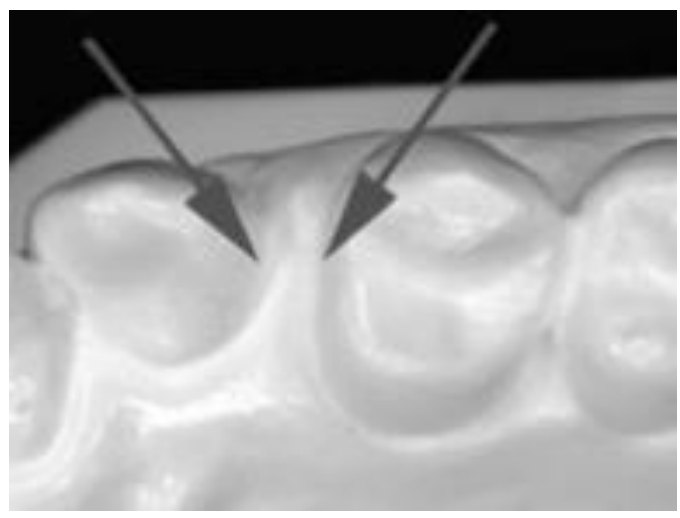

Figure 21. Deviation from ideal interproximal contacts (American Board of Orthodontics, 2012) 
Once all criteria were judged, the scores were compiled to determine the overall treatment of the each case. Models that scored $\leq 27$ points were considered to be successfully treated cases. If the models received a score $>27$, the case was not considered to be successfully treated.

\section{STATISTICAL ANALYSIS}

All statistical tests were conducted using SAS (version 9.4, 2013, SAS institute Inc, Cary, NC). A descriptive analysis was performed for all study variables. The average oral hygiene score was computed across treatment time. One-way analysis of variance (ANOVA) was conducted to compare the mean difference in oral hygiene scores and the actual treatment length among payment types. Chi-square analysis was incorporated to evaluate the association between treatment outcome and payment types, age (group), and gender. We utilized Wilcoxon rank sum test for comparison of difference in travel distance between treatment outcomes. Kruskal Wallis test was performed to examine the difference in travel distance among payment types. Association between oral hygiene, discrepancy scores, $\mathrm{ABO}$ scores, actual treatment length, and estimated treatment length was analyzed using Pearson correlation test. To assess the association between treatment outcome and oral hygiene scores, actual treatment length, and discrepancy

scores, logistic regression test was used. Finally, a multiple regression analysis was conducted to analyze the association between $\mathrm{ABO}$ scores and covariates including age, gender, oral hygiene, discrepancy scores, payment types, actual treatment length, and travel distance. All statistical tests were two-sided and p-values <.05 were considered statistically significant. 


\section{CHAPTER 4: RESULTS}

\section{RELIABILITY OF MEASUREMENTS}

Inter-rater reliability test was performed to evaluate the operator's reliability to properly grade subjects according to the American Board of Orthodontic guidelines. One board certified orthodontist scored twenty subjects, and these scores were compared to that of the investigator for this study. The intraclass correlation coefficient is 0.96 with $95 \%$ confidence interval (lower bound 0.90, upper bound 0.98). This indicates a high level of agreement between the two raters, and therefore, the investigator's rating is reliable.

\section{SAMPLE ANALYSIS}

\section{SAMPLE SIZE, AGE, GENDER}

The sample size consisted of 91 subjects ranging in age from 8 to 20 years with an average age of 12 years. Of these, 32 were males and 59 were females. (Table 1)

Table 1. Sex distribution of the sample studied.

\begin{tabular}{|c|r|r|r|r|}
\hline Gender & Frequency & Percent & $\begin{array}{c}\text { Cumulative } \\
\text { Frequency }\end{array}$ & $\begin{array}{c}\text { Cumulative } \\
\text { Percent }\end{array}$ \\
\hline Male & 32 & 35.16 & 32 & 35.16 \\
\hline Female & 59 & 64.84 & 91 & 100.00 \\
\hline
\end{tabular}




\section{VARIABLE ANALYSIS}

Table 2. Variable analysis. Variables analyzed in the study with the N, mean, Standard Deviation values, minimum, and maximum listed for each variable.

\begin{tabular}{|c|r|r|r|r|r|}
\hline Variable & \multicolumn{1}{|c|}{ N } & \multicolumn{1}{c|}{ Mean } & \multicolumn{1}{c|}{ Std Dev } & \multicolumn{1}{c|}{ Minimum } & \multicolumn{1}{c|}{ Maximum } \\
\hline Distance traveled (miles) & 85 & 23.14 & 16.07 & 0.60 & 60.30 \\
\hline Actual Tx Length (months) & 90 & 23.88 & 9.51 & 6.00 & 51.00 \\
\hline Estimated Tx Length (months) & 90 & 18.89 & 5.34 & 6.00 & 36.00 \\
\hline Age (years) & 91 & 12.14 & 2.22 & 8.00 & 20.00 \\
\hline ABO Score & 91 & 30.07 & 9.90 & 13.00 & 55.00 \\
\hline Discrepancy Index Score & 88 & 7.81 & 4.10 & 0.00 & 21.00 \\
\hline Average Oral Hygiene & 91 & 3.80 & 0.46 & 2.00 & 5.00 \\
\hline Cancelled Appointments & 91 & 1.68 & 1.87 & 0.00 & 7.00 \\
\hline Failed Appointments & 91 & 1.05 & 1.95 & 0.00 & 12.00 \\
\hline
\end{tabular}

Note: Sample sizes vary for variables because of missing values.

\section{VARIABLE DISTRIBUTION}

Variable distributions are presented in the following graphs and tables.

Figure 22. Number of subjects by payment type

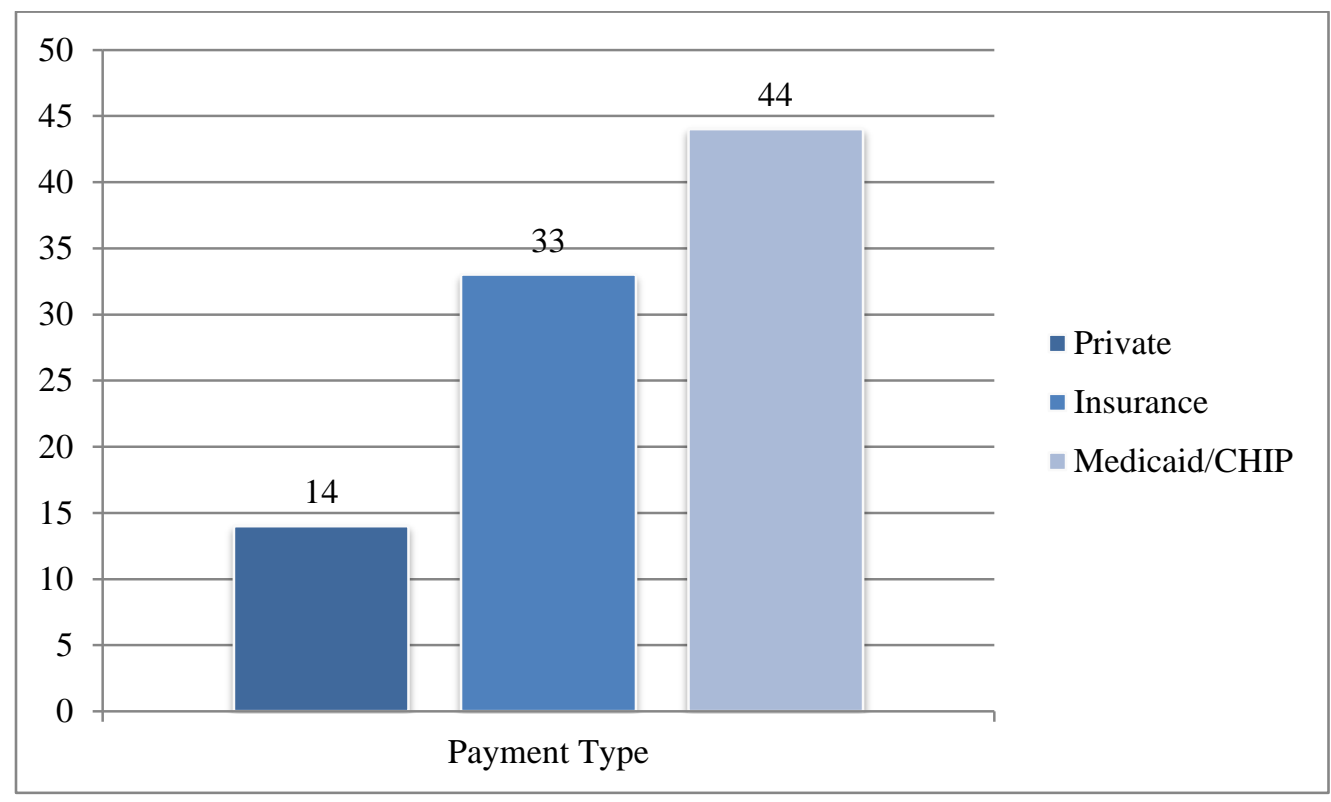


Table 3. Outcome distribution of the sample studied

\begin{tabular}{|c|r|r|r|r|}
\hline Outcome & Frequency & Percent & $\begin{array}{c}\text { Cumulative } \\
\text { Frequency }\end{array}$ & $\begin{array}{c}\text { Cumulative } \\
\text { Percent }\end{array}$ \\
\hline Unsuccessful & 48 & 52.75 & 48 & 52.75 \\
\hline Successful & 43 & 47.25 & 91 & 100.00 \\
\hline
\end{tabular}

A Chi-square analysis (Table 4) was used to determine an association between successful treatment outcome and payment type. This analysis revealed no significant difference among any payment type ( $\mathrm{p}=0.9358)$. Figure 23 shows $57.14 \%$ of private pay, $51.52 \%$ of insurance, and $52.27 \%$ of Medicaid/CHIP patients were unsuccessfully treated according to the standard established by the American Board of Orthodontics. In addition, Likelihood Ratio Chi-Square and Mantel-Haenszel Chi-Square analysis were performed, which found no significant difference between the groups as well.

Table 4. Chi-square analysis of the association between treatment outcome and payment type

\begin{tabular}{|c|r|c|r|}
\hline Statistic & DF & Value & Probability \\
\hline Chi-Square & 2 & 0.1326 & 0.9358 \\
\hline Likelihood Ratio Chi-Square & 2 & 0.1331 & 0.9356 \\
\hline Mantel-Haenszel Chi-Square & 1 & 0.0560 & 0.8129 \\
\hline
\end{tabular}

Figure 23. Outcome distribution by payment type

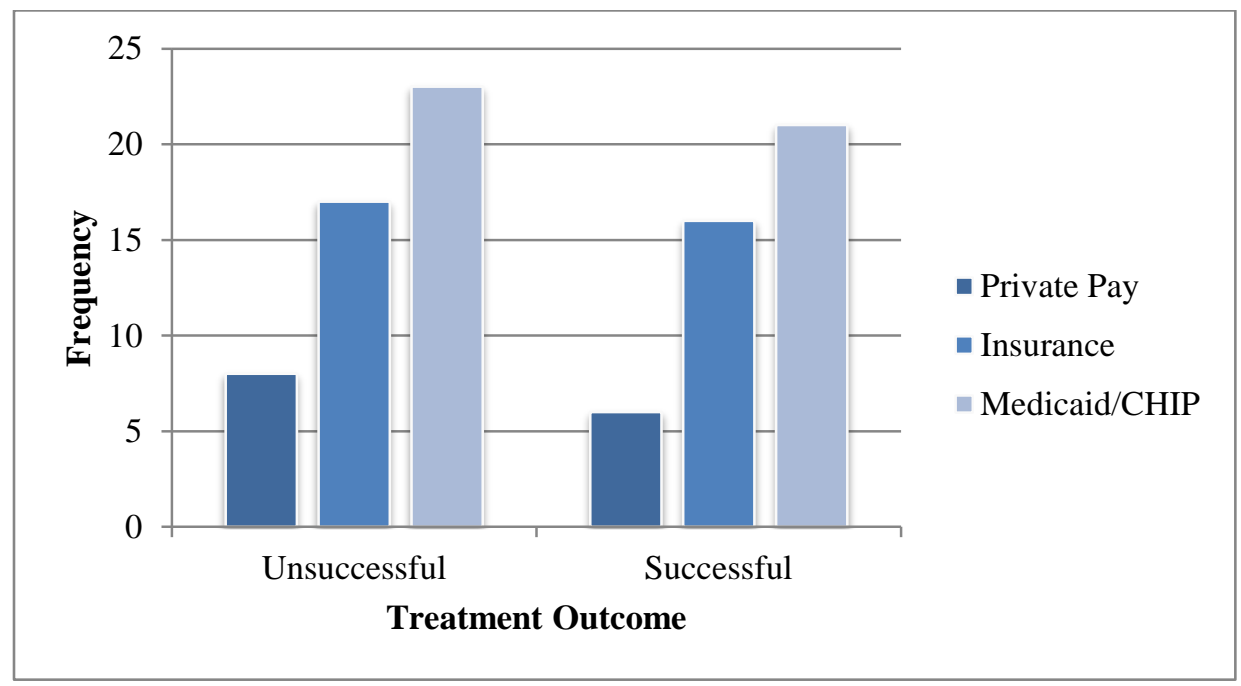


Table 5. Outcome distribution by payment type

\begin{tabular}{|c|c|c|c|c|}
\hline \multirow{2}{*}{$\begin{array}{l}\text { Treatment } \\
\text { Outcome }\end{array}$} & \multicolumn{4}{|c|}{ Payment Type } \\
\hline & Private Pay & Insurance & Medicaid/CHIP & Total \\
\hline Unsuccessful & 8 & 17 & 23 & 48 \\
\hline Successful & 6 & 16 & 21 & 43 \\
\hline Total & 14 & 33 & 44 & 91 \\
\hline
\end{tabular}

An average oral hygiene score was calculated for each patient across treatment time. As shown in Table 6, the mean oral hygiene score for private pay, insurance, and Medicaid/CHIP patients was $4.02,3.85$, and 3.69 , respectively. The difference in oral hygiene means between private pay and insurance patients was 0.18 , while the difference in means between insurance and Medicaid/CHIP patients was 0.15 . However, the comparison of private pay and Medicaid/CHIP patients showed a much greater difference in oral hygiene means at a value of 0.33 . One-way analysis of variance (ANOVA) revealed a significant difference overall, F $(2,90)=3.16$, $\mathrm{p}=0.0474$. As follow up, Tukey's Studentized Range (HSD) Test (Table 7) determined that the only significant difference was found when comparing the oral hygiene of private pay patients with that of Medicaid/CHIP patients ( $\mathrm{p}=0.0019)$, as shown in Figure 24.

\section{$\underline{\text { POWER ANALYSIS }}$}

A power analysis revealed a computed power of 0.638 , indicating that the small sample size may have introduced some variability. The comparison of private pay with insurance, as well as insurance with Medicaid/CHIP, both resulted in insignificant differences. 
Figure 24. Oral hygiene distribution by payment type

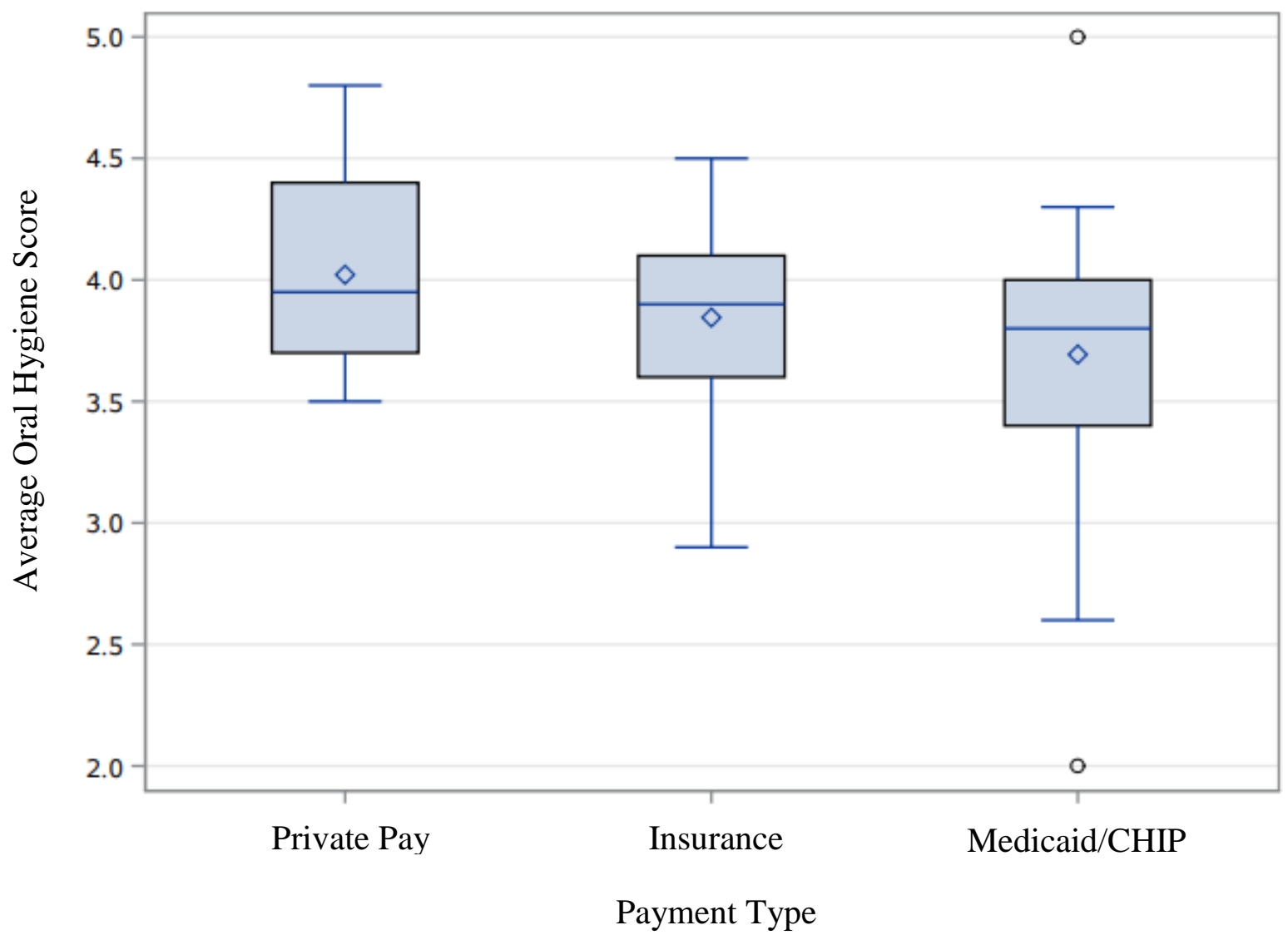

Table 6. Oral hygiene distribution by payment type

\begin{tabular}{|c|r|r|r|}
\hline \multirow{2}{*}{ Payment Type } & \multirow{2}{*}{ N } & \multicolumn{2}{|c|}{ Oral hygiene } \\
\cline { 3 - 4 } & & \multicolumn{1}{|c|}{ Mean } & \multicolumn{1}{c|}{ Std Dev } \\
\hline Private & 14 & 4.02 & 0.40 \\
\hline Insurance & 33 & 3.85 & 0.36 \\
\hline Medicaid/CHIP & 44 & 3.69 & 0.51 \\
\hline
\end{tabular}

Table 7. Tukey's Studentized Range Test for oral hygiene

\begin{tabular}{|l|r|}
\hline Alpha & 0.05 \\
\hline Error Degrees of Freedom & 88 \\
\hline Error Mean Square & 0.199015 \\
\hline Critical Value of Studentized Range & 3.37150 \\
\hline
\end{tabular}

A univariate logistic regression analysis was used to determine an association between oral hygiene and a successful treatment outcome. It was determined that oral hygiene is not a 
significant variable in the determination of treatment outcome. However, while not significant, it can be noted that based on the OR value, subjects who had a higher average oral hygiene score were $80 \%$ more likely to have a successful treatment outcome. This analysis also found significance in subjects with shorter treatment times and lower Discrepancy Index scores having more successful treatment outcomes. As shown in Table 8, a decrease in treatment time correlated with a 5\% greater chance of successful treatment outcome. Likewise, a decrease in one point on the Discrepancy Index was associated with a $12 \%$ chance of successful treatment outcome. This is sensible as Discrepancy Index is a measure of case complexity.

Table 8. Univariate logistic regression analyses for association between treatment outcome and average oral hygiene scores, actual treatment length, and Discrepancy Index scores.

\begin{tabular}{|c|c|c|c|}
\hline \multirow[t]{2}{*}{ Variable } & \multicolumn{3}{|c|}{$\begin{array}{l}\text { Successful treatment outcome (vs. unsuccessful treatment } \\
\text { outcome) }\end{array}$} \\
\hline & OR & 95\% Confidence Level & P-value \\
\hline $\begin{array}{l}\text { Average Oral } \\
\text { Hygiene }\end{array}$ & 1.80 & $0.69-4.65$ & 0.23 \\
\hline $\begin{array}{l}\text { Actual treatment } \\
\text { length }\end{array}$ & 0.95 & $0.91-0.99$ & $0.04 *$ \\
\hline $\begin{array}{l}\text { Discrepancy } \\
\text { Index }\end{array}$ & 0.88 & $0.79-0.98$ & $0.03^{*}$ \\
\hline
\end{tabular}

*p-value $<0.05$

The average distance traveled, one way, for each payment type was calculated and determined to be 36.7, 20.6, and 20.4 miles for private pay, insurance, and Medicaid/CHIP patients, respectively. The average one-way distance as classified by payment type is shown in Table 9 . When private pay patients were compared to both insurance and Medicaid/CHIP patients, the difference in the mean number of miles traveled was 16.09 and 16.27 miles, respectively, with private pay patients traveling the further distance. The difference in average miles traveled by insurance and Medicaid patients was only 0.18 miles. An ANOVA revealed a significant 
difference overall, $\mathrm{F}(2,84)=6.75, \mathrm{p}=0.0019$. Tukey's Studentized Range (HSD) Tests (Table 10) were performed and determined a statistically significant difference only between the mean distance traveled by private pay patients and the other two payment types ( $\mathrm{p}<0.0019)$, as shown in Figure 25.

Figure 25. Distribution of distance traveled by payment type

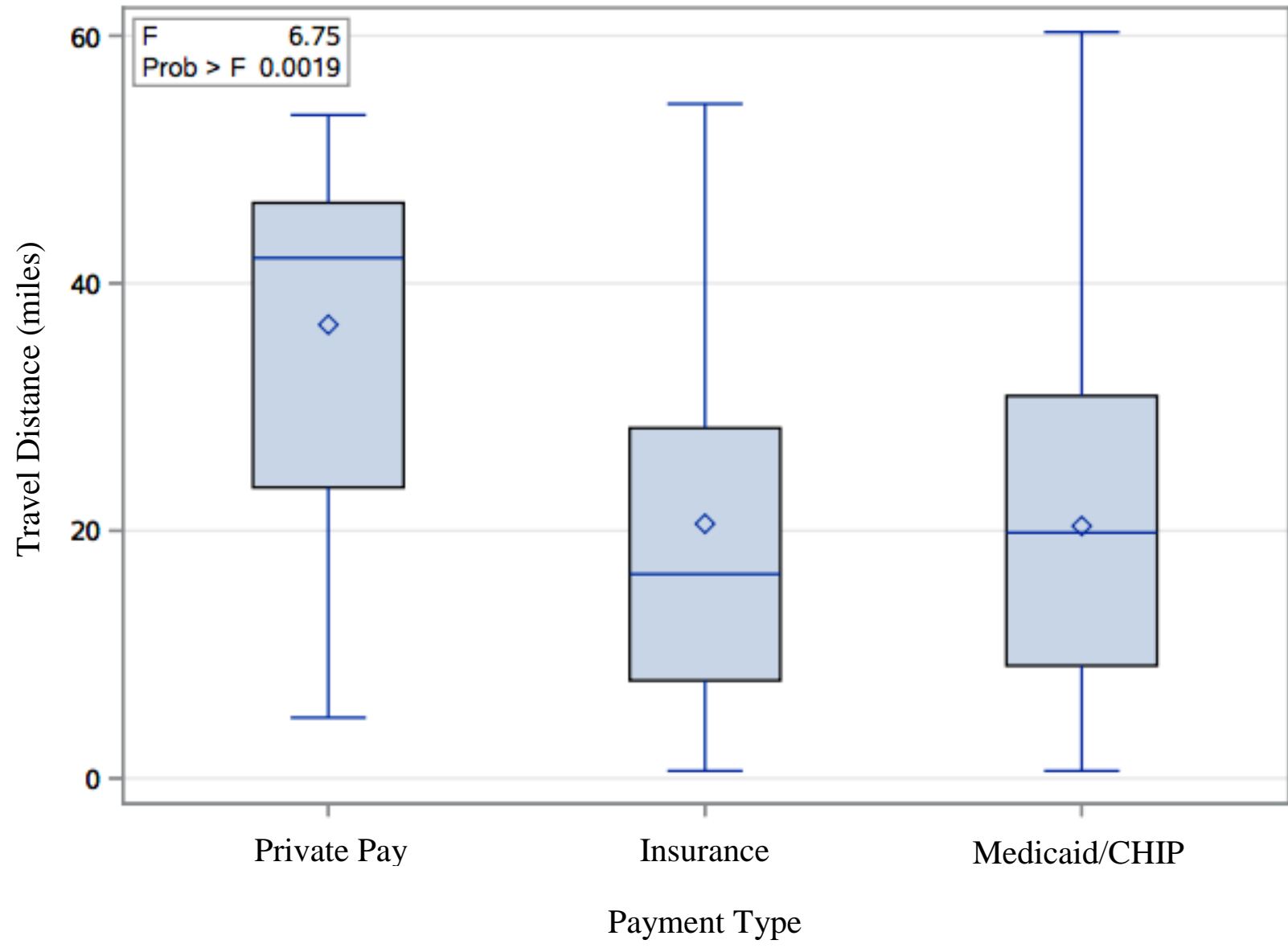

Table 9. Distribution of distance traveled by payment type

\begin{tabular}{|c|r|r|r|}
\hline \multirow{2}{*}{ Payment Type } & \multirow{2}{*}{$\mathbf{N}$} & \multicolumn{2}{|c|}{ Distance Traveled (miles) } \\
\cline { 3 - 4 } & & \multicolumn{1}{|c|}{ Mean } & \multicolumn{1}{c|}{ Std Dev } \\
\hline Private & 14 & 36.66 & 15.56 \\
\hline Insurance & 33 & 20.57 & 16.10 \\
\hline Medicaid/CHIP & 44 & 20.39 & 13.93 \\
\hline
\end{tabular}


Table 10. Tukey's Studentized Range (HSD) Test for distance traveled

\begin{tabular}{|l|r|}
\hline Alpha & 0.05 \\
\hline Error Degrees of Freedom & 82 \\
\hline Error Mean Square & 227.0816 \\
\hline Critical Value of Studentized Range & 3.37573 \\
\hline
\end{tabular}

The mean oral hygiene rating for each patient was calculated and compared to the length of each patient's treatment in months. This comparison was completed on the sample as a whole, and not subdivided in the categories of payment type. A Pearson Correlation Coefficient test was utilized to determine if an association exists between the mean oral hygiene rating for each patient and the actual length of treatment. As shown in Table 11, the test revealed there is no significant correlation between these two variables $(\mathrm{p}=0.46)$. This indicates that poor oral hygiene does not play a factor in lengthening patient treatment times.

Table 11. Pearson correlation test for association between variables

\begin{tabular}{|l|r|r|r|r|}
\hline & \multicolumn{3}{|c|}{ Pearson Correlation Coefficients } \\
\cline { 2 - 5 } & \multirow{2}{*}{ ABO } & Oral Hygiene & $\begin{array}{c}\text { Discrepancy } \\
\text { Index }\end{array}$ & $\begin{array}{c}\text { Actual Treatment } \\
\text { Length }\end{array}$ \\
\hline ABO Score & & -0.24 & 0.25 & 0.31 \\
& & $0.02 *$ & $0.02 *$ & $0.003^{*}$ \\
\hline Oral Hygiene & & & -0.27 & -0.08 \\
& & & $0.01 *$ & 0.46 \\
\hline Discrepancy Index & & & & 0.29 \\
& & & & $0.007 *$ \\
\hline
\end{tabular}

$*$ p-value $<0.05$

The mean of the actual length of orthodontic treatment was compared among the payment types using a one-way analysis of variance (ANOVA). The mean values of all data are presented in Table 12. The average treatment length in months for private pay, insurance, and Medicaid/CHIP patients was 19.3, 21.6, and 27.0 months, respectively. The mean values for private pay and insurance patients are relatively close, with a difference of 2.308 (Table 13). 
However, the mean difference when private pay and insurance patients are compared to that of Medicaid/CHIP patients is much higher, with a difference between means of 7.714 and 5.406 months, respectively. These values were tested using Tukey's Studentized Range (HSD) test and determined to be statistically significant $(\mathrm{p}<0.0061)$, as shown in Tables 13 and 14 .

Table 12. Distribution of treatment length by payment type

\begin{tabular}{|c|c|r|r|}
\hline \multirow{2}{*}{ Payment Type } & \multirow{2}{*}{ N } & \multicolumn{2}{|c|}{ Actual Treatment Length } \\
\cline { 3 - 4 } & & Mean (months) & \multicolumn{1}{c|}{ Std Dev } \\
\hline Private Pay & 14 & 19.29 & 6.58 \\
\hline Insurance & 33 & 21.59 & 10.44 \\
\hline Medicaid/CHIP & 44 & 27.00 & 8.65 \\
\hline
\end{tabular}

Table 13. Comparison of treatment length between payment types

\begin{tabular}{|c|r|r|r|l|}
\hline \multicolumn{6}{|c|}{ Comparisons significant at the 0.05 level are indicated by *** } \\
\hline Payment Types & $\begin{array}{c}\text { Difference } \\
\text { Between Means }\end{array}$ & $\begin{array}{c}\text { Simultaneous 95\% Confidence } \\
\text { Limits }\end{array}$ & \\
\hline Private Pay - Insurance & 2.308 & -4.622 & 9.238 & \\
\hline Insurance - Medicaid/CHIP & 5.406 & 0.382 & 10.431 & $* * *$ \\
\hline Medicaid/CHIP - Private Pay & 7.714 & 1.078 & 14.350 & $* * *$ \\
\hline
\end{tabular}

Table 14. Tukey Studentized Range (HSD) Test for treatment length.

\begin{tabular}{|l|r|}
\hline Alpha & 0.05 \\
\hline Error Degrees of Freedom & 87 \\
\hline Error Mean Square & 82.25949 \\
\hline Critical Value of Studentized Range & 3.37216 \\
\hline
\end{tabular}


Figure 26. Difference in actual treatment length between payment types

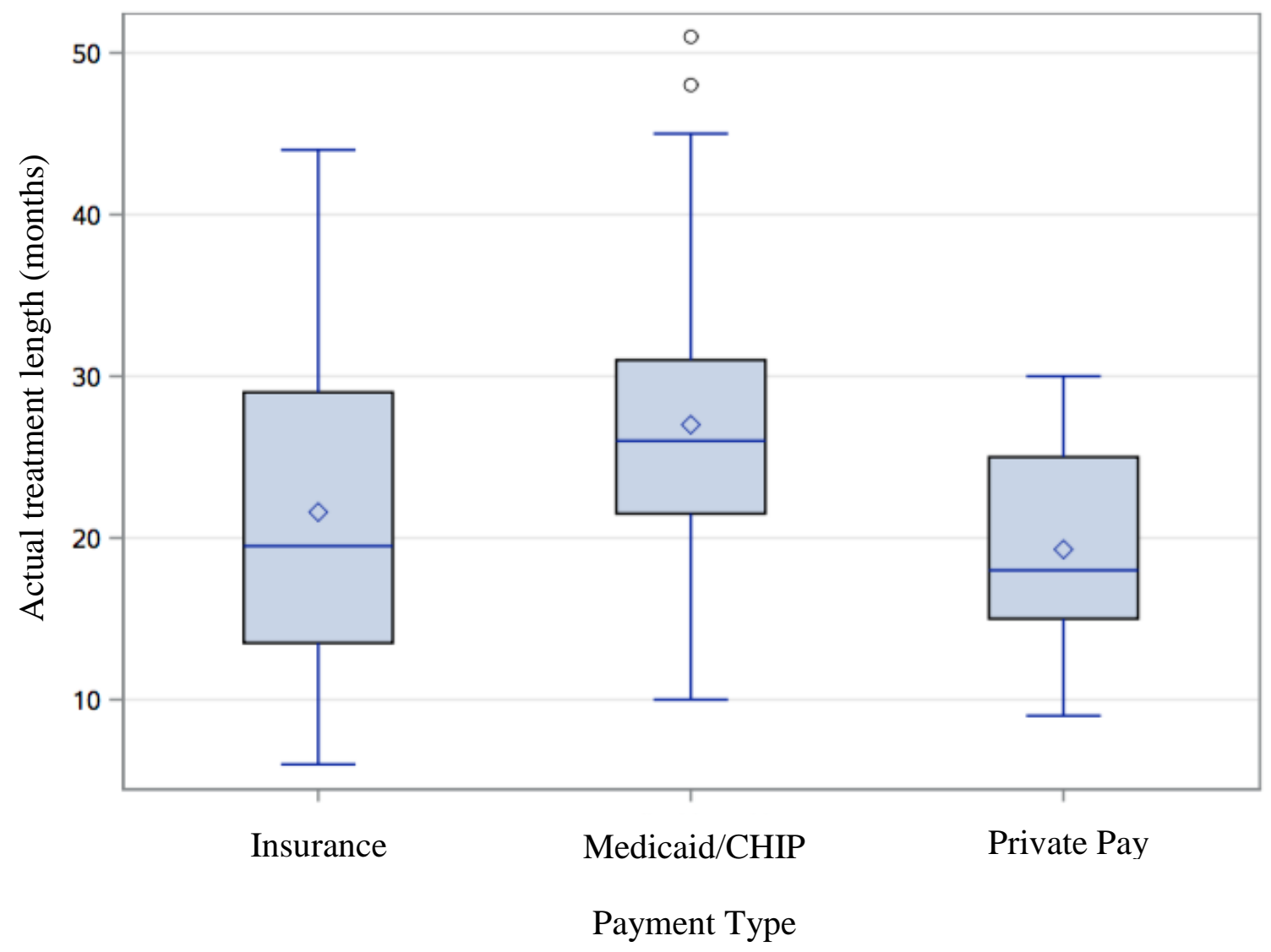

A broken appointment is defined within this study as a missed appointment in which no prior notification was given. Each payment type was evaluated using a Chi-square analysis to determine if any significance exists in the percentage of patients who had broken at least one appointment over the course of treatment. As shown in Table 15,50\% of Medicaid patients broke at least one appointment during their orthodontic treatment compared to approximately $30 \%$ of both private pay and insurance patients. While no statistical significance was found, it should be noted that the private pay subcategory had the lowest percentage of patients with at least one broken appointment with over 70\% having never broken a single appointment during the course of treatment. 
Table 15. Chi-square analysis for association between broken appointment and payment types

\begin{tabular}{|c|c|c|c|}
\hline \multirow[b]{2}{*}{ Payment Type } & \multicolumn{2}{|c|}{ Broken Appointment } & \multirow[b]{2}{*}{ P-value } \\
\hline & No $(\%)$ & Yes $(\%)$ & \\
\hline Private Pay & 71.3 & 28.6 & 0.14 \\
\hline Insurance & 69.7 & 30.3 & -- \\
\hline Medicaid/Chip & 50.0 & 50.0 & -- \\
\hline
\end{tabular}




\section{CHAPTER 5: DISCUSSION}

\section{TREATMENT OUTCOME}

The current study analyzed treatment outcome as it relates to each type of payment. A successful treatment outcome is defined in this study as receiving a score of 27 or less based on the American Board of Orthodontics Model Grading System, excluding the radiographic analysis criterion. In an ideal scenario, there would be a large and equal number of subjects representing each of the payment types; however, this was not the case. With only 14 subjects in the private pay category, there was an important shortcoming in adequate sample size. Specifically, some of the analyses that were performed may have actually been significant, but did not reach significance because of this small sample size.

While there are limited data currently available on how factors specifically affect treatment outcome as defined in this study, considerable research has been done on evaluating a patient's compliance during treatment. ${ }^{27,29,36}$ Proper patient compliance to an orthodontic treatment plan allows for successful fulfillment of treatment objectives, and therefore a positive outcome. ${ }^{29}$ It is important to note that patient compliance may vary considerably with difference aspects of orthodontic treatment. Previous research has presented contradictory results with some studies finding a lack of cooperation in the Medicaid population, ${ }^{27}$ while others found no difference. ${ }^{36}$ The current study found no difference between payment types with regard to treatment outcome. This is interesting as a significant difference was found in the oral hygiene ratings between payment types, which will be further discussed. However, according to the logistic regression analysis completed within this study, oral hygiene does not play a significant role in determining treatment outcome. 


\section{ORAL HYGIENE}

The current study was looking to determine if a subject's oral hygiene throughout treatment was related to their payment type, and more loosely, their socioeconomic status. Some studies have looked at the trend of oral hygiene as one progresses through treatment to determine the level of predictability of cooperation. ${ }^{30-32}$ However, for the purposes of this study it was determined to be most effective to average each patient's oral hygiene scores over the course of their treatment and utilize a mean oral hygiene as the variable compared to payment type. The mean oral hygiene scores follow a trend with private pay subjects ranking the highest, followed by insurance subjects, and then Medicaid/CHIP subjects.

It is widely accepted that maintaining proper oral hygiene throughout treatment is crucial and non-compliance in this regard can be detrimental. ${ }^{7}$ It is also widely known that certain perceptions exist surrounding Medicaid populations that may have effect on provider participation. $^{2}$ The University of North Carolina found the reluctance to participate with Medicaid to partially be due to poor compliance with regard to oral hygiene. ${ }^{3}$ One goal of the current study was to evaluate if these assumptions of non-compliance with regard to oral hygiene in the Medicaid population are valid. The results suggest that private pay patients have significantly better oral hygiene over the course of treatment than Medicaid patients. However, this finding is inconsistent with other literature, which concludes that there are no clinically important differences between Medicaid and non-Medicaid patients with regard to oral hygiene. ${ }^{36}$ A power analysis revealed a computed power of 0.638 , indicating that this small sample size may have introduced some variability. Therefore, it would be beneficial to continue research in this area on a larger sample to determine if the significance remains. 


\section{ACCESS TO CARE}

One of the more interesting findings of the current study was the distance in which subjects from each payment type traveled to receive their orthodontic treatment. The results suggest that individuals from the private pay subgroup travel a significantly longer one-way distance for orthodontic treatment than individuals from the insurance and Medicaid/CHIP subgroups. While it is unknown what motivated these private pay subjects to travel further for their treatment, it could be explained by cost benefit. These findings are congruent with those of Proffit et al., who found that Medicaid patients tend to seek care at the shortest possible distance in order to be cost effective, while private pay patients are willing to travel a greater distance if the treatment fee was more economical. ${ }^{27}$ It would be advantageous to explore this causation with a prospective study.

The existing literature largely supports the idea that Medicaid patients must travel further for orthodontic treatment due to the lack of providers that participate with Medicaid. ${ }^{22,25,26}$ However, West Virginia is an economically depressed state and the large number of providers that are now accepting West Virginia Medicaid within their practices could explain our findings. Medicaid patients in many regions of the state are no longer having to travel great distances to surrounding cities to obtain orthodontic treatment. Specifically, there are at least two private practice orthodontists within the town in which this data was collected who accept West Virginia Medicaid. Therefore not only meeting the need, but also providing options for patients within the Medicaid population. This is the case in many towns and cities across the state. 


\section{APPOINTMENT KEEPING BEHAVIOR}

One of the most important variables to review when considering treatment duration is the number of appointments missed. This study evaluated the appointment keeping behavior of each patient within their respective payment type. It was found that $50 \%$ of Medicaid patients failed at least one appointment during the course of orthodontic treatment, however only $30 \%$ of the non-Medicaid populations failed at least one appointment. It could be inferred that this relates to other variables in a significant way. It was previously noted that private pay and insurance patients both have significantly shorter overall length of treatment than Medicaid patients, which directly ties into number of broken appointments. One study found that each failed appointment was associated with just over 1 month additional treatment time. ${ }^{39}$ Fink and Smith also looked at broken appointments during treatment and found that failed appointments added significantly to treatment time. ${ }^{10}$

The findings within this study are inconsistent with other research that has been completed in this area. Previous studies have evaluated this variable as it relates to treatment time. Wilson and Harris found that Medicaid patients failed significantly more appointments than non-Medicaid patients. The subjects within their study were similar to those within the current study in that the commute time for private pay patients was significantly greater than for Medicaid patients. It would be advantageous to look at the data within the current study and determine the exact number of appointments failed by each patient to evaluate if there is significance in the number of appointments failed, rather than whether or not the patient failed at least one appointment. Further research should also be done on a larger sample size to determine if this variable reaches a significant level. 


\section{HYPOTHESIS TESTING:}

1. ACCEPTED: There is no significant difference in successful treatment outcome between various payment types.

2. There is no significant difference in oral hygiene ratings between various payment types.

a. ACCEPTED: Between private pay and insurance, and between insurance and Medicaid.

b. REJECTED: There is a significant difference in oral hygiene ratings between private pay and Medicaid/CHIP patients.

3. ACCEPTED: There is no significant effect of oral hygiene ratings on successful treatment outcome.

4. There is no significant difference in distance traveled between various payment types.

a. ACCEPTED: Between insurance and Medicaid/CHIP patients.

b. REJECTED: There is a significant difference in distance traveled between private pay and insurance patients, and between private pay and Medicaid/CHIP patients.

5. ACCEPTED: There is no significant effect of oral hygiene ratings on actual length of orthodontic treatment.

6. There is no significant difference in actual treatment length between various payment types.

a. ACCEPTED: Between private pay and insurance patients

b. REJECTED: There is a significant difference in actual treatment length between insurance and Medicaid/CHIP patients, and between Medicaid/CHIP and private pay patients. 
7. ACCEPTED: There is no significant difference in broken appointments between various payment types. 


\section{CHAPTER 6: SUMMARY AND CONCLUSIONS}

\section{SUMMARY}

The specific aim of this study was to utilize pre- and post-treatment records, as well as patient charts, to investigate factors that affect the outcome of orthodontic treatment. Furthermore, the study was looking to analyze specific payment types, and determine if differences existed between them in regard to treatment outcome and the affecting factors. The final 91 subjects used in this study represent an unbiased sample that met the inclusion criteria collected from the private practices of Dr. Daniel Foley in Beckley and Mt. Nebo, West Virginia. Pre-treatment records and post-treatment models were scored using the standardized method established by the American Board of Orthodontics, excluding radiographic criterion. Statistical analysis was performed for all the variables, with several variables showing statistical significance.

\section{CONCLUSIONS}

Based on the results of this study, the following conclusions have been reached:

1. There is no difference in the ability of private pay, insurance, or Medicaid/CHIP patients to attain a successful treatment outcome, nor is there a difference in their appointment keeping behavior.

2. On average, private pay patients have significantly better oral hygiene and travel a significantly longer distance for orthodontic treatment than Medicaid/CHIP patients.

3. More research needs to be conducted to determine the specific impact of oral hygiene on the ability to obtain a successful treatment outcome. 
4. Medicaid/CHIP patients are in active orthodontic treatment significantly longer than private pay and insurance patients. 


\section{CHAPTER 7: RECOMMENDATIONS FOR FUTURE RESEARCH}

\section{RECOMMENDATIONS ON SAMPLE COLLECTION}

There is a need for more research on this subject matter and specifically with a larger sample size. This study should be repeated with a larger sample in order to see if some of the data that was observed is significant and failed to reach significance due to a small sample size. One limitation that was faced within this study was the small number of patients, especially from the private pay group. Having more patients from within this group would increase the reliability of the results found. Furthermore, including only the patients who have a Discrepancy Index score of 10 or greater would yield more substantial results, as these patients would initially qualify as a "Board quality case." Because of the limited number of subjects within this sample whose Discrepancy Index was greater than $10(\mathrm{~N}=38)$, all subjects were included regardless of Discrepancy Index.

\section{RECOMMENDATIONS ON METHODOLOGY}

Further research should include the radiographic analysis of both the Discrepancy Index and Model Grading System. Due to the lack of pre- and post-treatment radiographs for all subjects studied, this portion of the scoring was omitted. By including this criterion, a greater number of patients would have higher Discrepancy Index scores, therefore deeming them more difficult cases to treat and providing greater validation of the treatment outcome. 


\section{REFERENCES}

1. Medicaid \& CHIP: June 2016 Monthly Applications, Eligibility Determinations and Enrollment Report. https://www.medicaid.gov/medicaid-chip-programinformation/program-information/downloads/june-2016-enrollment-report.pdf Accessed August 31, 2016.

2. Lang, W. \& Weintraub, J. (1986) Comparison of Medicaid and non-Medicaid dental providers. J Public Health Dentistry. 46: 207-211.

3. Im, J., Phillips, C., Lee, J., \& Bean, R. (2007) The North Carolina Medicaid Program: Participation and perceptions among orthodontists. Am J Orthod Dentofacial Orthop. 132: e15-e21.

4. Horsley, B., Lindauer, S., Shroff, B., Tufekci, E., Abubaker, O., Fowler, C., \& Maxfield, B. (2005) Appointment keeping behavior of Medicaid vs. non-Medicaid orthodontic patient. Am J Orthod Dentofacial Orthop. 132: 49-53.

5. Albino, J., Lawrence, S., Lopes, C., Nash, L., \& Tedesco L. (1991) Cooperation of adolescents in orthodontic treatment. J Behav Med. 14: 53-70

6. Southard, K., Tolley, E., Arheart, K., Hackett-Renner, C., \& Southard, T. (1991) Application of the million adolescent personality inventory in evaluating orthodontic compliance. Am J Orthod Dentofacial Orthop. 100: 553-561

7. Rinchuse, D., Rinchuse, D., \& Zullo, T. (1992) Oral hygiene compliance: A clinical investigation. J Clinical Orthod. 16: 33-38.

8. Loe, H., Theilade, E. \& Jensen, S. (1965) Experimental gingivitis in man. J Periodontol. 36 (3): 177-187.

9. Boyles, G. \& Ngan, P. (2006) Management of orthodontic patients with oral hygiene problems: a case report. J Ped Dent. 12: 18-20.

10. Fink, D. \& Smith, R. (1992) The duration of orthodontic treatment. Am J Orthod Dentofacial Orthop. 102: 45-51.

11. Albino, J., Lawrence, S., Lopes, C., Nash, L., \& Tedesco, L. (1991) Cooperation of adolescents in orthodontic treatment. J Beh Med. 14:53-70. 
12. Department of Health and Human Resources, West Virginia. (2017) Your 2017 Guide to Medicaid. Available from: https://dhhr.wv.gov/bms/Pages/default.aspx Web. Accessed 2 February 2018.

13. Kaiser, Henry J. Family Foundation. (2017) Medicaid in West Virginia. Web. Available from https://www.kff.org. Accessed 2 February 2018.

14. Norris, L. (2017) West Virginia and the ACA's Medicaid expansion. Web. Available from https://www.healthinsurance.org/west-virginia-medicaid/ Accessed 2 February 2018.

15. Salzmann, J. (1966) Orthodontics under Medicare and Medicaid. Am J Orthod 52:922926.

16. Parker, W. (2000) Useful data from application of the HLD (CalMod) index. Am J Orthod Dentofacial Orthop. 117:435-437.

17. American Association of Orthodontists. (2015) AAO Leads Effort to Establish Consistency on Medically Necessary Orthodontic Care. Web. Available from: https://www.aaoinfo.org/news/2015/07/aao-leads-effort-establish-consistency-medicallynecessary-orthodontic-care

18. Department of Health and Human Resources, West Virginia. (2016) Chapter 505 Dental, Orthodontics, and Oral Health Services. BMS Provider Manual.

19. BMS/UMC. Comprehensive Orthodontic Treatment Prior Authorization Request Form. 2010.

20. El-Gheriani, A., Ehrmantrout, Z., Oesterle, L., Berg, R., \& Wilkerson, D. (2007) Medicaid expenditures for orthodontic services. Am J Orthod Dentofacial Orthop. 728 : e1-e8.

21. Damiano, P., Brown, E., Johnson, J., \& Scheetz, J. (1990) Factors affecting dentist participation in a state Medicaid Program. J Dent Educ. 54: 638-643.

22. Minick, G., Tilliss, T., Shellhart, W., Newman, S., Carey, C., Horne, A., Whitt, S., \& Oesterle, L. (2017) Comparison of Orthodontic Medicaid Funding in the United States 2006 to 2015. Front Public Health 5:221 
23. Nainar, S. \& Tinanoff, N. (1997) Effect of Medicaid reimbursement rates on children's access to dental care. Am Academy of Ped Dent. 19: 315-316.

24. McKernan, S., Kuthy, R., Momany, E., McQuistan, M., Hanley, P., \& Jones, M. (2013) Geographic accessibility and utilization of orthodontic services among Medicaid children and adolescents. J Public Health Dent. 73: 56-64.

25. King, G., Hall, C., Milgrom, P., \& Grembowski, D. (2006) Early orthodontic treatment as a means to increase access for children enrolled in Medicaid in Washington state. $J$ Am Dent Assoc. 137: 86-94

26. Proffit, W. (2000) Contemporary orthodontics. $3^{\text {rd }}$ ed. St. Louis: Mosby.

27. Wilson, J. \& Harris, E. (2014) Compliance by state-subsidized and self-pay orthodontic patients. Am J Orthod Dentofacial Orthop. 148: 628-632.

28. Proffit, W., Fields, H., \& Moray, L. (1998) Prevalence of malocclusion and orthodontic treatment need in the United States: estimates from NHANES III survey. Int J Adult Orthod Orthognath Surg. 13: 97-106.

29. Bartsch, A., Witt, E., Sahm, G., \& Schneider, S. (1993) Correlates of objective patient compliance with removable appliance wear. Am J Orthod Dentofacial Orthop. 104: 378386.

30. Slakter, M., Albino, J., Fox, R., \& Lewis, E. (1980) Reliability and stability of the orthodontic patient cooperation scale. Am J of Orthod. 78: 559-563

31. Richter, D., Nanda, R., Sinha, P., \& Smith, D. (1998) Effect of behavior modification on patient compliance in orthodontics. Angle Orthod. 68: 123-132.

32. Jay, M. (1997) Compliance: The adolescent/provider partnership. In: Creating the compliant patient. McNamara, J. \& Trotman, C. (Eds) Center for human growth and development. University of Michigan, Ann Arbor.

33. Sergl, H., Klages, U., \& Zentner, A. (2000) Functional and social discomfort during orthodontic treatment - effects on compliance and prediction of patients' adaptation by personality variables. European J Orthod. 22: 307-315. 
34. Mirabelli, J., Huang, G., Siun, C., King, G., \& Omnell, L. (2005) The effectiveness of phase I orthodontic treatment in a Medicaid population. Am J Orthod Dentofacial Orthop. 127 (5): $592-598$

35. Martin, C., Dieringer, B., \& McNeil, D. (2017) Orthodontic treatment completion and discontinuation in a rural sample from North Central Appalachia in the USA. Front Public Health. 5: 1-6.

36. Dickens, S., Beane, R., Caplan, D., \& Vann, W. (2008) Comparison of treatment result and compliance between private practice Medicaid and non-Medicaid orthodontic patients - a brief communication. J Public Health Dent. 68: 167-169.

37. Gorelick, L., Geiger, A., \& Gwinnett, A. (1982) Incidence of white spot formation after bonding and banding. Am J Orthod. 81: 93-98

38. Mitchell, L. (1992) Decalcification during orthodontic treatment with fixed appliances an overview. Br J Orthod. 19: 199-205.

39. Beckwith, F., Ackerman, R., Cobb, C., \& Tira, D. (1999) An evaluation of factors affecting orthodontic treatment. Am J Orthod Dentofacial Orthop. 115: 439-447

40. Skidmore, K., Brook, K., Thomson, W., \& Harding, W. (2004) Factors influencing treatment time in orthodontic patients. Am J Orthod Dentofacial Orthop. 129: 230-238

41. Egolf, R., BeGole, E., \& Upshaw, H. (1981) Factors associated with orthodontic patient compliance with intraoral elastic and headgear wear. Am J Orthod Dentofacial Orthop. 97: 336-348.

42. Shia, G. (1986) Treatment overruns. J Clin Orthod. 20: 602-604.

43. Trenouth, M. (2003) Do failed appointments lead to discontinuation of orthodontic treatment? Angle Orthod. 73: 51-55.

44. Richardson, A. (1998) Failed appointments in an academic orthodontic clinic. Br Dent J. 184: 612-615.

45. Can, S., Macfarlane, T., \& O'Brien, K. (2003) The use of postal reminders to reduce nonattendance at an orthodontic clinic: a randomized controlled trial. Br Dent J. 19:199-201. 
46. Fazio, R. \& Boffa, J. (1977) A study of "broken appointment patients in a children's hospital dental clinic. J Dent Res. 56: 1071-1076.

47. DiStasio, J. (1969) The occurrence of "no show" appointments among Medicaid and private dental patients. J Mass Dent Soc. 18: 82-84.

48. Bukhari, O., Sohrabi, K., \& Tavares, M. (2015) Factors affecting patients' adherence to orthodontic appointments. Am J Orthod Dentofacial Orthop. 149: 319-324.

49. American Board of Orthodontics. (2016) Discrepancy Index: A Measure of Case Complexity. Web. Available from: https://www.americanboardortho.com/media/1189/ discrepancy_index_scoring_system.pdf. Accessed: February 10, 2018.

50. American Board of Orthodontics. (2012) Grading System for Dental Casts and Panoramic Radiographs. Web. Available from: https://www.americanboardortho.com /media /1191/grading-system-casts-radiographs.pdf. Accessed: February 10, 2018. 


\section{APPENDICES}

\section{APPENDIX A - IRB EXEMPTION}

\section{WesthriginiaUniversity, \\ Office of Research Integrity and Compliance \\ 886 CHESNUT RADGE ROAD MORGANTOWN, WV 26506}

Acknowledgement Letter Exempt Initial Protocol Review

$\begin{array}{ll}\text { Action Date } & \text { 05/25/2017 } \\ \text { To } & \text { Chris Martin } \\ \text { From } & \text { WVU Office of Research Integrity and Compliance } \\ \text { Approval Date } & 05 / 25 / 2017 \\ \text { Expiration Date } & 05 / 24 / 2020 \\ \text { Subject } & \text { Acknowledgement Letter Exempt Initial Protocol Review } \\ \text { Protocol Number } & 1705579750 \\ \text { Title } & \text { Factors affecting orthodontic treatment outcomes in West Virginia. }\end{array}$

The above-referenced study was reviewed by the West Virginia University Institutional Review Board IRB and was granted exemption in accordance with 45 CFR 46.101.

- This research study was granted an exemption in accordance with Research on existing data, documents, records, pathological specimens, or diagnostic specimens [45 CFR 46.101(4)]. In accordance with the Health Insurance Portability and Accountability Act, a waiver of research authorization has been granted. Please fulfill the subject accounting requirements associated with the granting of this waiver. All exemptions are only good for three years. If this research extends more than three years beyond the approved date, then the researcher will have to request another exemption. The following documents have been acknowledged for use in this study and are available in the WVU+kc system:

Documents reviewed and/or approved as part of this submission:

Permission Letter.pdf: 2017-05-23-04:00

HIPAA Waiver Form 1.docx: 2017-05-10-04:00

Documents for use in this study have been acknowledged and are available in the WVUkc system in the Notes and Attachments section of your protocol.

The Office of Research Integrity and Compliance is here to provide assistance to you from the initial submission of an IRB protocol and all subsequent activity. Please feel free to contact us by phone at 304.293 .7073 with any question you may have. Thank you. 
WVU Office of Research Integrity and Compliance

Date:05/25/2017

Signed:

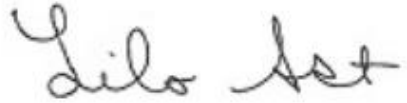

Lilo Ast

Senior Program Coordinator 


\title{
APPENDIX B - LEGEND
}

\author{
LEGEND| \\ Gender \\ 1: Male \\ 2: Female \\ Practice Location \\ 1: Beckley \\ 2: Mt. Nebo \\ Payment Type \\ 1: Private Pay \\ 2: Insurance \\ 3: Medicaid/CHIP \\ Oral Hygiene $(\mathrm{OH})$ \\ 5: Excellent \\ 4: VeryGood \\ 3: Good \\ 2: Fair \\ 1: Poor \\ Treatment \\ 1: Records \\ 2: Placement of Separators \\ 3: Banding and Bonding (braces) \\ 4: Impression for Appliance \\ 5: Device Adjustment \\ 6: Deband/Debond \\ 7: Emergency (Replace/Recement bracket or band) \\ 8: Cancelled Appointment \\ 9: Failed/Broken Appointment \\ 10: Refer for Extraction \\ 999: Missing information
}




\section{APPENDIX C - ORAL HYGIENE RELIABILITY}

Employee number:

\section{ORAL HYGIENE GRADING SHEET}

Please rate the oral hygiene in the following photos from 1 to 5 according to the following scale: $1=$ poor, $2=$ fair, $3=$ good, $4=$ great, $5=$ excellent. Place the number on the line to the right of the corresponding photo. Thank you!
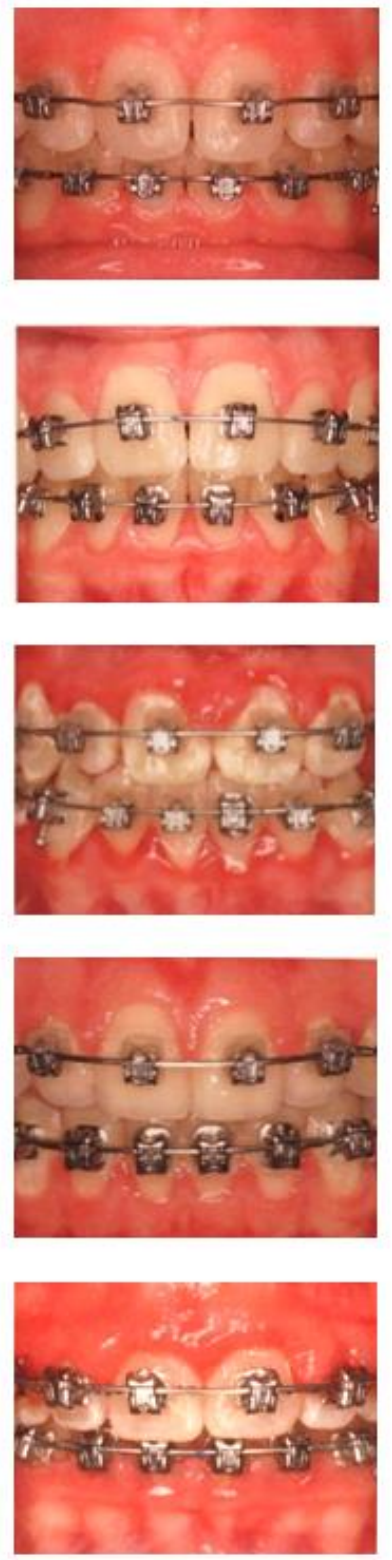


\begin{tabular}{|c|c|c|c|c|}
\hline Patient ID & Gender & Distance Traveled (miles) & Marital Status & Age Beginning \\
\hline 3 & 1 & 2.4 & Mother -- married & 12 \\
\hline 5 & 2 & 50.7 & Mother and Father -- married & 14 \\
\hline 6 & 1 & 16.6 & Married & 16 \\
\hline 8 & 2 & 20.7 & & 14 \\
\hline 9 & 1 & 36.1 & Mother -- single & 12 \\
\hline 10 & 2 & 23.2 & Mother and Father -. married & 13 \\
\hline 11 & 2 & 32.9 & Grandmother and Grandfather -- marri & 12 \\
\hline 12 & 2 & 5.3 & Mother -- single & 11 \\
\hline 13 & 2 & 34.9 & Mother and Father -- married & 14 \\
\hline 14 & 2 & 11.3 & Foster mother & 15 \\
\hline 15 & 1 & & Mother and Father -- married & 14 \\
\hline 16 & 2 & & Mother and Stepfather -- married & 15 \\
\hline 17 & 1 & & & 11 \\
\hline 18 & 2 & 9 & & 10 \\
\hline 19 & 2 & & Mother and Stepfather -- married & 12 \\
\hline 20 & 1 & 36.3 & Divorced & 13 \\
\hline 22 & 2 & 5.9 & Mother and Father -- married & 17 \\
\hline 23 & 2 & 34.6 & Grandmother and Grandfather -- divord & 10 \\
\hline 24 & 2 & 17.8 & Grandmother and Grandfather - - marri & 11 \\
\hline 25 & 2 & 9.9 & Mother and Father -- married & 15 \\
\hline 26 & 2 & & Mother -- single & 14 \\
\hline 27 & 1 & 39.1 & & 12 \\
\hline 29 & 1) & 0.6 & Mother -- widowed & 12 \\
\hline 30 & 2 & 11.1 & Mother and Father $\cdots$ divorced & 12 \\
\hline 32 & 1 & & & 12 \\
\hline 33 & 2 & 2.7 & & 12 \\
\hline 34 & 1 & 20.1 & & 12 \\
\hline 35 & 2 & 20.8 & Mother and Father $\cdots$ divorced & 14 \\
\hline 36 & 2 & 17.3 & Grandmother and Grandfather -- marri & 15 \\
\hline 37 & 1 & 27.5 & Mother and Father -- married & 12 \\
\hline 38 & 2 & 4.9 & Mother and Father -- married & 11 \\
\hline 39 & 1 & 30.9 & & 15 \\
\hline 40 & 2 & 21 & Father and Stepmom -- married & 13 \\
\hline 41 & 2 & 21 & Mother and Stepfather -- married & 10 \\
\hline 42 & 2 & 28.3 & & 20 \\
\hline 43 & 2 & 21.4 & & 20 \\
\hline 44 & 2 & 12.1 & Mother and Father -. married & 12 \\
\hline 45 & 2 & 19.6 & Mother and Father -- divorced & 11 \\
\hline 46 & 2 & 33.7 & Mother and Father -- married & 8 \\
\hline 47 & 2 & 9.1 & & 14 \\
\hline 48 & 2 & 5.3 & Mother and Father -- married & 13 \\
\hline 49 & 2 & 60.3 & Mother and Father -- married & 13 \\
\hline 50 & 1 & 4.6 & Mother and Father $\cdots$ divorced & 12 \\
\hline 51 & 1 & 54.5 & Mother and Stepfather -- married & 12 \\
\hline 52 & 1 & 7.6 & Mother and Father -- married & 12 \\
\hline 53 & 2 & 18.3 & Father -- single & 8 \\
\hline
\end{tabular}




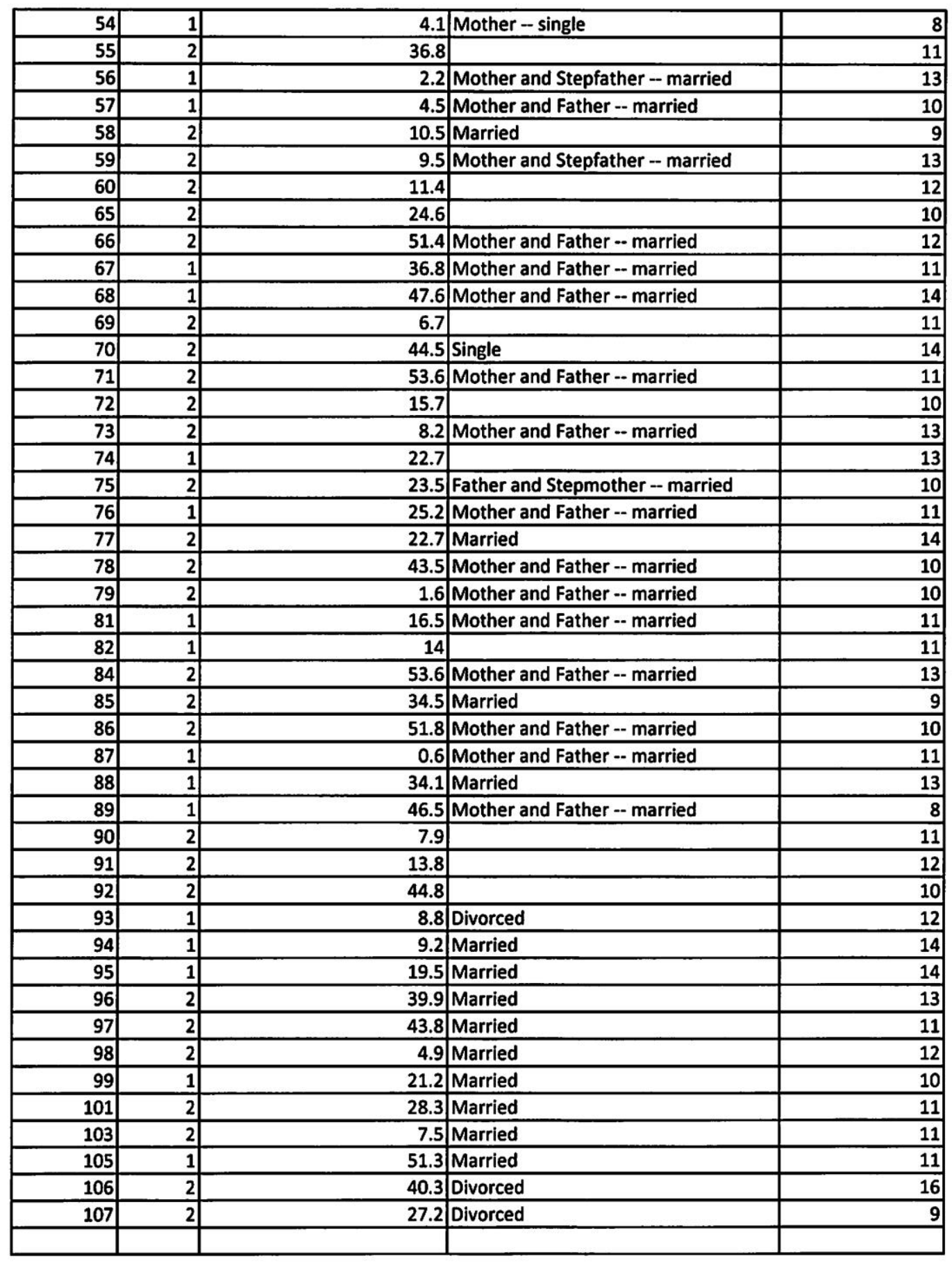




\begin{tabular}{|c|c|c|c|c|}
\hline Est. Tx Length (mos) & Actual Tx Length (mos) & Practice Location & Pay & Discrepancy Index \\
\hline 18 & 19 & 1 & 3 & 11 \\
\hline 16 & 26 & 1 & 3 & 11 \\
\hline 24 & 30 & 1 & 3 & 10 \\
\hline 22 & 45 & 1 & 3 & 10 \\
\hline 18 & 26 & 1 & 3 & 13 \\
\hline 18 & 25 & 1 & 3 & 9 \\
\hline 14 & 22 & 1 & 3 & 2 \\
\hline 18 & 27 & 1 & 3 & 4 \\
\hline 18 & 27 & 1 & 3 & 8 \\
\hline 18 & 28 & 1 & 3 & 10 \\
\hline 18 & 29 & 1 & 3 & 12 \\
\hline 18 & 25 & 1 & 3 & 10 \\
\hline 18 & 15 & 1 & 3 & 8 \\
\hline 36 & 36 & 1 & 4 & 12 \\
\hline 18 & 22 & 1 & 3 & $\underline{6}$ \\
\hline 24 & 34 & 1 & 3 & 16 \\
\hline 18 & 48 & 1 & 4 & 9 \\
\hline 18 & 36 & 1 & 3 & 4 \\
\hline 18 & 24 & 1 & 3 & 11 \\
\hline 18 & 27 & 1 & 3 & 17 \\
\hline 18 & 31 & 1 & 3 & 11 \\
\hline 18 & 31 & 1 & 3 & 11 \\
\hline 24 & 10 & 1 & 3 & 11 \\
\hline 20 & 22 & 1 & 3 & 5 \\
\hline 24 & 51 & 1 & 3 & 2 \\
\hline 18 & 17 & 1 & 3 & 13 \\
\hline 18 & 36 & 2 & 4 & 6 \\
\hline 24 & 37 & 2 & 4 & 10 \\
\hline 18 & 26 & 2 & 3 & 6 \\
\hline 18 & 20 & 2 & 3 & 7 \\
\hline 18 & 29 & 2 & 3 & 11 \\
\hline 18 & 20 & 2 & 3 & 15 \\
\hline 20 & 37 & 2 & 3 & 10 \\
\hline 18 & 32 & 2 & 3 & 7 \\
\hline 18 & 21 & 2 & 3 & 8 \\
\hline 7 & 15 & 2 & 3 & 11 \\
\hline 14 & 23 & 2 & 3 & 8 \\
\hline 18 & 25 & 2 & 3 & 6 \\
\hline 18 & 18 & 2 & 4 & 8 \\
\hline 18 & 30 & 2 & 3 & 13 \\
\hline 18 & 19 & 2 & 3 & 3 \\
\hline 18 & 15 & 2 & 4 & 4 \\
\hline 20 & 29 & 2 & 3 & 21 \\
\hline 18 & 20 & 1 & 2 & 13 \\
\hline 18 & 18 & 1 & 2 & 5 \\
\hline 36 & 44 & 1 & 2 & 5 \\
\hline
\end{tabular}




\begin{tabular}{|c|c|c|c|c|}
\hline 36 & 31 & 1 & 2 & 0 \\
\hline 8 & 8 & 1 & 2 & 12 \\
\hline 18 & 26 & 1 & 2 & 12 \\
\hline 30 & 32 & 1 & 2 & 0 \\
\hline 22 & 35 & 1 & 2 & 7 \\
\hline 18 & 14 & 1 & 2 & 9 \\
\hline 19 & 8 & 1 & 2 & 4 \\
\hline 36 & 35 & 1 & 2 & 11 \\
\hline 12 & 11 & 1 & 1 & 1 \\
\hline 18 & 17 & 1 & 1 & 2 \\
\hline 18 & 27 & 1 & 2 & 6 \\
\hline 30 & 43 & 1 & 2 & 11 \\
\hline 12 & 9 & 1 & 1) & 4 \\
\hline 18 & 15 & 1 & 1 & 2 \\
\hline 17 & 23 & 1 & 3 & 6 \\
\hline 10 & 8 & 1 & 2 & 0 \\
\hline 18 & 25 & 1 & 1 & 6 \\
\hline 22 & 28 & 1 & 1 & 10 \\
\hline 18 & 13 & 1 & 2 & 10 \\
\hline 18 & 13 & 1 & 2 & 10 \\
\hline 18 & 17 & 1 & 2 & 3 \\
\hline 6 & 20 & 1 & 2 & 3 \\
\hline 30 & 38 & 1 & 2 & 12 \\
\hline 12 & 9 & 1 & 2 & 10 \\
\hline 12 & 15 & 1 & 2 & 0 \\
\hline 18 & 16 & 1 & 2 & 5 \\
\hline 18 & 18 & 1 & 2 & 10 \\
\hline 18 & 20 & 1 & 2 & 7 \\
\hline 18 & 37 & 1 & 2 & 999 \\
\hline 14 & 15 & 2 & 1) & 11 \\
\hline 18 & 13 & 2 & 2 & 5 \\
\hline 18 & 24 & 2 & 2 & 2 \\
\hline 18 & 28 & 2 & 1 & 4 \\
\hline 18 & 17 & 2 & 2 & 7 \\
\hline 20 & 14 & 2 & 1 & 8 \\
\hline 12 & 12 & 2 & 2 & 3 \\
\hline 18 & 30 & 2 & 1 & 10 \\
\hline 18 & 19 & 2 & 1 & 8 \\
\hline 18 & 23 & 2 & 1 & 10 \\
\hline 17 & 21 & 2 & 2 & 3 \\
\hline 18 & 19 & 2 & 2 & 7 \\
\hline 12 & 6 & 2 & 2 & 4 \\
\hline 18 & 19 & 2 & 1 & 6 \\
\hline 16 & 17 & 2 & 1 & 2 \\
\hline 24 & 22 & 2 & 2 & 6 \\
\hline & 1 & & & \\
\hline
\end{tabular}




\begin{tabular}{|c|c|}
\hline$\overline{A B O}$ & Successful/Not Successful \\
\hline 28 & 2 \\
\hline 28 & 2 \\
\hline 31 & 2 \\
\hline 44 & 2 \\
\hline 38 & 2 \\
\hline 26 & $\overline{1}$ \\
\hline 31 & 2 \\
\hline 15 & 1 \\
\hline 37 & 2 \\
\hline 53 & 2 \\
\hline 53 & 2 \\
\hline 21 & 1 \\
\hline 23 & 1 \\
\hline 26 & 1 \\
\hline 22 & 1 \\
\hline 26 & 1 \\
\hline 42 & 2 \\
\hline 32 & 2 \\
\hline 27 & 1 \\
\hline 45 & 2 \\
\hline 14 & 1 \\
\hline 30 & 2 \\
\hline 44 & 2 \\
\hline 27 & 1 \\
\hline 21 & 1 \\
\hline 35 & 2 \\
\hline 24 & 1 \\
\hline 34 & 2 \\
\hline 13 & 1 \\
\hline 25 & 1 \\
\hline 31 & 2 \\
\hline 31 & 2 \\
\hline 25 & 1 \\
\hline 33 & 2 \\
\hline 28 & 2 \\
\hline 44 & 2 \\
\hline 20 & 1 \\
\hline 27 & 1 \\
\hline 23 & 1 \\
\hline 41 & 2 \\
\hline 26 & 1 \\
\hline 23 & 1 \\
\hline 39 & 2 \\
\hline 46 & 2 \\
\hline 30 & 2 \\
\hline 34 & 2 \\
\hline
\end{tabular}




\begin{tabular}{|c|c|}
\hline 24 & \\
\hline 25 & 1 \\
\hline 19 & 1 \\
\hline 52 & 2 \\
\hline 27 & 1 \\
\hline 18 & 1 \\
\hline 19 & 1 \\
\hline 46 & 2 \\
\hline 23 & 1 \\
\hline 17 & 1 \\
\hline 22 & 1 \\
\hline 48 & 2 \\
\hline 15 & 1 \\
\hline 27 & 1 \\
\hline 26 & 1 \\
\hline 21 & 1 \\
\hline 27 & 1 \\
\hline 31 & 2 \\
\hline 16 & 1 \\
\hline 42 & 2 \\
\hline 17 & 1 \\
\hline 31 & 2 \\
\hline 37 & 2 \\
\hline 17 & 1 \\
\hline 31 & 2 \\
\hline 20 & 1 \\
\hline 20 & 1 \\
\hline 26 & 1 \\
\hline 39 & 2 \\
\hline 28 & 2 \\
\hline 27 & 1 \\
\hline 45 & 2 \\
\hline 55 & 2 \\
\hline 43 & 2 \\
\hline 13 & 1 \\
\hline 25 & 1 \\
\hline 29 & 2 \\
\hline 33 & 2 \\
\hline 42 & 2 \\
\hline 32 & 2 \\
\hline 33 & 2 \\
\hline 34 & 2 \\
\hline 31 & 2 \\
\hline 32 & 2 \\
\hline 35 & 2 \\
\hline . & \\
\hline
\end{tabular}




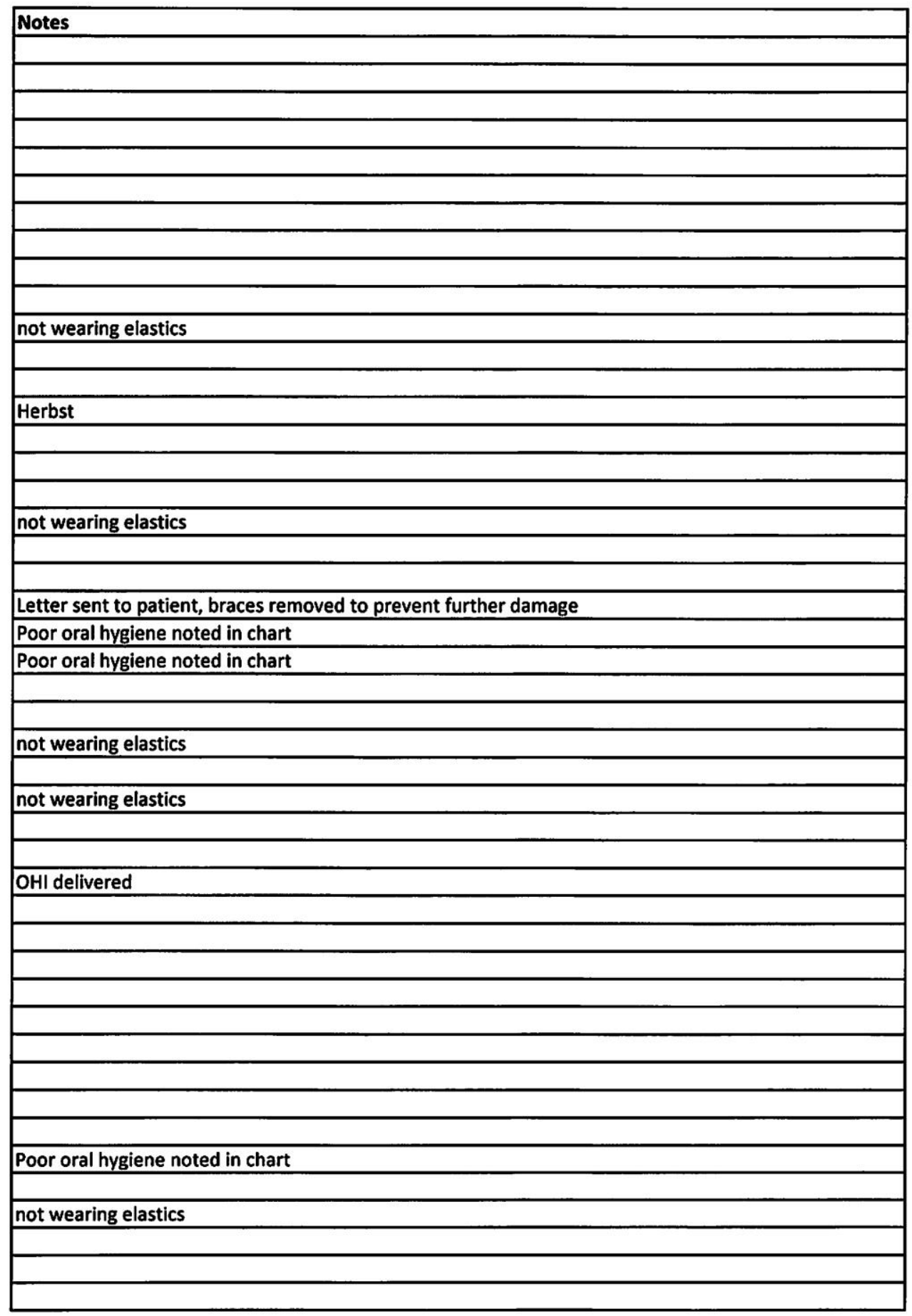




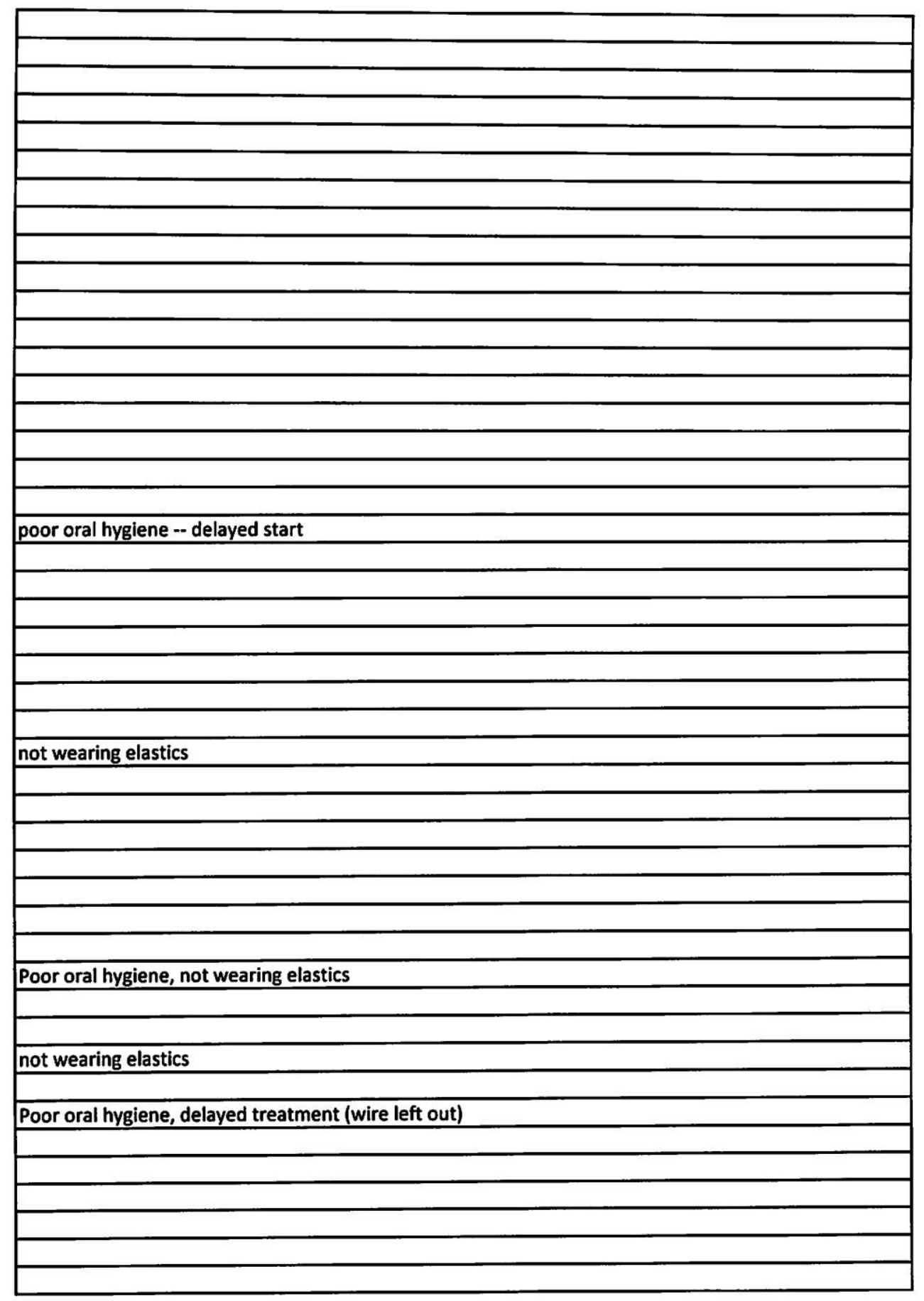




\begin{tabular}{|c|c|c|c|c|c|c|c|c|}
\hline 1-Date & $1-\mathrm{OH}$ & 1 - Asst & $1-T x$ & 2-Date & $2-\mathrm{OH}$ & 2-Asst & $2-T x$ & 3 - Date \\
\hline $10 / 7 / 2015$ & 5 & 152 & 1 & $11 / 5 / 2015$ & 4 & 159 & 2 & $2 / 1 / 2016$ \\
\hline $3 / 25 / 2015$ & 4 & 107 & 1 & $4 \quad 4 / 16 / 2015$ & 5 & 164 & 2 & $6 / 17 / 2015$ \\
\hline \begin{tabular}{|l|}
$12 / 10 / 2014$ \\
\end{tabular} & 5 & 152 & 1 & $\begin{array}{ll}1 / 19 / 2015 \\
\end{array}$ & 5 & 152 & 3 & $3 / 24 / 2015$ \\
\hline $8 / 7 / 2013$ & 4 & 132 & 1 & $9 / 9 / 2013$ & 4 & 159 & 2 & $10 / 23 / 2013$ \\
\hline $3 / 25 / 2015$ & 4 & 163 & 1 & $4 / 16 / 2015$ & 5 & 11 & 2 & $6 / 17 / 2015$ \\
\hline $3 / 26 / 2015$ & 3 & 159 & 1 & $5 / 6 / 2015$ & 3 & 110 & 2 & $7 / 15 / 2015$ \\
\hline $7 / 15 / 2015$ & 4 & 163 & 1 & $8 / 3 / 2015$ & 4 & 164 & 2 & $10 / 21 / 2015$ \\
\hline $2 / 25 / 2015$ & 4 & 159 & 1 & $13 / 23 / 2015$ & 4 & 104 & 2 & $3 / 24 / 2015$ \\
\hline $2 / 25 / 2015$ & 4 & 164 & 1 & \begin{tabular}{l|l|} 
& $3 / 16 / 2015$ \\
\end{tabular} & 4 & 107 & 2 & $3 / 18 / 2015$ \\
\hline $1 / 19 / 2015$ & 4 & 164 & 1 & $2 / 2 / 2015$ & 3 & 113 & 2 & $3 / 25 / 2015$ \\
\hline $12 / 3 / 2014$ & 3 & 164 & 1 & $11 / 12 / 2015$ & 4 & 132 & 2 & $4 / 15 / 2015$ \\
\hline $4 / 27 / 2015$ & 4 & 163 & 1 & $5 / 13 / 2015$ & 4 & 163 & 3 & $5 / 20 / 2015$ \\
\hline $12 / 2 / 2015$ & 4 & 163 & 1 & $12 / 28 / 2015$ & 5 & 159 & 3 & $3 / 9 / 2016$ \\
\hline $5 / 19 / 2014$ & 5 & 132 & 1 & 1 $6 / 16 / 2014$ & 4 & 113 & 4 & $8 / 18 / 2014$ \\
\hline $4 / 29 / 2015$ & 4 & 163 & 1 & $6 / 1 / 2015$ & 4 & 159 & 2 & $8 / 5 / 2015$ \\
\hline $7 / 14 / 2014$ & 2 & 159 & 1 & $8 / 4 / 2014$ & 4 & 104 & 3 & $8 / 7 / 2014$ \\
\hline $3 / 27 / 2013$ & 4 & 110 & 1 & $16 / 12 / 2013$ & 5 & 152 & 4 & $8 / 14 / 2013$ \\
\hline $5 / 19 / 2014$ & 4 & 132 & 1 & $6 / 2 / 2014$ & 4 & 107 & 2 & $6 / 5 / 2014$ \\
\hline $6 / 11 / 2015$ & 5 & 152 & 1 & $6 / 25 / 2015$ & 5 & 11 & 2 & $8 / 31 / 2015$ \\
\hline $8 / 13 / 2014$ & 4 & 132 & 1 & $12 / 8 / 2014$ & 1 & 159 & 4 & $3 / 9 / 2015$ \\
\hline \begin{tabular}{|l|}
$10 / 20 / 2014$ \\
\end{tabular} & 4 & 132 & 1 & $11 / 17 / 2014$ & 4 & 159 & 2 & $2 / 4 / 2015$ \\
\hline $10 / 20 / 2014$ & 4 & 163 & 1 & $11 / 17 / 2014$ & 5 & 152 & 2 & $11 / 24 / 2014$ \\
\hline $5 / 9 / 2016$ & 4 & 164 & 1 & $6 / 6 / 2016$ & 3 & 104 & 2 & $8 / 24 / 2016$ \\
\hline $6 / 24 / 2015$ & 4 & 163 & 1 & $8 / 3 / 2015$ & 4 & 159 & 2 & $10 / 21 / 2015$ \\
\hline $2 / 25 / 2013$ & 4 & 107 & 1 & $3 / 11 / 2013$ & 5 & 154 & 3 & $5 / 8 / 2013$ \\
\hline $1 / 18 / 2016$ & 4 & 163 & 1 & $1 / 28 / 2016$ & 4 & 132 & 2 & $4 / 4 / 2016$ \\
\hline $4 / 8 / 2014$ & 3 & 113 & 1 & $6 / 17 / 2014$ & 4 & 159 & 2 & $8 / 5 / 2014$ \\
\hline $3 / 11 / 2014$ & 5 & 152 & 1 & $5 / 27 / 2014$ & 4 & 159 & 4 & $7 / 22 / 2014$ \\
\hline $3 / 17 / 2015$ & 4 & 159 & 1 & $4 / 21 / 2015$ & 5 & 152 & 3 & $4 / 22 / 2015$ \\
\hline $7 / 21 / 2015$ & 3 & 113 & 1 & $10 / 6 / 2015$ & 4 & 132 & 2 & $12 / 1 / 2015$ \\
\hline $10 / 7 / 2014$ & 3 & 147 & 1 & $11 / 18 / 2014$ & 999 & 999 & 8 & $1 / 13 / 2015$ \\
\hline $7 / 28 / 2015$ & 4 & 132 & 1 & $8 / 31 / 2015$ & 999 & 999 & 8 & $9 / 1 / 2015$ \\
\hline $3 / 18 / 2014$ & 4 & 110 & 1 & $5 / 20 / 2014$ & 4 & 132 & 2 & $7 / 29 / 2014$ \\
\hline $9 / 9 / 2014$ & 4 & 152 & 1 & $10 / 28 / 2014$ & 3 & 104 & 3 & $12 / 23 / 2014$ \\
\hline $9 / 1 / 2015$ & 5 & 132 & 1 & \begin{tabular}{|l|}
$9 / 15 / 2015$ \\
\end{tabular} & 5 & 132 & 2 & $11 / 10 / 2015$ \\
\hline $12 / 29 / 2015$ & 3 & 104 & 1 & $1 / 19 / 2016$ & 999 & 999 & 8 & $2 / 2 / 2016$ \\
\hline $6 / 9 / 2015$ & 4 & 132 & 1 & $7 / 14 / 2015$ & 4 & 132 & 2 & $9 / 1 / 2015$ \\
\hline $3 / 17 / 2015$ & 3 & 113 & 1 & $5 / 5 / 2015$ & 3 & 113 & 2 & $6 / 26 / 2015$ \\
\hline $9 / 29 / 2015$ & 4 & 152 & 1 & $12 / 1 / 2015$ & 5 & 152 & 3 & $2 / 2 / 2016$ \\
\hline $11 / 4 / 2014$ & 4 & 164 & 1 & $12 / 9 / 2014$ & 4 & 163 & 4 & $2 / 24 / 2015$ \\
\hline $10 / 20 / 2015$ & 4 & 107 & 1 & $11 / 17 / 2015$ & 3 & 152 & 3 & $1 / 19 / 2016$ \\
\hline $10 / 6 / 2015$ & 5 & 110 & 1 & $1 / 5 / 2016$ & 5 & 159 & 2 & $3 / 8 / 2016$ \\
\hline $10 / 7 / 2014$ & 4 & 110 & 1 & $1 / 13 / 2015$ & 4 & 163 & 4 & $3 / 17 / 2015$ \\
\hline $3 / 30 / 2015$ & 5 & 11 & 1 & $4 / 2 / 2015$ & 5 & 107 & 3 & $6 / 1 / 2015$ \\
\hline $4 / 27 / 2015$ & 4 & 159 & 1 & $6 / 4 / 2015$ & 5 & 132 & 3 & $7 / 30 / 2015$ \\
\hline $4 / 15 / 2013$ & \begin{tabular}{l|l}
4 \\
\end{tabular} & 159 & 1 & $6 / 10 / 2013$ & 5 & 154 & 2 & $6 / 17 / 2013$ \\
\hline
\end{tabular}




\begin{tabular}{|c|c|c|c|c|c|c|c|c|}
\hline $4 / 21 / 2014$ & 4 & 132 & 1 & $5 / 12 / 2014$ & 999 & 999 & 8 & $6 / 12 / 2014$ \\
\hline $10 / 24 / 2012$ & 5 & 11 & 1 & $12 / 17 / 2012$ & 5 & 154 & 3 & $2 / 20 / 2013$ \\
\hline $8 / 11 / 2014$ & 4 & 159 & 1 & $10 / 29 / 2014$ & 999 & 999 & 8 & $11 / 5 / 2014$ \\
\hline $5 / 15 / 2014$ & 4 & 11 & 1 & $5 / 22 / 2014$ & 999 & 999 & 8 & $5 / 28 / 2014$ \\
\hline $12 / 2 / 2013$ & 5 & 11 & 1 & $2 / 17 / 2014$ & 5 & 152 & 3 & $4 / 24 / 2014$ \\
\hline $7 / 15 / 2013$ & 4 & 11 & 1 & $12 / 28 / 2015$ & 4 & 164 & 3 & $1 / 14 / 2016$ \\
\hline $6 / 6 / 2016$ & 5 & 159 & 1 & $6 / 8 / 2016$ & 5 & 152 & 3 & $7 / 28 / 2016$ \\
\hline $3 / 17 / 2014$ & 5 & 163 & 1 & $3 / 31 / 2014$ & 5 & 152 & 3 & $6 / 5 / 2014$ \\
\hline $4 / 25 / 2016$ & 5 & 11 & 1 & $4 / 27 / 2016$ & 5 & 152 & 3 & $5 / 3 / 2016$ \\
\hline $10 / 14 / 2015$ & 4 & 159 & 1 & $12 / 17 / 2015$ & 999 & 999 & 8 & $1 / 6 / 2016$ \\
\hline $12 / 15 / 2014$ & 5 & 11 & 1 & $12 / 15 / 2014$ & 4 & 163 & 3 & $2 / 5 / 2015$ \\
\hline $8 / 5 / 2013$ & 5 & 11 & 1 & $8 / 14 / 2013$ & 5 & 132 & 3 & $10 / 21 / 2013$ \\
\hline $6 / 2 / 2016$ & 5 & 11 & 1 & $6 / 22 / 2016$ & 4 & 159 & 3 & $7 / 6 / 2016$ \\
\hline $1 / 29 / 2015$ & 5 & 152 & 1 & $1 / 4 / 2016$ & 5 & 163 & 3 & $3 / 28 / 2016$ \\
\hline $7 / 21 / 2014$ & 5 & 152 & 1 & $8 / 11 / 2014$ & 4 & 113 & 4 & $10 / 29 / 2014$ \\
\hline $2 / 12 / 2016$ & 5 & 11 & 1 & $8 / 8 / 2016$ & 4 & 163 & 3 & $10 / 5 / 2016$ \\
\hline $2 / 24 / 2015$ & 4 & 11 & 1 & $3 / 19 / 2015$ & 4 & 159 & 3 & $5 / 6 / 2015$ \\
\hline $12 / 8 / 2014$ & 5 & 11 & 1 & $12 / 22 / 2014$ & 4 & 164 & 3 & $2 / 25 / 2015$ \\
\hline $12 / 28 / 2015$ & 2 & 11 & 1 & $3 / 16 / 2016$ & 5 & 152 & 3 & $3 / 23 / 2016$ \\
\hline $10 / 10 / 2013$ & 5 & 11 & 1 & $3 / 14 / 2016$ & 4 & 164 & 3 & $3 / 21 / 2016$ \\
\hline $12 / 14 / 2015$ & 5 & 11 & 1 & $12 / 14 / 2015$ & 5 & 163 & 3 & $2 / 4 / 2016$ \\
\hline $6 / 9 / 2014$ & 4 & 11 & 1 & $9 / 14 / 2015$ & 4 & 159 & 1 & $9 / 28 / 2015$ \\
\hline $1 / 23 / 2013$ & 5 & 11 & 1 & $2 / 25 / 2013$ & 4 & 154 & 2 & $3 / 4 / 2013$ \\
\hline $1 / 28 / 2013$ & 5 & 104 & 1 & $12 / 23 / 2013$ & 4 & 145 & 4 & $1 / 27 / 2014$ \\
\hline $1 / 29 / 2015$ & 4 & 107 & 1 & $1 / 4 / 2016$ & 4 & 164 & 3 & $4 / 4 / 2016$ \\
\hline $7 / 22 / 2015$ & 5 & 11 & 1 & $9 / 14 / 2015$ & 999 & 999 & 8 & $11 / 4 / 2015$ \\
\hline $8 / 3 / 2015$ & 4 & 11 & 1 & $10 / 5 / 2015$ & 999 & 999 & 8 & $10 / 7 / 2015$ \\
\hline $9 / 14 / 2015$ & 5 & 11 & 1 & $10 / 5 / 2015$ & 999 & 999 & 9 & $10 / 26 / 2015$ \\
\hline $4 / 30 / 2014$ & 5 & 11 & 1 & $5 / 15 / 2014$ & 4 & 159 & 3 & $5 / 28 / 2014$ \\
\hline $9 / 15 / 2015$ & 4 & 107 & 1 & $9 / 29 / 2015$ & 5 & 104 & 3 & $12 / 1 / 2015$ \\
\hline $3 / 3 / 2015$ & 5 & 11 & 1 & $12 / 15 / 2015$ & 4 & 104 & 3 & $12 / 29 / 2015$ \\
\hline $11 / 11 / 2014$ & 5 & 11 & 1 & $1 / 20 / 2015$ & 5 & 104 & 3 & $1 / 27 / 2015$ \\
\hline $9 / 9 / 2014$ & 5 & 11 & 1 & $9 / 30 / 2014$ & 4 & 113 & 3 & $12 / 9 / 2014$ \\
\hline $7 / 28 / 2015$ & 4 & 11 & 1 & $8 / 4 / 2015$ & 4 & 113 & 3 & $8 / 11 / 2015$ \\
\hline $10 / 20 / 2015$ & 4 & 11 & 1 & $11 / 3 / 2015$ & 4 & 104 & 3 & $12 / 29 / 2015$ \\
\hline $12 / 8 / 2015$ & 5 & 11 & 1 & $1 / 5 / 2016$ & 4 & 113 & 3 & $3 / 8 / 2016$ \\
\hline $7 / 15 / 2014$ & 4 & 11 & 1 & $8 / 12 / 2014$ & 4 & 104 & 3 & $10 / 28 / 2014$ \\
\hline $11 / 11 / 2014$ & 5 & 11 & 1 & $7 / 21 / 2015$ & 4 & 113 & 3 & $9 / 15 / 2015$ \\
\hline $1 / 27 / 2015$ & 4 & 11 & 1 & $2 / 3 / 2015$ & 4 & 113 & 3 & $3 / 17 / 2015$ \\
\hline $5 / 12 / 2015$ & 5 & 11 & 1 & $5 / 26 / 2015$ & 5 & 104 & 3 & $7 / 21 / 2015$ \\
\hline $6 / 24 / 2014$ & 5 & 11 & 1 & $8 / 25 / 2015$ & 4 & 104 & 3 & $10 / 20 / 2015$ \\
\hline $9 / 29 / 2015$ & 5 & 11 & 1 & $3 / 15 / 2016$ & 2 & 104 & 3 & $5 / 24 / 2016$ \\
\hline $9 / 29 / 2015$ & 5 & 11 & 1 & $10 / 13 / 2015$ & 4 & 113 & 3 & $12 / 8 / 2015$ \\
\hline $11 / 17 / 2015$ & 5 & 11 & 1 & $12 / 8 / 2015$ & 4 & 113 & 3 & $1 / 5 / 2016$ \\
\hline $8 / 11 / 2015$ & 5 & 159 & 1 & $8 / 25 / 2015$ & 3 & 113 & 3 & $10 / 20 / 2015$ \\
\hline & & & & & & & & \\
\hline
\end{tabular}




\begin{tabular}{|c|c|c|c|c|c|c|c|c|}
\hline $3-\mathrm{OH}$ & 3 -Asst & $3-7 x$ & 4-Date & $4 . \mathrm{OH}$ & 4 -Asst & $4-T x$ & 5 - Date & $5-\mathrm{OH}$ \\
\hline 4 & 159 & 3 & $2 / 1 / 2016$ & 4 & 113 & 7 & $4 / 14 / 2016$ & 5 \\
\hline 5 & 132 & 3 & $9 / 2 / 2016$ & 4 & 107 & 3 & $11 / 16 / 2015$ & 3 \\
\hline 5 & 152 & 3 & $5 / 27 / 2015$ & 5 & 152 & 3 & $7 / 27 / 2015$ & 999 \\
\hline 4 & 159 & 3 & $12 / 12 / 2013$ & 4 & 159 & 7 & $1 / 8 / 2014$ & 999 \\
\hline 5 & 159 & 3 & $8 / 31 / 2015$ & 4 & 159 & 5 & $11 / 11 / 2015$ & 3 \\
\hline 3 & 113 & 3 & $7 / 15 / 2015$ & 4 & 104 & 7 & $9 / 16 / 2015$ & 4 \\
\hline 4 & 164 & 3 & $1 / 11 / 2016$ & 4 & 159 & 3 & $3 / 2 / 2016$ & 4 \\
\hline 4 & 132 & 7 & $5 / 13 / 2015$ & 4 & 163 & 3 & $7 / 27 / 2015$ & 3 \\
\hline 4 & 132 & 7 & $5 / 8 / 2015$ & 4 & 104 & 3 & $7 / 22 / 2015$ & 4 \\
\hline 4 & 107 & 3 & $3 / 26 / 2015$ & 4 & 163 & 7 & $5 / 27 / 2015$ & 4 \\
\hline 3 & 104 & 3 & $6 / 16 / 2015$ & 4 & 132 & 5 & $8 / 26 / 2015$ & 4 \\
\hline 4 & 132 & 4 & $7 / 23 / 2015$ & 5 & 104 & 3 & $10 / 7 / 2015$ & 5 \\
\hline 3 & 104 & 3 & $6 / 6 / 2016$ & 5 & 159 & 5 & $8 / 25 / 2016$ & 4 \\
\hline 3 & 159 & 2 & $8 / 27 / 2014$ & 4 & 164 & 5 & $11 / 12 / 2014$ & 999 \\
\hline 4 & 164 & 3 & $10 / 26 / 2015$ & 4 & 164 & 7 & $12 / 31 / 2015$ & 4 \\
\hline 4 & 132 & 2 & $10 / 30 / 2014$ & 3 & 113 & 3 & $11 / 12 / 2014$ & 999 \\
\hline 5 & 152 & 5 & $8 / 14 / 2013$ & 5 & 132 & 7 & $9 / 4 / 2013$ & 999 \\
\hline 4 & 132 & 7 & $8 / 11 / 2014$ & 4 & 104 & 3 & $10 / 29 / 2014$ & 999 \\
\hline 4 & 159 & 5 & $10 / 1 / 2015$ & 4 & 132 & 7 & $11 / 11 / 2015$ & 2 \\
\hline 4 & 107 & 5 & $4 / 27 / 2015$ & 3 & 113 & 3 & $6 / 29 / 2015$ & 999 \\
\hline 999 & 999 & 8 & $2 / 12 / 2015$ & 999 & 999 & 8 & $2 / 23 / 2015$ & 999 \\
\hline 5 & 132 & 7 & $2 / 9 / 2015$ & 999 & 999 & 9 & $4 / 24 / 2015$ & 3 \\
\hline 3 & 104 & 3 & $8 / 29 / 2016$ & 4 & 169 & 7 & $9 / 12 / 2016$ & 3 \\
\hline 4 & 163 & 5 & $11 / 9 / 2015$ & 4 & 159 & 7 & $1 / 11 / 2016$ & 4 \\
\hline 4 & 147 & 5 & $7 / 15 / 2013$ & 4 & 113 & 5 & $9 / 9 / 2013$ & 4 \\
\hline 4 & 159 & 5 & $6 / 1 / 2016$ & 4 & 164 & 5 & $8 / 27 / 2016$ & 999 \\
\hline 5 & 152 & 3 & $8 / 12 / 2014$ & 5 & 152 & 7 & $10 / 21 / 2014$ & 4 \\
\hline 4 & 159 & 5 & $10 / 7 / 2014$ & 4 & 164 & 3 & $11 / 5 / 2014$ & 4 \\
\hline 5 & 132 & 2 & $6 / 30 / 2015$ & 4 & 164 & 5 & $9 / 1 / 2015$ & 999 \\
\hline 4 & 164 & 3 & $2 / 2 / 2016$ & 4 & 164 & 5 & $4 / 5 / 2016$ & 4 \\
\hline 999 & 999 & 8 & $1 / 21 / 2015$ & 999 & 999 & 8 & $1 / 27 / 2015$ & 4 \\
\hline 5 & 164 & 10 & $11 / 3 / 2015$ & 4 & 152 & 3 & $1 / 5 / 2016$ & 4 \\
\hline 4 & 159 & 4 & $10 / 7 / 2014$ & 999 & 999 & 8 & $10 / 14 / 2014$ & 5 \\
\hline 3 & 113 & 3 & $3 / 3 / 2015$ & 3 & 159 & 2 & $3 / 31 / 2015$ & 4 \\
\hline 4 & 159 & 3 & $1 / 12 / 2016$ & 3 & 113 & 5 & $3 / 8 / 2016$ & 4 \\
\hline 999 & 999 & 8 & $2 / 16 / 2016$ & 999 & 999 & 8 & $3 / 1 / 2016$ & 2 \\
\hline 5 & 152 & 3 & $10 / 20 / 2015$ & 4 & 104 & 3 & $12 / 8 / 2015$ & 4 \\
\hline 4 & 164 & 3 & $7 / 14 / 2015$ & 4 & 159 & 7 & $8 / 11 / 2015$ & 5 \\
\hline 3 & 113 & 3 & $4 / 12 / 2016$ & 5 & 164 & 5 & $6 / 21 / 2016$ & 5 \\
\hline 5 & 163 & 5 & $4 / 21 / 2015$ & 5 & 152 & 3 & $6 / 9 / 2015$ & 3 \\
\hline 3 & 113 & 3 & $3 / 15 / 2016$ & 1 & 164 & 5 & $5 / 24 / 2016$ & 2 \\
\hline 4 & 159 & 3 & $5 / 31 / 2016$ & 4 & 159 & 5 & $7 / 5 / 2016$ & 999 \\
\hline 3 & 163 & 5 & $5 / 12 / 2015$ & 3 & 113 & 5 & $7 / 14 / 2015$ & 3 \\
\hline 999 & 999 & 8 & $7 / 20 / 2015$ & 999 & 999 & 8 & $9 / 16 / 2015$ & 4 \\
\hline 4 & 101 & 5 & $10 / 1 / 2015$ & 5 & 101 & 5 & $11 / 18 / 2015$ & 999 \\
\hline 5 & 104 & 4 & $8 / 28 / 2013$ & 4 & 113 & 5 & $11 / 11 / 2013$ & 5 \\
\hline
\end{tabular}




\begin{tabular}{|c|c|c|c|c|c|c|c|c|}
\hline 5 & 132 & 3 & $8 / 13 / 2014$ & 999 & 999 & 9 & $8 / 14 / 2014$ & 4 \\
\hline 4 & 104 & 5 & $4 / 18 / 2013$ & 3 & 104 & 5 & $6 / 12 / 2013$ & 999 \\
\hline 4 & 113 & 5 & $11 / 6 / 2014$ & 4 & 164 & 7 & $1 / 21 / 2015$ & 4 \\
\hline 5 & 107 & 3 & $7 / 3 / 2014$ & 4 & 152 & 2 & $7 / 24 / 2014$ & 4 \\
\hline 5 & 152 & 5 & $6 / 25 / 2014$ & 5 & 164 & 5 & $9 / 8 / 2014$ & 4 \\
\hline 4 & 107 & 7 & $3 / 7 / 2016$ & 4 & 152 & 5 & $4 / 27 / 2016$ & 999 \\
\hline 4 & 104 & 5 & $9 / 21 / 2016$ & 999 & 999 & 8 & $10 / 3 / 2016$ & 4 \\
\hline 999 & 999 & 8 & $6 / 9 / 2014$ & 4 & 104 & 5 & $8 / 6 / 2014$ & 3 \\
\hline 4 & 169 & 3 & $6 / 29 / 2016$ & 4 & 164 & 5 & $8 / 29 / 2016$ & 4 \\
\hline 4 & 132 & 5 & $3 / 9 / 2016$ & 3 & 113 & 5 & $3 / 31 / 2016$ & 4 \\
\hline 3 & 107 & 5 & $4 / 13 / 2015$ & 999 & 999 & 8 & $6 / 3 / 2015$ & 4 \\
\hline 4 & 162 & 3 & $12 / 2 / 2013$ & 3 & 132 & 7 & $12 / 16 / 2013$ & 999 \\
\hline 4 & 164 & 7 & $8 / 18 / 2016$ & 4 & 169 & 5 & $10 / 5 / 2016$ & 5 \\
\hline 999 & 999 & 8 & $4 / 4 / 2016$ & 5 & 104 & 5 & $6 / 9 / 2016$ & 5 \\
\hline 4 & 104 & 5 & $1 / 5 / 2015$ & 5 & 152 & 7 & $1 / 19 / 2015$ & 5 \\
\hline 3 & 113 & 5 & $11 / 14 / 2016$ & 4 & 152 & 5 & $2 / 1 / 2017$ & 4 \\
\hline 3 & 164 & 5 & $7 / 1 / 2015$ & 4 & 163 & 5 & $9 / 10 / 2015$ & 3 \\
\hline 999 & 999 & 8 & $3 / 4 / 2015$ & 4 & 107 & 5 & $3 / 7 / 2015$ & 999 \\
\hline 4 & 159 & 7 & $5 / 4 / 2016$ & 4 & 159 & 5 & $7 / 6 / 2016$ & 2 \\
\hline 3 & 104 & 7 & $5 / 3 / 2016$ & 3 & 113 & 5 & $7 / 6 / 2016$ & 4 \\
\hline 999 & 999 & 8 & $2 / 10 / 2016$ & 999 & 999 & 8 & $3 / 3 / 2016$ & 4 \\
\hline 4 & 164 & 3 & $10 / 8 / 2015$ & 999 & 159 & 7 & $11 / 11 / 2015$ & 5 \\
\hline 4 & 147 & 4 & $4 / 29 / 2013$ & 4 & 132 & 5 & $5 / 1 / 2013$ & 4 \\
\hline 999 & 999 & 8 & $1 / 30 / 2014$ & 999 & 999 & 8 & $2 / 3 / 2014$ & 4 \\
\hline 5 & 152 & 5 & $6 / 9 / 2016$ & 5 & 132 & 5 & $8 / 3 / 2016$ & 999 \\
\hline 5 & 159 & 3 & $1 / 11 / 2016$ & 5 & 169 & 3 & $3 / 14 / 2016$ & 4 \\
\hline 5 & 152 & 3 & $12 / 22 / 2015$ & 4 & 164 & 5 & $3 / 9 / 2016$ & 4 \\
\hline 5 & 163 & 3 & $12 / 16 / 2015$ & 5 & 159 & 5 & $2 / 8 / 2016$ & 3 \\
\hline 4 & 132 & 7 & $7 / 17 / 2014$ & 5 & 104 & 5 & $10 / 16 / 2014$ & 999 \\
\hline 5 & 104 & 5 & $2 / 2 / 2016$ & 5 & 169 & 5 & $4 / 12 / 2016$ & 5 \\
\hline 3 & 113 & 7 & $1 / 12 / 2016$ & 999 & 999 & 8 & $1 / 19 / 2016$ & 3 \\
\hline 5 & 152 & 7 & $1 / 28 / 2015$ & 5 & 163 & 2 & $3 / 17 / 2015$ & 5 \\
\hline 3 & 104 & 5 & $2 / 10 / 2015$ & 4 & 159 & 5 & $4 / 14 / 2015$ & 5 \\
\hline 4 & 164 & 7 & $9 / 29 / 2015$ & 4 & 159 & 7 & $10 / 20 / 2015$ & 4 \\
\hline 4 & 164 & 7 & $2 / 2 / 2016$ & 4 & 152 & 5 & $3 / 22 / 2016$ & 4 \\
\hline 4 & 107 & 5 & $3 / 15 / 2016$ & 5 & 152 & 7 & $6 / 7 / 2016$ & 4 \\
\hline 4 & 159 & 5 & $12 / 23 / 2014$ & 5 & 152 & 5 & $3 / 17 / 2015$ & 999 \\
\hline 4 & 164 & 5 & $11 / 3 / 2015$ & 4 & 104 & 5 & $12 / 29 / 2015$ & 5 \\
\hline 3 & 132 & 3 & $5 / 12 / 2015$ & 999 & 999 & 8 & $6 / 26 / 2015$ & 4 \\
\hline 4 & 107 & 5 & $9 / 15 / 2015$ & 4 & 159 & 3 & $11 / 17 / 2015$ & 1 \\
\hline 5 & 107 & 5 & $12 / 15 / 2015$ & 5 & 164 & 5 & $2 / 16 / 2016$ & 5 \\
\hline 3 & 113 & 5 & $6 / 21 / 2016$ & 4 & 163 & 7 & $7 / 5 / 2016$ & 4 \\
\hline 5 & 164 & 3 & $2 / 16 / 2016$ & 4 & 104 & 5 & $4 / 12 / 2016$ & 2 \\
\hline 4 & 113 & 7 & $2 / 2 / 2016$ & 3 & 113 & 5 & $3 / 22 / 2016$ & 2 \\
\hline 4 & 113 & 5 & $12 / 29 / 2015$ & 4 & 113 & 5 & $2 / 9 / 2016$ & 5 \\
\hline & & & & & & & & \\
\hline
\end{tabular}




\begin{tabular}{|c|c|c|c|c|c|c|c|c|}
\hline 5 - Asst & $5-T x$ & 6 - Date & $6-\mathrm{OH}$ & 6 - Asst & $6 \cdot T x$ & 7 -Date & $7 . \mathrm{OH}$ & 7 -Asst \\
\hline 107 & 5 & $7 / 20 / 2016$ & 5 & 104 & 3 & $10 / 5 / 2016$ & 3 & 104 \\
\hline 113 & 5 & $1 / 29 / 2016$ & 3 & 113 & 5 & $4 / 11 / 2016$ & 4 & 164 \\
\hline 999 & 9 & 9/14/2015 & 999 & 999 & 9 & $11 / 4 / 2015$ & 5 & 152 \\
\hline 999 & 9 & $1 / 13 / 2014$ & 4 & 113 & 5 & $3 / 17 / 2014$ & 4 & 113 \\
\hline 113 & 5 & $2 / 8 / 2016$ & 999 & 999 & 8 & $4 / 27 / 2016$ & 3 & 104 \\
\hline 164 & 7 & $9 / 28 / 2015$ & 4 & 159 & 5 & $10 / 5 / 2015$ & 4 & 132 \\
\hline 152 & 7 & $3 / 16 / 2016$ & 4 & 152 & 5 & $6 / 8 / 2016$ & 4 & 163 \\
\hline 113 & 5 & $10 / 14 / 2015$ & 4 & 152 & 5 & $12 / 16 / 2015$ & 999 & 999 \\
\hline 159 & 3 & $8 / 26 / 2015$ & 4 & 163 & 7 & $9 / 30 / 2015$ & 4 & 164 \\
\hline 159 & 5 & $6 / 1 / 2015$ & 999 & 999 & 8 & $8 / 5 / 2015$ & 4 & 113 \\
\hline 132 & 5 & $11 / 11 / 2015$ & 3 & 113 & 5 & $2 / 8 / 2016$ & 999 & 999 \\
\hline 163 & 5 & $12 / 22 / 2015$ & 5 & 152 & 5 & $3 / 9 / 2016$ & 4 & 164 \\
\hline 104 & 5 & $11 / 8 / 2016$ & 4 & 152 & 5 & $1 / 4 / 2017$ & 4 & 164 \\
\hline 999 & 8 & $12 / 1 / 2014$ & 4 & 107 & 5 & $1 / 28 / 2015$ & 4 & 159 \\
\hline 164 & 7 & $1 / 18 / 2016$ & 4 & 159 & 5 & $3 / 30 / 2016$ & 4 & 159 \\
\hline 999 & 8 & $1 / 21 / 2015$ & 3 & 164 & 5 & $3 / 26 / 2015$ & 999 & 999 \\
\hline 999 & 8 & $10 / 16 / 2013$ & 4 & 104 & 3 & $12 / 18 / 2013$ & 5 & 152 \\
\hline 999 & 9 & $11 / 10 / 2014$ & 999 & 999 & 9 & $12 / 1 / 2014$ & 4 & 163 \\
\hline 132 & 7 & $2 / 8 / 2016$ & 1 & 104 & 7 & $4 / 27 / 2016$ & 999 & 999 \\
\hline 999 & 8 & $7 / 15 / 2015$ & 4 & 163 & 5 & $8 / 31 / 2015$ & 999 & 999 \\
\hline 999 & 9 & $4 / 24 / 2015$ & 4 & 164 & 3 & $6 / 29 / 2015$ & 5 & 152 \\
\hline 113 & 3 & $6 / 3 / 2015$ & 3 & 164 & 7 & $6 / 25 / 2015$ & 4 & 132 \\
\hline 164 & 7 & $11 / 8 / 2016$ & 3 & 132 & 5 & $12 / 28 / 2016$ & 1 & 104 \\
\hline 163 & 5 & $3 / 21 / 2016$ & 3 & 104 & 5 & $6 / 1 / 2016$ & 5 & 132 \\
\hline 162 & 5 & $9 / 16 / 2013$ & 4 & 107 & 5 & $11 / 14 / 2013$ & 4 & 163 \\
\hline 999 & 8 & $9 / 8 / 2016$ & 2 & 104 & 7 & $12 / 7 / 2016$ & 2 & 113 \\
\hline 104 & 5 & $1 / 6 / 2015$ & 5 & 163 & 5 & $2 / 24 / 2015$ & 999 & 999 \\
\hline 113 & 7 & $11 / 11 / 2014$ & 999 & 999 & 9 & $12 / 9 / 2014$ & 4 & 132 \\
\hline 999 & 8 & $10 / 20 / 2015$ & 5 & 132 & 5 & $12 / 29 / 2015$ & 5 & 164 \\
\hline 132 & 5 & $5 / 31 / 2016$ & 4 & 132 & 5 & $7 / 26 / 2016$ & 3 & 113 \\
\hline 159 & 2 & $3 / 17 / 2015$ & 3 & 163 & 3 & $5 / 12 / 2015$ & 4 & 164 \\
\hline 104 & 3 & $3 / 8 / 2016$ & 4 & 132 & 5 & $4 / 26 / 2016$ & 3 & 113 \\
\hline 163 & 3 & $1 / 6 / 2015$ & 999 & 999 & 9 & $1 / 20 / 2016$ & 4 & 164 \\
\hline 164 & 3 & $5 / 26 / 2015$ & 999 & 999 & 9 & $7 / 28 / 2015$ & 999 & 999 \\
\hline 164 & 5 & $4 / 26 / 2016$ & 2 & 107 & 5 & $7 / 5 / 2016$ & 999 & 999 \\
\hline 107 & 3 & $4 / 12 / 2016$ & 2 & 113 & 5 & $4 / 26 / 2016$ & 999 & 999 \\
\hline 113 & 5 & $2 / 9 / 2016$ & 3 & 113 & 7 & $4 / 19 / 2016$ & 4 & 152 \\
\hline 104 & 5 & $8 / 17 / 2015$ & 999 & 140 & 7 & $8 / 25 / 2015$ & 4 & 104 \\
\hline 152 & 5 & $8 / 23 / 2016$ & 5 & 132 & 5 & $10 / 25 / 2016$ & 5 & 132 \\
\hline 113 & 3 & $8 / 11 / 2015$ & 3 & 107 & 5 & $10 / 6 / 2015$ & 4 & 152 \\
\hline 169 & 5 & $7 / 19 / 2016$ & 2 & 164 & 7 & 9/6/2016 & 2 & 169 \\
\hline 139 & 7 & $8 / 2 / 2016$ & 4 & 164 & 5 & $9 / 20 / 2016$ & 4 & 164 \\
\hline 159 & 5 & $9 / 8 / 2015$ & 3 & 159 & 5 & $10 / 13 / 2015$ & 3 & 159 \\
\hline 159 & 5 & $11 / 4 / 2015$ & 2 & 104 & 5 & $1 / 4 / 2016$ & 999 & 999 \\
\hline 999 & 8 & $12 / 7 / 2015$ & 3 & 169 & 5 & $2 / 1 / 2016$ & 3 & 169 \\
\hline 107 & 5 & $1 / 27 / 2014$ & 4 & 162 & 5 & $1 / 28 / 2014$ & 4 & 132 \\
\hline
\end{tabular}




\begin{tabular}{|c|c|c|c|c|c|c|c|c|}
\hline 111 & 7 & $8 / 25 / 2014$ & 4 & 164 & 7 & $9 / 8 / 2014$ & 4 & 107 \\
\hline 999 & 8 & $7 / 25 / 2013$ & 5 & 132 & 5 & $9 / 25 / 2013$ & 999 & 999 \\
\hline 159 & 5 & $1 / 22 / 2015$ & 4 & 163 & 7 & $3 / 23 / 2015$ & 3 & 113 \\
\hline 159 & 3 & $9 / 29 / 2014$ & 3 & 104 & 5 & $11 / 19 / 2014$ & 5 & 107 \\
\hline 113 & 5 & $11 / 17 / 2014$ & 4 & 159 & 5 & $2 / 12 / 2015$ & 4 & 104 \\
\hline 999 & 8 & $5 / 3 / 2016$ & 4 & 152 & 5 & $6 / 29 / 2016$ & 4 & 163 \\
\hline 132 & 5 & $11 / 14 / 2016$ & 4 & 159 & 5 & $12 / 21 / 2016$ & 4 & 163 \\
\hline 164 & 5 & $10 / 30 / 2014$ & 999 & 999 & 9 & $11 / 16 / 2014$ & 4 & 104 \\
\hline 104 & 5 & $10 / 13 / 2016$ & 4 & 107 & 5 & $11 / 17 / 2016$ & 3 & 107 \\
\hline 152 & 7 & $4 / 27 / 2016$ & 3 & 113 & 5 & $7 / 6 / 2016$ & 3 & 113 \\
\hline 101 & 5 & $7 / 29 / 2015$ & 4 & 132 & 5 & $9 / 10 / 2015$ & 4 & 159 \\
\hline 999 & 8 & $2 / 12 / 2014$ & 3 & 132 & 5 & $3 / 13 / 2014$ & 2 & 107 \\
\hline 163 & 5 & $11 / 17 / 2016$ & 5 & 164 & 5 & $1 / 12 / 2017$ & 4 & 169 \\
\hline 107 & 5 & $9 / 7 / 2016$ & 5 & 163 & 5 & $10 / 19 / 2016$ & 4 & 107 \\
\hline 152 & 5 & $3 / 24 / 2015$ & 3 & 104 & 5 & $5 / 27 / 2015$ & 3 & 113 \\
\hline 132 & 5 & $4 / 5 / 2017$ & 4 & 132 & 7 & $4 / 20 / 2017$ & 5 & 132 \\
\hline 113 & 5 & $11 / 12 / 2015$ & 3 & 107 & 5 & $11 / 13 / 2015$ & 3 & 107 \\
\hline 999 & 8 & $4 / 27 / 2015$ & 4 & 152 & 5 & $6 / 29 / 2015$ & 3 & 163 \\
\hline 104 & 5 & $9 / 1 / 2016$ & 4 & 159 & 5 & $9 / 19 / 2016$ & 4 & 164 \\
\hline 132 & 5 & $8 / 31 / 2016$ & 4 & 164 & 5 & $10 / 17 / 2016$ & 3 & 104 \\
\hline 163 & 5 & $5 / 26 / 2016$ & 5 & 164 & 5 & $5 / 26 / 2016$ & 4 & 163 \\
\hline 152 & 5 & $1 / 11 / 2016$ & 4 & 104 & 5 & $3 / 9 / 2016$ & 3 & 113 \\
\hline 107 & 7 & $5 / 22 / 2013$ & 999 & 999 & 9 & $6 / 26 / 2013$ & 999 & 999 \\
\hline 107 & 2 & $2 / 13 / 2014$ & 999 & 999 & 8 & $2 / 19 / 2014$ & 4 & 152 \\
\hline 999 & 8 & $9 / 7 / 2016$ & 1 & 104 & 5 & $10 / 19 / 2016$ & 5 & 164 \\
\hline 159 & 5 & $5 / 3 / 2016$ & 999 & 999 & 8 & $6 / 29 / 2016$ & 4 & 169 \\
\hline 164 & 5 & $6 / 8 / 2016$ & 4 & 164 & 5 & $8 / 31 / 2016$ & 4 & 164 \\
\hline 169 & 5 & $4 / 4 / 2016$ & 999 & 999 & 8 & $4 / 25 / 2016$ & 4 & 164 \\
\hline 999 & 8 & $12 / 1 / 2014$ & 3 & 164 & 5 & $2 / 4 / 2015$ & 4 & 159 \\
\hline 164 & 5 & $5 / 31 / 2016$ & 4 & 107 & 7 & $6 / 21 / 2016$ & 999 & 999 \\
\hline 1 & 7 & $2 / 2 / 2016$ & 4 & 163 & 7 & $3 / 1 / 2016$ & 4 & 132 \\
\hline 164 & 5 & $4 / 14 / 2015$ & 999 & 999 & 8 & $4 / 21 / 2015$ & 5 & 152 \\
\hline 159 & 5 & $6 / 2 / 2015$ & 5 & 164 & 5 & $7 / 28 / 2015$ & 5 & 159 \\
\hline 132 & 7 & $11 / 17 / 2015$ & 4 & 164 & 5 & $1 / 5 / 2016$ & 4 & 132 \\
\hline 132 & 5 & $5 / 31 / 2016$ & 3 & 113 & 5 & $7 / 26 / 2016$ & 3 & 159 \\
\hline 152 & 5 & $8 / 2 / 2016$ & 4 & 159 & 5 & $9 / 20 / 2016$ & 4 & 132 \\
\hline 999 & 9 & $5 / 12 / 2015$ & 4 & 107 & 5 & $7 / 21 / 2015$ & 4 & 107 \\
\hline 164 & 5 & $2 / 9 / 2016$ & 999 & 999 & 8 & $2 / 16 / 2016$ & 999 & 999 \\
\hline 107 & 5 & $9 / 1 / 2015$ & 3 & 113 & 5 & $10 / 20 / 2015$ & 4 & 159 \\
\hline 159 & 7 & $2 / 2 / 2016$ & 3 & 159 & 5 & $4 / 12 / 2016$ & 3 & 104 \\
\hline 132 & 5 & $4 / 12 / 2016$ & 3 & 113 & 5 & $6 / 21 / 2016$ & 4 & 152 \\
\hline 164 & 5 & $8 / 30 / 2016$ & 3 & 107 & 5 & $11 / 1 / 2016$ & 3 & 113 \\
\hline 164 & 5 & $6 / 21 / 2016$ & 5 & 104 & 5 & $8 / 30 / 2016$ & 4 & 164 \\
\hline 104 & 5 & $5 / 31 / 2016$ & 4 & 107 & 5 & $7 / 19 / 2016$ & 4 & 169 \\
\hline 132 & 5 & $3 / 30 / 2016$ & 3 & 113 & 7 & $5 / 31 / 2016$ & 3 & 104 \\
\hline & & & & & & & & \\
\hline
\end{tabular}




\begin{tabular}{|c|c|c|c|c|c|c|c|c|}
\hline $7-T x$ & 8 -Date & $8-\mathrm{OH}$ & 8-Asst & $8-T x$ & 9 - Date & $9-\mathrm{OH}$ & 9-Asst & $9-T x$ \\
\hline 5 & $11 / 15 / 2016$ & 3 & 107 & 5 & $1 / 3 / 2017$ & 4 & 169 & 6 \\
\hline 5 & $6 / 30 / 2016$ & 3 & 113 & 5 & $10 / 3 / 2016$ & 4 & 132 & 5 \\
\hline 5 & $1 / 18 / 2016$ & 999 & 999 & 9 & $2 / 29 / 2016$ & 5 & 152 & 5 \\
\hline 5 & $4 / 30 / 2014$ & 4 & 104 & 7 & \begin{tabular}{l|l}
7 & $5 / 21 / 2014$ \\
\end{tabular} & 4 & 163 & 5 \\
\hline 7 & $7 / 25 / 2016$ & 4 & 159 & 5 & $10 / 6 / 2016$ & 999 & 999 & 8 \\
\hline 7 & $10 / 21 / 2015$ & 4 & 164 & 7 & $\begin{array}{l}72 / 9 / 2015 \\
\end{array}$ & 4 & 132 & 5 \\
\hline 5 & $8 / 24 / 2016$ & 999 & 999 & 9 & $\begin{array}{ll}90 / 11 / 2016 \\
\end{array}$ & 4 & 164 & 5 \\
\hline 9 & $2 / 8 / 2016$ & 3 & 113 & 5 & \begin{tabular}{l|l}
5 & $4 / 27 / 2016$ \\
\end{tabular} & 4 & 132 & 5 \\
\hline 7 & $11 / 18 / 2015$ & 4 & 152 & 7 & $\begin{array}{ll}1 / 14 / 2016 \\
\end{array}$ & 999 & 999 & 8 \\
\hline 5 & $8 / 24 / 2015$ & 4 & 132 & 7 & $7 / 10 / 26 / 2015$ & 4 & 132 & 7 \\
\hline 8 & $4 / 25 / 2016$ & 4 & 152 & 7 & $5 / 9 / 2016$ & 3 & 169 & 7 \\
\hline 5 & $6 / 8 / 2016$ & 3 & 113 & 5 & $8 / 18 / 2016$ & 4 & 159 & 5 \\
\hline 5 & $3 / 9 / 2017$ & 4 & 159 & 6 & & & & \\
\hline 5 & $3 / 26 / 2015$ & 999 & 999 & 8 & $3 / 30 / 2015$ & 999 & 999 & 8 \\
\hline 5 & $6 / 20 / 2016$ & 4 & 104 & 5 & $9 / 7 / 2016$ & 4 & 163 & 7 \\
\hline 8 & $3 / 30 / 2015$ & 999 & 999 & 8 & $4 / 13 / 2015$ & 4 & 104 & 5 \\
\hline 5 & $2 / 27 / 2014$ & 4 & 132 & 5 & $4 / 30 / 2014$ & 999 & 999 & 9 \\
\hline 5 & $3 / 4 / 2015$ & 999 & 999 & 8 & $4 / 27 / 2015$ & 999 & 999 & 9 \\
\hline 9 & $7 / 27 / 2016$ & 3 & 152 & 5 & $10 / 19 / 2016$ & 3 & 169 & 5 \\
\hline 8 & 9/28/2015 & 2 & 163 & 5 & $12 / 14 / 2015$ & 3 & 113 & 5 \\
\hline 3 & $9 / 16 / 2015$ & 5 & 152 & 5 & $12 / 2 / 2015$ & 999 & 999 & 8 \\
\hline 7 & 9/14/2015 & 3 & 132 & 7 & $12 / 2 / 2015$ & 3 & 132 & 5 \\
\hline 7 & $1 / 3 / 2017$ & 1 & 104 & 5 & $3 / 22 / 2017$ & 1 & 169 & 5 \\
\hline 7 & $8 / 24 / 2016$ & 5 & 152 & 5 & $11 / 7 / 2016$ & 4 & 104 & 5 \\
\hline 5 & $1 / 24 / 2014$ & 4 & 152 & 5 & $3 / 17 / 2014$ & 4 & 113 & 5 \\
\hline 5 & $2 / 15 / 2017$ & 999 & 999 & 8 & $3 / 29 / 2017$ & 3 & 163 & 5 \\
\hline 8 & $3 / 3 / 2015$ & 4 & 159 & 7 & $3 / 10 / 2015$ & 4 & 132 & 5 \\
\hline 7 & $3 / 3 / 2015$ & 4 & 164 & 5 & $5 / 5 / 2015$ & 999 & 999 & 9 \\
\hline 5 & $2 / 2 / 2016$ & 4 & 107 & 7 & $3 / 1 / 2016$ & 3 & 113 & 5 \\
\hline 5 & $9 / 6 / 2016$ & 4 & 152 & 5 & $11 / 1 / 2016$ & 4 & 164 & 5 \\
\hline 5 & $7 / 14 / 2015$ & 999 & 999 & 9 & $9 / 8 / 2015$ & 4 & 159 & 5 \\
\hline 5 & $6 / 28 / 2016$ & 3 & 107 & 5 & $8 / 23 / 2016$ & 999 & 999 & 9 \\
\hline 3 & $3 / 31 / 2015$ & 2 & 159 & 7 & $5 / 26 / 2015$ & 999 & 999 & 9 \\
\hline 9 & $9 / 8 / 2015$ & 4 & 159 & 5 & $11 / 10 / 2015$ & 999 & 999 & 9 \\
\hline 8 & $8 / 2 / 2016$ & 4 & 104 & 5 & $10 / 4 / 2016$ & 5 & 152 & 5 \\
\hline 9 & $5 / 24 / 2016$ & 3 & 104 & 7 & $7 / 5 / 2016$ & 999 & 999 & 9 \\
\hline 5 & $6 / 28 / 2016$ & 5 & 104 & 5 & $8 / 30 / 2016$ & 999 & 999 & 9 \\
\hline 7 & $9 / 15 / 2015$ & 4 & 132 & 7 & $10 / 6 / 2015$ & 3 & 113 & 5 \\
\hline 5 & $12 / 27 / 2016$ & 5 & 132 & 5 & $2 / 28 / 2017$ & 2 & 104 & 5 \\
\hline 5 & $12 / 1 / 2015$ & 4 & 104 & 5 & $2 / 2 / 2016$ & 4 & 163 & 5 \\
\hline 5 & $9 / 23 / 2016$ & 999 & 999 & 8 & $11 / 11 / 2016$ & 3 & 152 & 7 \\
\hline 5 & $11 / 29 / 2016$ & 4 & 107 & 5 & $1 / 31 / 2017$ & 4 & 164 & 5 \\
\hline 7 & $11 / 3 / 2015$ & 2 & 159 & 5 & $1 / 5 / 2016$ & 3 & 159 & 5 \\
\hline 9 & $2 / 10 / 2016$ & 3 & 104 & 5 & $4 / 11 / 2016$ & 3 & 152 & 5 \\
\hline 5 & $3 / 28 / 2016$ & 1 & 101 & 5 & $6 / 30 / 2016$ & 1 & 132 & 5 \\
\hline 7 & $3 / 26 / 2014$ & 4 & 159 & 5 & $6 / 4 / 2014$ & 4 & 159| & 5 \\
\hline
\end{tabular}




\begin{tabular}{|c|c|c|c|c|c|c|c|c|}
\hline 5 & $11 / 13 / 2014$ & 999 & 999 & 9 & $12 / 8 / 2014$ & 2 & 104 & 5 \\
\hline 8 & $10 / 2 / 2013$ & 5 & 159 & 5 & $12 / 9 / 2013$ & 4 & 162 & 5 \\
\hline 5 & $5 / 28 / 2015$ & 3 & 107 & 5 & $7 / 22 / 2015$ & 2 & 104 & 5 \\
\hline 5 & $12 / 17 / 2014$ & 3 & 164 & 7 & $5 / 7 / 2015$ & 4 & 159 & 5 \\
\hline 5 & $2 / 26 / 2015$ & 999 & 999 & 8 & $4 / 16 / 2015$ & 4 & 107 & 5 \\
\hline 5 & $8 / 31 / 2016$ & 4 & 164 & 5 & $10 / 26 / 2016$ & 4 & 163 & 5 \\
\hline 5 & $2 / 23 / 2017$ & 4 & 164 & 6 & & & & \\
\hline 5 & $11 / 11 / 2014$ & 999 & 999 & 9 & $11 / 12 / 2014$ & 4 & 132 & 7 \\
\hline 5 & $12 / 29 / 2016$ & 4 & 104 & 5 & $3 / 2 / 2017$ & 5 & 152 & 6 \\
\hline 5 & $8 / 29 / 2016$ & 4 & 163 & 5 & $10 / 19 / 2016$ & 3 & 152 & 5 \\
\hline 7 & $10 / 15 / 2015$ & 4 & 159 & 5 & $11 / 11 / 2015$ & 4 & 152 & 7 \\
\hline 7 & $4 / 21 / 2014$ & 999 & 999 & 8 & $5 / 22 / 2014$ & 999 & 999 & 8 \\
\hline 5 & $3 / 23 / 2017$ & 4 & 159 & 6 & & & & \\
\hline 5 & $12 / 8 / 2016$ & 3 & 113 & 5 & $2 / 1 / 2017$ & 4 & 163 & 5 \\
\hline 5 & $6 / 18 / 2015$ & 4 & 163 & 7 & $7 / 27 / 2015$ & 3 & 104 & 5 \\
\hline 6 & & & & & & & & \\
\hline 5 & $1 / 28 / 2016$ & 4 & 104 & 5 & $3 / 21 / 2016$ & 3 & 164 & 5 \\
\hline 5 & $8 / 31 / 2016$ & 4 & 152 & 5 & $10 / 26 / 2015$ & 4 & 163 & 5 \\
\hline 7 & $10 / 27 / 2016$ & 4 & 104 & 5 & $12 / 8 / 2016$ & 3 & 104 & 5 \\
\hline 5 & $12 / 12 / 2016$ & 3 & 104 & 5 & $2 / 2 / 2017$ & 4 & 113 & 5 \\
\hline 7 & $8 / 4 / 2016$ & 5 & 164 & 5 & $10 / 20 / 2016$ & 4 & 113 & 7 \\
\hline 5 & $4 / 27 / 2016$ & 999 & 999 & 8 & $6 / 8 / 2016$ & 4 & 104 & 7 \\
\hline 9 & $7 / 17 / 2013$ & 4 & 132 & 5 & $9 / 11 / 2013$ & 3 & 104 & 5 \\
\hline 5 & $4 / 23 / 2014$ & 4 & 132 & 5 & $6 / 23 / 2014$ & 999 & 999 & 9 \\
\hline 5 & $12 / 8 / 2016$ & 3 & 104 & 5 & $2 / 1 / 2017$ & 4 & 164 & 5 \\
\hline 5 & $8 / 31 / 2016$ & 999 & 999 & 8 & $10 / 6 / 2016$ & 1 & 104 & 5 \\
\hline 5 & $11 / 9 / 2016$ & 4 & 163 & 5 & $1 / 9 / 2017$ & 4 & 159 & 5 \\
\hline 5 & $6 / 22 / 2016$ & 999 & 999 & 8 & $8 / 3 / 2016$ & 3 & 113 & 5 \\
\hline 7 & $3 / 30 / 2015$ & 4 & 159 & 7 & $6 / 1 / 2015$ & 4 & 159 & 7 \\
\hline 8 & $6 / 28 / 2016$ & 999 & 999 & 8 & $7 / 19 / 2016$ & 5 & 169 & 5 \\
\hline 5 & $4 / 5 / 2016$ & 5 & 107 & 7 & $4 / 26 / 2016$ & 2 & 140 & 7 \\
\hline 7 & $5 / 12 / 2015$ & 5 & 132 & 5 & $7 / 14 / 2015$ & 5 & 164 & 5 \\
\hline 5 & $11 / 17 / 2015$ & 4 & 104 & 5 & $1 / 19 / 2016$ & 5 & 152 & 5 \\
\hline 5 & $2 / 9 / 2016$ & 999 & 999 & 8 & $2 / 16 / 2016$ & 3 & 159 & 7 \\
\hline 5 & $9 / 6 / 2016$ & 4 & 152 & 5 & $11 / 1 / 2016$ & 999 & 999 & 9 \\
\hline 5 & $11 / 29 / 2016$ & 4 & 164 & 5 & $1 / 31 / 2017$ & 5 & 152 & 6 \\
\hline 5 & $9 / 8 / 2015$ & 4 & 152 & 5 & $11 / 10 / 2015$ & 4 & 164 & 5 \\
\hline 8 & $3 / 1 / 2016$ & 4 & 113 & 5 & $4 / 19 / 2016$ & 999 & 999 & 9 \\
\hline 5 & $12 / 8 / 2015$ & 999 & 999 & 8 & $12 / 15 / 2015$ & 3 & 104 & 5 \\
\hline 5 & $6 / 21 / 2016$ & 3 & 169 & 5 & $6 / 28 / 2016$ & 999 & 999 & 8 \\
\hline 5 & $8 / 23 / 2016$ & 5 & 159 & 5 & $10 / 18 / 2016$ & 2 & 104 & 5 \\
\hline 5 & $12 / 27 / 2016$ & 4 & 132 & 5 & $3 / 21 / 2017$ & 4 & 163 & 6 \\
\hline 5 & $11 / 1 / 2016$ & 4 & 159 & 5 & $1 / 10 / 2017$ & 4 & 164 & 5 \\
\hline 5 & $9 / 13 / 2016$ & 4 & 107 & 5 & $11 / 1 / 2016$ & 2 & 113 & 5 \\
\hline 5 & $7 / 19 / 2016$ & 3 & 113 & 5 & $10 / 25 / 2016$ & 4 & 159 & 5 \\
\hline & & & & & & & & \\
\hline
\end{tabular}




\begin{tabular}{|c|c|c|c|c|c|c|c|c|}
\hline 10 -Date & $10-\mathrm{OH}$ & 10 - Asst & $10-\mathrm{Tx}$ & 11 - Date & $11-\mathrm{OH}$ & 11 - Asst & $11-\mathrm{Tx}$ & 12-Date \\
\hline $11 / 8 / 2016$ & 4 & 104 & 5 & $1 / 3 / 2017$ & 4 & 169 & 6 & \\
\hline $6 / 29 / 2016$ & 5 & 152 & 5 & $8 / 8 / 2016$ & 999 & 999 & 9 & $9 / 19 / 2016$ \\
\hline $7 / 30 / 2014$ & 999 & 999 & 9 & $9 / 8 / 2014$ & 4 & 164 & 7 & $10 / 22 / 2014$ \\
\hline \begin{tabular}{|l|}
$11 / 10 / 2016$ \\
\end{tabular} & 999 & 999 & 9 & $12 / 7 / 2016$ & 999 & 999 & 9 & $1 / 12 / 2017$ \\
\hline $1 / 20 / 2016$ & 4 & 132 & 7 & $2 / 12 / 2016$ & 3 & 169 & 5 & $3 / 23 / 2016$ \\
\hline $12 / 13 / 2016$ & 4 & 104 & 5 & $2 / 16 / 2017$ & 4 & 132 & 6 & \\
\hline \begin{tabular}{|l|}
$7 / 20 / 2016$ \\
\end{tabular} & 4 & 152 & 7 & $10 / 12 / 2016$ & 3 & 104 & 5 & $12 / 14 / 2016$ \\
\hline $2 / 12 / 2016$ & 4 & 132 & 5 & $5 / 3 / 2016$ & 4 & 163 & 5 & $7 / 25 / 2016$ \\
\hline $12 / 17 / 2015$ & 4 & 104 & 5 & $2 / 24 / 2016$ & 4 & 163 & 5 & $5 / 25 / 2016$ \\
\hline \begin{tabular}{|l}
$7 / 20 / 2016$ \\
\end{tabular} & 999 & 999 & 8 & $10 / 5 / 2016$ & 999 & 999 & 8 & $10 / 17 / 2016$ \\
\hline $10 / 26 / 2016$ & 2 & 159 & 5 & $12 / 21 / 2016$ & 3 & 113 & 5 & $2 / 23 / 2017$ \\
\hline & & & & & & & & \\
\hline $4 / 2 / 2015$ & 4 & 107 & 5 & $5 / 27 / 2015$ & 999 & 999 & 9 & $6 / 4 / 2015$ \\
\hline 11/16/2016 & 4 & 104 & 5 & $1 / 12 / 2017$ & 4 & 159 & 5 & $4 / 6 / 2017$ \\
\hline $6 / 15 / 2015$ & 4 & 104 & 5 & $8 / 5 / 2015$ & 4 & 163 & 5 & $10 / 28 / 2015$ \\
\hline $5 / 7 / 2014$ & 4 & 132 & 5 & $6 / 26 / 2014$ & 4 & 132 & 5 & $9 / 10 / 2014$ \\
\hline $7 / 1 / 2015$ & 999 & 999 & 9 & $7 / 2 / 2015$ & 3 & 152 & 5 & $7 / 6 / 2015$ \\
\hline $5 / 11 / 2016$ & 3 & 113 & 5 & $8 / 1 / 2016$ & 3 & 163 & 5 & $10 / 3 / 2016$ \\
\hline $12 / 28 / 2015$ & 3 & 159 & 7 & $2 / 29 / 2016$ & 999 & 999 & 8 & $3 / 31 / 2016$ \\
\hline $12 / 9 / 2015$ & 3 & 113 & 5 & $2 / 12 / 2016$ & 999 & 999 & 8 & $4 / 4 / 2016$ \\
\hline $1 / 27 / 2016$ & 3 & 163 & 7 & $5 / 23 / 2016$ & 4 & 164 & 5 & $8 / 22 / 2016$ \\
\hline $5 / 18 / 2017$ & 3 & 152 & 6 & & & & & \\
\hline $1 / 3 / 2017$ & 4 & 132 & 5 & $3 / 29 / 2017$ & 3 & 113 & 5 & $5 / 25 / 2017$ \\
\hline $5 / 28 / 2014$ & 4 & 163 & 5 & $7 / 30 / 2014$ & 4 & 132 & 7 & $10 / 22 / 2014$ \\
\hline $6 / 8 / 2017$ & 3 & 159 & 6 & & & & & \\
\hline $5 / 15 / 2015$ & 999 & 999 & 8 & $6 / 26 / 2015$ & 4 & 132 & 5 & $7 / 14 / 2015$ \\
\hline $6 / 26 / 2015$ & 5 & 159 & 5 & $8 / 11 / 2015$ & 2 & 107 & 5 & $10 / 13 / 2015$ \\
\hline $4 / 26 / 2016$ & 4 & 164 & 5 & $6 / 28 / 2016$ & 4 & 152 & 5 & $7 / 26 / 2016$ \\
\hline $1 / 17 / 2017$ & 4 & 163 & 6 & & & & & \\
\hline $11 / 3 / 2015$ & 999 & 999 & 9 & $12 / 1 / 2015$ & 999 & 999 & 8 & $1 / 19 / 2016$ \\
\hline $9 / 13 / 2016$ & 3 & 104 & 5 & $11 / 29 / 2016$ & 4 & 152 & 5 & $1 / 31 / 2017$ \\
\hline $7 / 28 / 2015$ & 999 & 999 & 9 & $9 / 8 / 2015$ & 4 & 104 & 5 & $11 / 10 / 2015$ \\
\hline $1 / 19 / 2016$ & 3 & 164 & 7 & $3 / 22 / 2016$ & 4 & 104 & 5 & $5 / 31 / 2016$ \\
\hline $11 / 29 / 2016$ & 4 & 159 & 7 & $12 / 20 / 2016$ & 5 & 104 & 5 & $2 / 28 / 2017$ \\
\hline $8 / 9 / 2016$ & 999 & 999 & 9 & $10 / 4 / 2016$ & 1 & 132 & 5 & $12 / 27 / 2016$ \\
\hline $10 / 25 / 2016$ & 4 & 159 & 5 & $1 / 10 / 2017$ & 5 & 164 & 5 & $3 / 21 / 2017$ \\
\hline $11 / 3 / 2015$ & 3 & 113 & 7 & $12 / 1 / 2015$ & 999 & 999 & 8 & $3 / 8 / 2016$ \\
\hline $5 / 2 / 2017$ & 4 & 163 & 6 & & & & & \\
\hline $4 / 12 / 2016$ & 4 & 159 & 5 & $6 / 21 / 2016$ & 4 & 169 & 5 & $8 / 23 / 2016$ \\
\hline $1 / 17 / 2017$ & 3 & 152 & 5 & $3 / 21 / 2017$ & 3 & 159 & 5 & $5 / 16 / 2017$ \\
\hline $3 / 1 / 2017$ & 999 & 139 & 7 & $3 / 7 / 2017$ & 999 & 999 & 8 & $3 / 21 / 2017$ \\
\hline $3 / 8 / 2016$ & 4 & 164 & 5 & $4 / 12 / 2016$ & 4 & 107 & 5 & $5 / 10 / 2016$ \\
\hline $6 / 8 / 2016$ & 1 & 132 & 5 & $8 / 18 / 2016$ & 999 & 999 & 9 & $9 / 8 / 2016$ \\
\hline $8 / 31 / 2016$ & 5 & 132 & 5 & $11 / 3 / 2016$ & 4 & 152 & 5 & $12 / 13 / 2016$ \\
\hline $6 / 5 / 2016$ & 999 & 999 & 8 & $7 / 30 / 2014$ & 4 & 159 & 5 & $8 / 14 / 2014$ \\
\hline
\end{tabular}




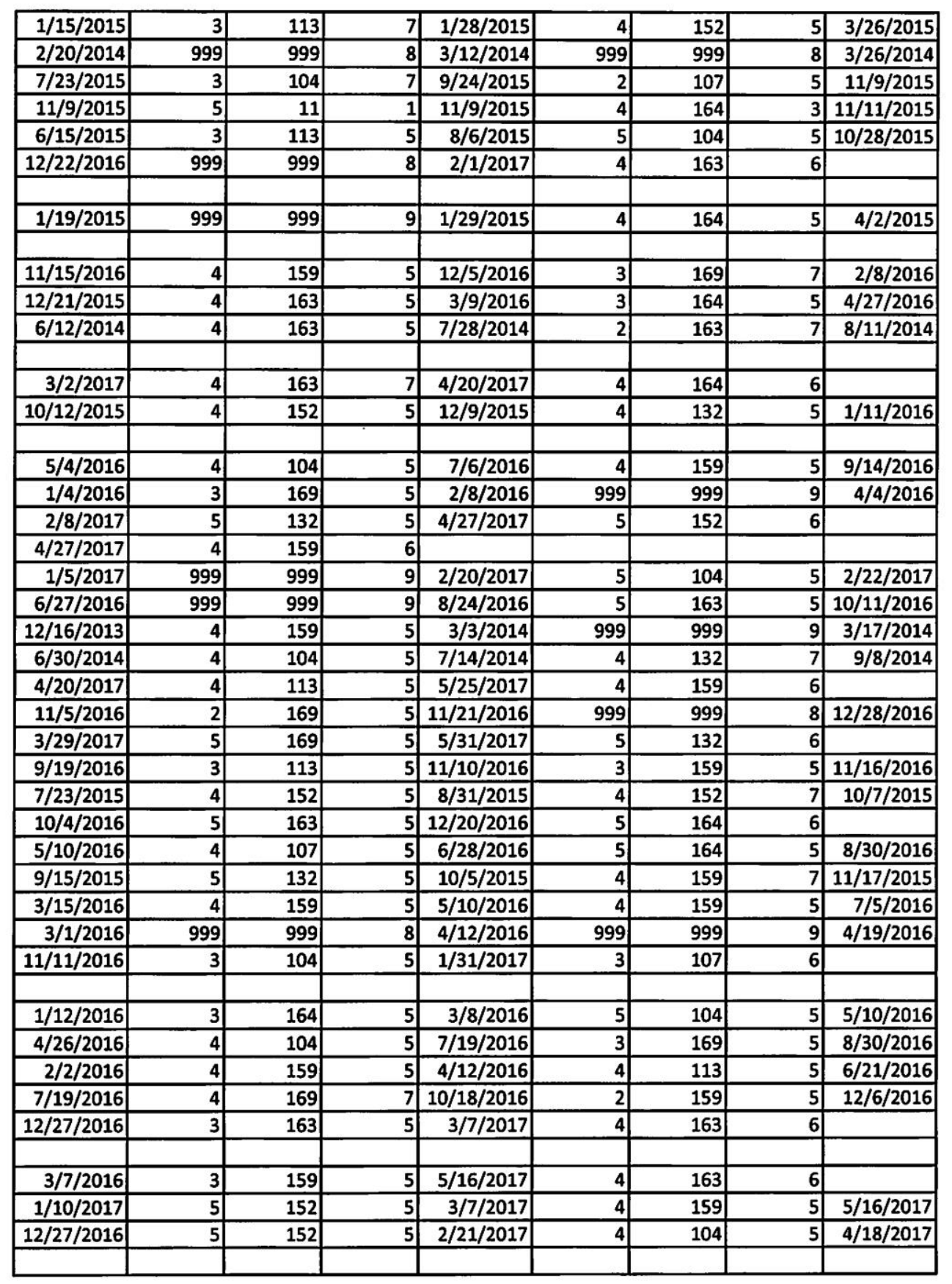




\begin{tabular}{|c|c|c|c|c|c|c|c|c|}
\hline $12-\mathrm{OH}$ & 12 - Asst & $12-\mathrm{Tx}$ & 13 - Date & $13-\mathrm{OH}$ & 13 - Asst & $13-T x$ & 14-Date & $14-\mathrm{OH}$ \\
\hline & & & & & & & & \\
\hline & & & & & & & & \\
\hline 5 & 152 & 5 & $11 / 22 / 2016$ & 5 & 152 & 5 & $1 / 3 / 2017$ & 5 \\
\hline 999 & 999 & 9 & $11 / 12 / 2014$ & 4 & 159 & 7 & $1 / 14 / 2015$ & 4 \\
\hline 3 & 104 & 6 & & & & & & \\
\hline 3 & 159 & 7 & $4 / 18 / 2016$ & 3 & 159 & 7 & $5 / 4 / 2016$ & 2 \\
\hline & & & & & & & & \\
\hline 3 & 104 & 5 & $2 / 16 / 2017$ & 5 & 152 & 6 & & \\
\hline 4 & 152 & 5 & $10 / 12 / 2016$ & 3 & 159 & 5 & $12 / 13 / 2016$ & 4 \\
\hline 4 & 132 & 7 & $8 / 1 / 2016$ & 3 & 113 & 5 & $10 / 19 / 2016$ & 3 \\
\hline 3 & 159 & 5 & $12 / 22 / 2016$ & 3 & 159 & 5 & $2 / 23 / 2017$ & 2 \\
\hline 4 & 140 & 6 & & & & & & \\
\hline & & & & & & & & \\
\hline 5 & 104 & 5 & $7 / 20 / 2015$ & 4 & 152 & 7 & $8 / 12 / 2015$ & 5 \\
\hline 4 & 140 & 6 & & & & & & \\
\hline 3 & 159 & 5 & $12 / 21 / 2015$ & 3 & 113 & 5 & $1 / 18 / 2016$ & 999 \\
\hline 3 & 132 & 5 & $12 / 1 / 2014$ & 4 & 107 & 5 & $2 / 18 / 2015$ & 4 \\
\hline 999 & 113 & 7 & $7 / 22 / 2015$ & 999 & 999 & 8 & $7 / 27 / 2015$ & 4 \\
\hline 4 & 164 & 6 & & & & & & \\
\hline 3 & 152 & 5 & $5 / 12 / 2016$ & 999 & 999 & 8 & $6 / 23 / 2016$ & 999 \\
\hline 999 & 999 & 9 & $4 / 21 / 2016$ & 5 & 159 & 5 & $1 / 3 / 2017$ & 999 \\
\hline 4 & 132 & 6 & & & & & & \\
\hline & & & & & & & & \\
\hline 3 & 104 & 6 & & & & & & \\
\hline 2 & 104 & 5 & $1 / 14 / 2015$ & 3 & 104 & 7 & $4 / 13 / 2015$ & 4 \\
\hline & & & & & & & & \\
\hline 5 & 104 & 7 & $8 / 25 / 2015$ & 4 & 164 & 5 & $10 / 13 / 2015$ & 4 \\
\hline 4 & 132 & 5 & $12 / 15 / 2015$ & 2 & 107 & 5 & $1 / 5 / 2016$ & 3 \\
\hline 3 & 104 & 7 & $8 / 30 / 2016$ & 4 & 113 & 5 & $11 / 11 / 2016$ & 4 \\
\hline & & & & & & & & \\
\hline 999 & 999 & 8 & $2 / 2 / 2016$ & 2 & 169 & 5 & $3 / 29 / 2016$ & 999 \\
\hline 2 & 163 & 6 & & & & & & \\
\hline 999 & 999 & 9 & $1 / 19 / 2016$ & 3 & 159 & 7 & $3 / 22 / 2016$ & 4 \\
\hline 999 & 999 & 9 & $8 / 2 / 2016$ & 999 & 999 & 9 & $8 / 23 / 2016$ & 999 \\
\hline 4 & 163 & 6 & & & & & & \\
\hline 999 & 999 & 9 & $3 / 7 / 2017$ & 1 & 163 & 6 & & \\
\hline 4 & 163 & 6 & & & & & & \\
\hline 4 & 113 & 5 & $4 / 26 / 2016$ & 3 & 107 & 5 & $7 / 5 / 2016$ & 4 \\
\hline & & & & & & & & \\
\hline 999 & 999 & 8 & $9 / 16 / 2016$ & 4 & 107 & 5 & $11 / 1 / 2016$ & 3 \\
\hline 3 & 163 & 6 & & & & & & \\
\hline 4 & 159 & 7 & $4 / 4 / 2017$ & 4 & 132 & 5 & $6 / 6 / 2017$ & 5 \\
\hline 999 & 999 & 8 & $6 / 21 / 2016$ & 999 & 999 & 8 & $6 / 28 / 2016$ & 3 \\
\hline 999 & 999 & 9 & $10 / 27 / 2016$ & 4 & 169 & 5 & $12 / 22 / 2016$ & 3 \\
\hline 999 & 999 & 8 & $12 / 29 / 2016$ & 1 & 101 & 6 & & \\
\hline 5 & 152 & 7 & $10 / 22 / 2014$ & 4 & 164 & 5 & $12 / 18 / 2014$ & 5 \\
\hline
\end{tabular}




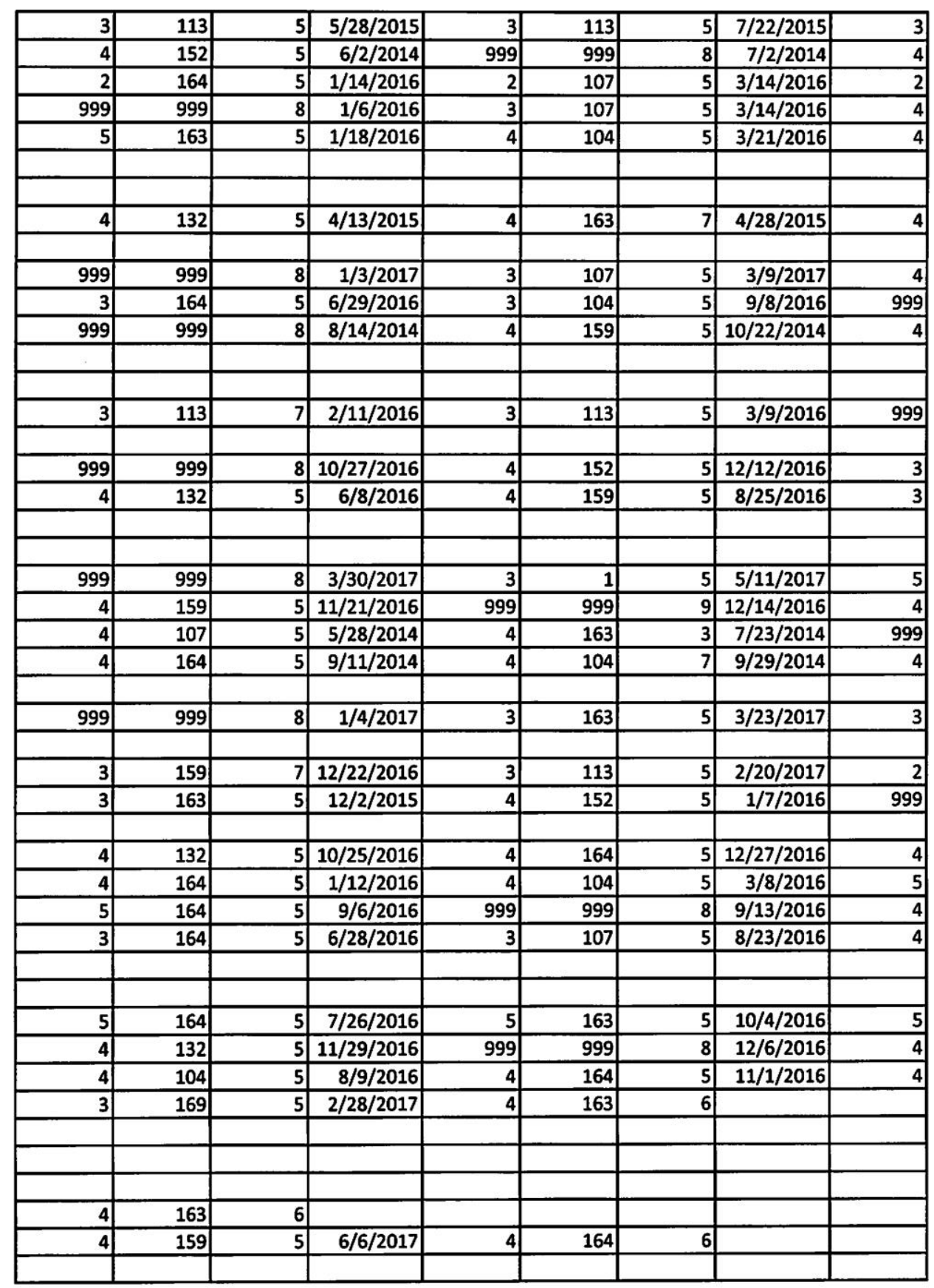




\begin{tabular}{|c|c|c|c|c|c|c|c|c|}
\hline 14-Asst & $14-\mathrm{Tx}$ & 15-Date & $15-\mathrm{OH}$ & 15 - Asst & $15-T x$ & 16-Date & $16 . \mathrm{OH}$ & 16 - Asst \\
\hline & & & & & & & & \\
\hline & & & & & & & & \\
\hline 152 & 6 & & & & & & & \\
\hline 113 & 7 & $2 / 9 / 2015$ & 3 & 113 & 5 & $4 / 15 / 2015$ & 3 & 132 \\
\hline & & & & & & & & \\
\hline \multirow[t]{3}{*}{164} & 5 & $7 / 27 / 2016$ & 2 & 113 & 5 & $10 / 12 / 2016$ & 2 & 104 \\
\hline & & & & & & & & \\
\hline & & & & & & & & \\
\hline 159 & 5 & $2 / 16 / 2017$ & 2 & 169 & 6 & & & \\
\hline 113 & 5 & $12 / 22 / 2016$ & 999 & 999 & 8 & $1 / 12 / 2017$ & 999 & 999 \\
\hline \multirow[t]{3}{*}{152} & 6 & & & & & & & \\
\hline & & & & & & & & \\
\hline & & & & & & & & \\
\hline \multirow[t]{2}{*}{152} & 3 & $8 / 18 / 2015$ & 3 & 113 & 7 & $11 / 2 / 2015$ & 3 & 113 \\
\hline & & & & & & & & \\
\hline 999 & 8 & $4 / 20 / 2016$ & 3 & 164 & 5 & $5 / 9 / 2016$ & 999 & 999 \\
\hline 159 & 5 & $4 / 16 / 2015$ & 4 & 132 & 5 & $6 / 11 / 2015$ & 3 & 113 \\
\hline \multirow[t]{2}{*}{164} & 7 & $9 / 3 / 2015$ & 3 & 113 & 5 & $10 / 29 / 2015$ & 4 & 163 \\
\hline & & & & & & & & \\
\hline 999 & 9 & $8 / 18 / 2016$ & 4 & 169 & 5 & $10 / 6 / 2016$ & 999 & 999 \\
\hline \multirow[t]{3}{*}{999} & 9 & $3 / 2 / 2017$ & 2 & 164 & 5 & $5 / 11 / 2017$ & 2 & 164 \\
\hline & & & & & & & & \\
\hline & & & & & & & & \\
\hline & & & & & & & & \\
\hline \multirow[t]{2}{*}{104} & 5 & $6 / 3 / 2015$ & 5 & 104 & 5 & $6 / 10 / 2015$ & 999 & 999 \\
\hline & & & & & & & & \\
\hline 132 & 5 & $12 / 15 / 2015$ & 4 & 164 & 5 & $2 / 16 / 2016$ & 4 & 132 \\
\hline 107 & 7 & $2 / 16 / 2016$ & 4 & 159 & 7 & $4 / 12 / 2016$ & 5 & 152 \\
\hline \multirow[t]{2}{*}{159} & 5 & $1 / 17 / 2017$ & 4 & 164 & 6 & & & \\
\hline & & & & & & & & \\
\hline \multirow[t]{2}{*}{999} & 8 & $4 / 19 / 2016$ & 999 & 999 & 8 & $5 / 31 / 2016$ & 3 & 3 \\
\hline & & & & & & & & \\
\hline 132 & 5 & $5 / 24 / 2016$ & 999 & 999 & 8 & $5 / 31 / 2016$ & 999 & 999 \\
\hline \multirow[t]{2}{*}{999} & 9 & $8 / 24 / 2016$ & 999 & 999 & 8 & $10 / 4 / 2016$ & 2 & 132 \\
\hline & & & & & & & & \\
\hline & & & & & & & & \\
\hline & & & & & & & & \\
\hline \multirow[t]{2}{*}{132} & 5 & $9 / 20 / 2016$ & 5 & 107 & 5 & $11 / 29 / 2016$ & 4 & 159 \\
\hline & & & & & & & & \\
\hline \multirow[t]{2}{*}{113} & 5 & $1 / 17 / 2017$ & 5 & 104 & 5 & $3 / 21 / 2017$ & 4 & 159 \\
\hline & & & & & & & & \\
\hline \multirow{2}{*}{\begin{tabular}{l|}
152 \\
164
\end{tabular}} & 6 & & & & & & & \\
\hline & 5 & $9 / 20 / 2016$ & 1 & 164 & 5 & $11 / 29 / 2016$ & 3 & 164 \\
\hline \multirow[t]{2}{*}{107} & 6 & & & & & & & \\
\hline & & & & & & & & \\
\hline 152 & 7 & $12 / 29 / 2014$ & 999 & 999 & 8 & $3 / 5 / 2015$ & 999 & 999 \\
\hline
\end{tabular}




\begin{tabular}{|c|c|c|c|c|c|c|c|c|}
\hline 132 & 5 & $9 / 24 / 2015$ & 3 & 113 & 5 & $10 / 22 / 2015$ & 4 & 132 \\
\hline 164 & 5 & $9 / 11 / 2014$ & 3 & 163 & 5 & $9 / 11 / 2014$ & 5 & 152 \\
\hline 104 & 5 & $5 / 3 / 2016$ & 2 & 104 & 7 & $7 / 6 / 2016$ & 2 & 107 \\
\hline 132 & 5 & $5 / 3 / 2016$ & 4 & 163 & 5 & $6 / 8 / 2016$ & 3 & 132 \\
\hline \multirow[t]{3}{*}{152} & 5 & $5 / 9 / 2016$ & 999 & 999 & 8 & $5 / 11 / 2016$ & 5 & 164 \\
\hline & & & & & & & & \\
\hline & & & & & & & & \\
\hline \multirow[t]{2}{*}{132} & 7 & $5 / 27 / 2015$ & 2 & 113 & 5 & $7 / 30 / 2015$ & 4 & 159 \\
\hline & & & & & & & & \\
\hline \multirow{2}{*}{\begin{tabular}{|l|}
107 \\
999
\end{tabular}} & 6 & & & & & & & \\
\hline & 8 & $10 / 5 / 2016$ & 4 & 104 & 5 & $11 / 14 / 2016$ & 4 & 152 \\
\hline \multirow[t]{2}{*}{163} & 5 & $12 / 29 / 2014$ & 999 & 999 & 9 & $1 / 14 / 2015$ & 999 & 999 \\
\hline & & & & & & & & \\
\hline & & & & & & & & \\
\hline \multirow[t]{2}{*}{999} & 8 & $3 / 14 / 2016$ & 3 & 104 & 5 & $5 / 11 / 2016$ & 4 & 159 \\
\hline & & & & & & & & \\
\hline 163 & 5 & $2 / 2 / 2017$ & 4 & 152 & 5 & $4 / 20 / 2017$ & 4 & 159 \\
\hline \multirow[t]{3}{*}{104} & 5 & $10 / 26 / 2016$ & 4 & 159 & 5 & $12 / 7 / 2016$ & 4 & 163 \\
\hline & & & & & & & & \\
\hline & & & & & & & & \\
\hline 132 & 6 & & & & & & & \\
\hline \multirow{2}{*}{\begin{tabular}{|l|}
104 \\
999
\end{tabular}} & 5 & $2 / 1 / 2017$ & 4 & 152 & 5 & $3 / 20 / 2017$ & 4 & 104 \\
\hline & 9 & $9 / 4 / 2014$ & 3 & 159 & 5 & $11 / 6 / 2014$ & 999 & 999 \\
\hline \multirow[t]{2}{*}{164} & 7 & $11 / 10 / 2014$ & 4 & 159 & 5 & $12 / 15 / 2014$ & 4 & 164 \\
\hline & & & & & & & & \\
\hline \multirow[t]{2}{*}{104} & 5 & $5 / 25 / 2017$ & 4 & 152 & 6 & & & \\
\hline & & & & & & & & \\
\hline 163 & 7 & $4 / 20 / 2017$ & 4 & 152 & 5 & $6 / 13 / 2017$ & 2 & 132 \\
\hline \multirow[t]{2}{*}{999} & 8 & $2 / 3 / 2016$ & 3 & 152 & 5 & $4 / 7 / 2016$ & 3 & 132 \\
\hline & & & & & & & & \\
\hline 152 & 5 & $1 / 17 / 2017$ & 4 & 163 & 6 & & & \\
\hline \multirow{2}{*}{\begin{tabular}{|l|}
152 \\
164
\end{tabular}} & 5 & $4 / 26 / 2016$ & 3 & 113 & 5 & $6 / 21 / 2016$ & 4 & 101 \\
\hline & 5 & $11 / 29 / 2016$ & 4 & 164 & 5 & $1 / 31 / 2017$ & 4 & 163 \\
\hline \multirow[t]{2}{*}{132} & 5 & $10 / 18 / 2016$ & 999 & 999 & 8 & $11 / 29 / 2016$ & 3 & 164 \\
\hline & & & & & & & & \\
\hline & & & & & & & & \\
\hline 132 & 5 & $12 / 20 / 2016$ & 999 & 999 & 8 & $2 / 21 / 2017$ & 5 & 163 \\
\hline 164 & 5 & $1 / 10 / 2017$ & 3 & 104 & 7 & $2 / 21 / 2017$ & 3 & 163 \\
\hline 163 & 5 & $12 / 20 / 2016$ & 3 & 113 & 5 & $1 / 31 / 2017$ & 4 & 132 \\
\hline & & & & & & & & \\
\hline & & & & & & & & \\
\hline & & & & & & & & \\
\hline & & & & & & & & \\
\hline & & & & & & & & \\
\hline & & & & & & & & \\
\hline & & & & & & & & \\
\hline
\end{tabular}




\begin{tabular}{|c|c|c|c|c|c|c|c|c|}
\hline $16-\mathrm{Tx}$ & 17 - Date & $17 \cdot \mathrm{OH}$ & 17 - Asst & $17-T x$ & 18-Date & $18-\mathrm{OH}$ & 18 - Asst & $18-\mathrm{Tx}$ \\
\hline & & & & & & & & \\
\hline & & & & & & & & \\
\hline & & & & & & & & \\
\hline 5 & $8 / 26 / 2015$ & 4 & 152 & 7 & $10 / 14 / 2015$ & 4 & 164 & 7 \\
\hline & & & & & & & & \\
\hline 5 & $11 / 2 / 2016$ & 4 & 164 & 7 & $12 / 14 / 2016$ & 3 & 152 & 5 \\
\hline & & & & & & & & \\
\hline & & & & & & & & \\
\hline & & & & & & & & \\
\hline 9 & $1 / 13 / 2017$ & 999 & 159 & 7 & $1 / 16 / 2017$ & 4 & 104 & 7 \\
\hline & & & & & & & & \\
\hline & & & & & & & & \\
\hline & & & & & & & & \\
\hline 5 & $1 / 18 / 2016$ & 999 & 999 & 8 & $2 / 24 / 2016$ & 3 & 164 & 7 \\
\hline & & & & & & & & \\
\hline 8 & $10 / 12 / 2016$ & 5 & 152 & 7 & $12 / 14 / 2016$ & 3 & 152 & 5 \\
\hline 5 & $8 / 3 / 2015$ & 4 & 163 & 5 & $10 / 21 / 2015$ & 4 & 104 & 5 \\
\hline 7 & $12 / 9 / 2015$ & 999 & 999 & 8 & $12 / 21 / 2015$ & 3 & 104 & 7 \\
\hline & & & & & & & & \\
\hline 9 & $12 / 12 / 2016$ & 4 & 164 & 5 & $2 / 27 / 2017$ & 4 & 152 & 5 \\
\hline 999 & $11 / 10 / 2016$ & 999 & 999 & 9 & $12 / 29 / 2016$ & 999 & 999 & 9 \\
\hline & & & & & & & & \\
\hline & & & & & & & & \\
\hline & & & & & & & & \\
\hline 8 & $7 / 29 / 2015$ & 999 & 999 & 8 & $8 / 12 / 2015$ & 999 & 999 & 8 \\
\hline & & & & & & & & \\
\hline 7 & $4 / 26 / 2016$ & 4 & 163 & 5 & $7 / 19 / 2016$ & 4 & 163 & 6 \\
\hline 5 & $4 / 19 / 2016$ & 999 & 999 & 9 & $5 / 24 / 2016$ & 4 & 159 & 7 \\
\hline & & & & & & & & \\
\hline & & & & & & & & \\
\hline 5 & $9 / 13 / 2016$ & 3 & 164 & 5 & $11 / 29 / 2016$ & 4 & 107 & 5 \\
\hline & & & & & & & & \\
\hline 9 & $6 / 7 / 2016$ & 999 & 999 & 9 & $8 / 9 / 2016$ & 4 & 113 & 7 \\
\hline 5 & $12 / 6 / 2016$ & 3 & 164 & 5 & $2 / 21 / 2017$ & 3 & 113 & 6 \\
\hline & & & & & & & & \\
\hline & & & & & & & & \\
\hline & & & & & & & & \\
\hline 5 & $1 / 31 / 2017$ & 999 & 999 & 9 & $2 / 7 / 2017$ & 4 & 159 & 5 \\
\hline & & & & & & & & \\
\hline 5 & $5 / 16 / 2017$ & 4 & 163 & 6 & & & & \\
\hline & & & & & & & & \\
\hline & & & & & & & & \\
\hline 5 & $2 / 7 / 2017$ & 4 & 104 & 5 & $4 / 4 / 2017$ & 4 & 107 & 5 \\
\hline & & & & & & & & \\
\hline & & & & & & & & \\
\hline 8 & $4 / 22 / 2015$ & 4 & 159 & 5 & $6 / 17 / 2015$ & 999 & 999 & 8 \\
\hline
\end{tabular}




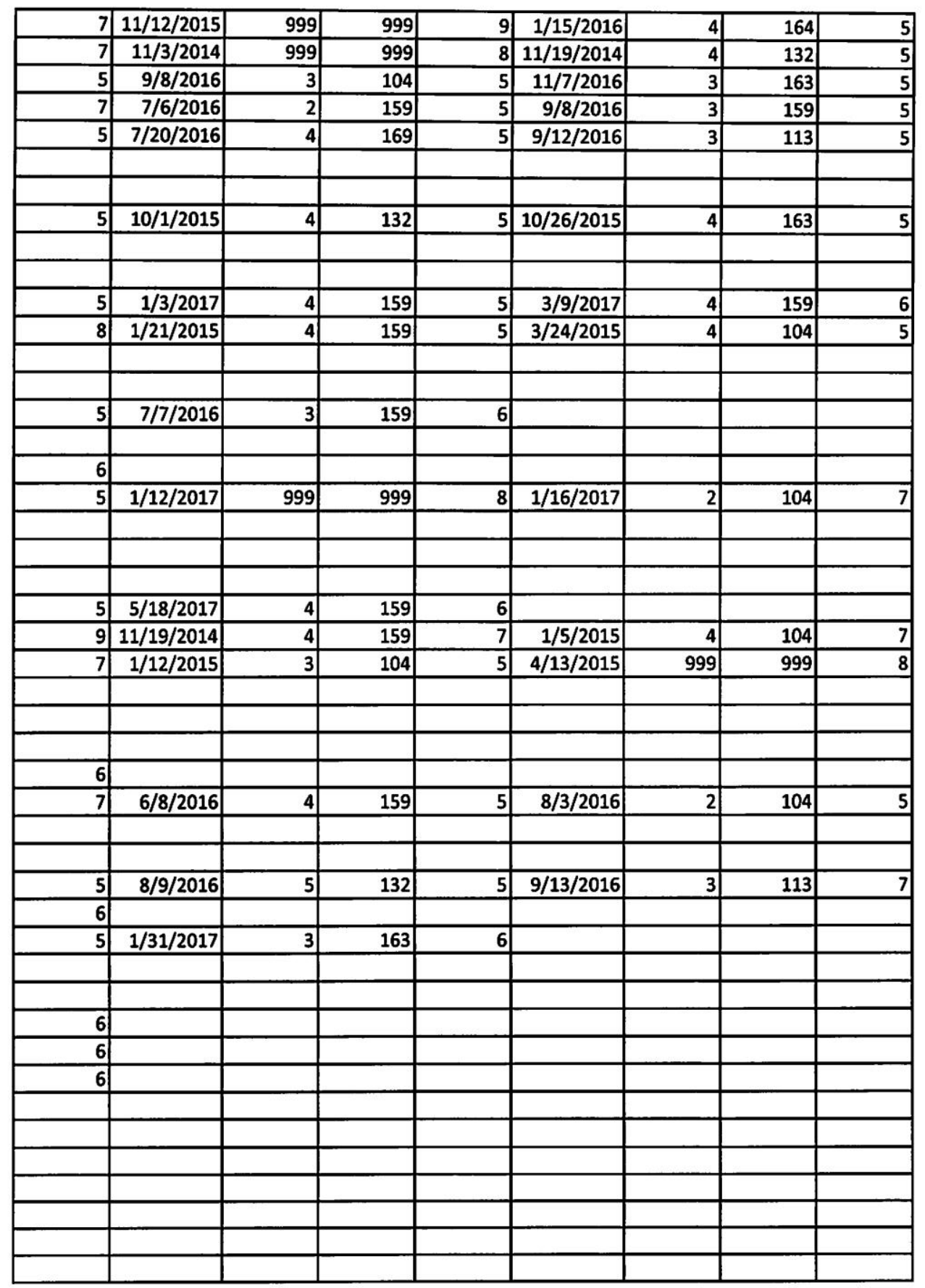




\begin{tabular}{|c|c|c|c|c|c|c|c|c|}
\hline 19 - Date & $19-\mathrm{OH}$ & 19 - Asst & $19-T x$ & 20 - Date & $20-\mathrm{OH}$ & 20 - Asst & $20-T x$ & 21 - Date \\
\hline & & & & & & & & \\
\hline & & & & & & & & \\
\hline & & & & & & & & \\
\hline $10 / 21 / 2015$ & 4 & 163 & 5 & $1 / 15 / 2016$ & 4 & 164 & 5 & $3 / 28 / 2016$ \\
\hline & & & & & & & & \\
\hline $2 / 16 / 2017$ & 2 & 159 & 6 & & & & & \\
\hline & & & & & & & & \\
\hline & & & & & & & & \\
\hline & & & & & & & & \\
\hline $2 / 23 / 2017$ & 4 & 159 & 6 & & & & & \\
\hline & & & & & & & & \\
\hline & & & & & & & & \\
\hline & & & & & & & & \\
\hline $2 / 26 / 2016$ & 4 & 152 & 7 & $5 / 3 / 2016$ & 4 & 152 & 5 & $5 / 9 / 2016$ \\
\hline & & & & & & & & \\
\hline $2 / 16 / 2017$ & 999 & 999 & 8 & $4 / 27 / 2017$ & 4 & 152 & 6 & \\
\hline $1 / 11 / 2016$ & 5 & 104 & 5 & $3 / 10 / 2016$ & 999 & 999 & 8 & $3 / 28 / 2016$ \\
\hline $1 / 4 / 2016$ & 2 & 132 & 5 & $3 / 3 / 2016$ & 999 & 999 & 9 & $5 / 26 / 2016$ \\
\hline & & & & & & & & \\
\hline $5 / 11 / 2017$ & 3 & 164 & 6 & & & & & \\
\hline $3 / 2 / 2017$ & 999 & 999 & 9 & $5 / 11 / 2017$ & 3 & 159 & 6 & \\
\hline & & & & & & & & \\
\hline & & & & & & & & \\
\hline & & & & & & & & \\
\hline $9 / 28 / 2015$ & 3 & 104 & 5 & $12 / 9 / 2015$ & 999 & 999 & 8 & $2 / 12 / 2016$ \\
\hline & & & & & & & & \\
\hline & & & & & & & & \\
\hline $6 / 21 / 2016$ & 999 & 999 & 9 & $8 / 23 / 2016$ & 3 & 113 & 5 & $10 / 18 / 2016$ \\
\hline & & & & & & & & \\
\hline & & & & & & & & \\
\hline $1 / 31 / 2017$ & 4 & 132 & 6 & & & & & \\
\hline & & & & & & & & \\
\hline $10 / 4 / 2016$ & 4 & 152 & 5 & $12 / 6 / 2016$ & 3 & 107 & 5 & $2 / 14 / 2017$ \\
\hline & & & & & & & & \\
\hline & & & & & & & & \\
\hline & & & & & & & & \\
\hline & & & & & & & & \\
\hline $4 / 4 / 2017$ & 3 & 163 & 6 & & & & & \\
\hline & & & & & & & & \\
\hline & & & & & & & & \\
\hline & & & & & & & & \\
\hline & & & & & & & & \\
\hline $6 / 6 / 2017$ & 2 & 107 & 6 & & & & & \\
\hline & & & & & & & & \\
\hline & & & & & & & & \\
\hline $7 / 29 / 2015$ & 4 & 132 & 5 & $8 / 12 / 2015$ & 3 & 113 & 5 & $8 / 17 / 2015$ \\
\hline
\end{tabular}




\begin{tabular}{|c|c|c|c|c|c|c|c|c|}
\hline $3 / 30 / 2016$ & 4 & 163 & 5 & $6 / 16 / 2016$ & 3 & 159 & 7 & $8 / 3 / 2016$ \\
\hline $2 / 4 / 2015$ & 4 & 107 & 5 & $4 / 16 / 2015$ & 4 & 113 & 5 & $6 / 10 / 2015$ \\
\hline $1 / 3 / 2017$ & 3 & 104 & 6 & & & & & \\
\hline $11 / 3 / 2016$ & 2 & 104 & 5 & $1 / 3 / 2017$ & 3 & 159 & 6 & \\
\hline $10 / 3 / 2016$ & 2 & 152 & 7 & $11 / 7 / 2016$ & 3 & 113 & 5 & $1 / 3 / 2017$ \\
\hline & & & & & & & & \\
\hline & & & & & & & - & \\
\hline $12 / 22 / 2015$ & 999 & 999 & 8 & $1 / 4 / 2016$ & 3 & 132 & 5 & $3 / 31 / 2016$ \\
\hline & & & & & & & & \\
\hline & & & & & & & & \\
\hline & & & & & & & & \\
\hline $5 / 13 / 2015$ & 4 & 132 & 5 & $7 / 20 / 2015$ & 3 & 159 & 5 & $9 / 24 / 2015$ \\
\hline & & & & & & & & \\
\hline & & & & & & & & \\
\hline & & & & & & & & \\
\hline & & & & & & & & \\
\hline & & & & & & & & \\
\hline $2 / 8 / 2017$ & 999 & 999 & 8 & $2 / 15 / 2017$ & 3 & 159 & 5 & $4 / 27 / 2017$ \\
\hline & & & & & & & & \\
\hline & & & & & & & & \\
\hline & & & & & & & & \\
\hline & & & & & & & & \\
\hline $1 / 15 / 2015$ & 999 & 999 & 8 & $2 / 18 / 2015$ & 999 & 999 & 9 & $3 / 23 / 2015$ \\
\hline $4 / 27 / 2015$ & 4 & 163 & 5 & $6 / 24 / 2015$ & 4 & 163 & 5 & $8 / 26 / 2015$ \\
\hline & & & & & & & & \\
\hline & & & & & & & & \\
\hline & & & & & & & & \\
\hline & & & & & & & & \\
\hline $10 / 3 / 2016$ & 4 & 152 & 5 & $11 / 16 / 2016$ & 4 & 159 & 5 & $12 / 28 / 2016$ \\
\hline & & & & & & & . & \\
\hline & & & & & & & - & \\
\hline $11 / 1 / 2016$ & 4 & 163 & 5 & $1 / 17 / 2017$ & 5 & 163 & 6 & \\
\hline & & & & & & & & \\
\hline & & & & & & & & \\
\hline & & & & & & & & \\
\hline & & & & & & & & \\
\hline & & & & & & & & \\
\hline & & & & & & & & \\
\hline & & & & & & & & \\
\hline & & & & & & & & \\
\hline & & & & & & & & \\
\hline & & & & & & & & \\
\hline & & & & & & & & \\
\hline & & & & & & & & \\
\hline & & & & & & & & \\
\hline & & & & & & & & \\
\hline
\end{tabular}




\begin{tabular}{|c|c|c|c|c|c|c|c|c|}
\hline $21-\mathrm{OH}$ & 21 - Asst & $21-T x$ & 22 - Date & $22-\mathrm{OH}$ & 22 - Asst & $22-T x$ & 23-Date & $23-\mathrm{OH}$ \\
\hline & & & & & & & & \\
\hline & & & & & & & & \\
\hline & & & & & & & & \\
\hline 3 & 113 & 5 & $6 / 29 / 2016$ & 2 & 104 & 5 & $9 / 21 / 2016$ & 3 \\
\hline & & & & & & & & \\
\hline & & & & & & & & \\
\hline & & & & & & & & \\
\hline & & & & & & & & \\
\hline & & & & & & & & \\
\hline & & & & & & & & \\
\hline & & & & & & & & \\
\hline & & & & & & & & \\
\hline & & & & & & & & \\
\hline 999 & 999 & 8 & $8 / 1 / 2016$ & 3 & 113 & 7 & $10 / 17 / 2016$ & 999 \\
\hline & & & & & & & & \\
\hline & & & & & & & & \\
\hline 3 & 113 & 5 & $5 / 25 / 2016$ & 999 & 999 & 9 & $7 / 21 / 2016$ & 999 \\
\hline 999 & 999 & 8 & $6 / 22 / 2016$ & 3 & 159 & 5 & $10 / 5 / 2016$ & 3 \\
\hline & & & & & & & & \\
\hline & & & & & & & & \\
\hline & & & & & & & & \\
\hline & & & & & & & & \\
\hline & & & & & & & & \\
\hline & & & & & & & & \\
\hline 999 & 999 & 9 & $6 / 29 / 2016$ & 4 & 113 & 7 & $7 / 27 / 2016$ & 999 \\
\hline & & & & & & & & \\
\hline & & & & & & & & \\
\hline 3 & 113 & 5 & $1 / 10 / 2017$ & 3 & 163 & 6 & & \\
\hline & & & & & & & & \\
\hline & & & & & & & & \\
\hline & & & & & & & & \\
\hline & & & & & & & & \\
\hline 999 & 999 & 8 & $2 / 21 / 2017$ & 3 & 163 & 6 & & \\
\hline & & & & & & & & \\
\hline & & & & & & & & \\
\hline & & & & & & & & \\
\hline & & & & & & & & \\
\hline & & & & & & & & \\
\hline & & & & & & & & \\
\hline & & & & & & & & \\
\hline & & & & & & & & \\
\hline & & & & & & & & \\
\hline & & & & & & & & \\
\hline & & & & & & & & \\
\hline & & & & & & & & \\
\hline 999 & 999 & 8 & $10 / 22 / 2015$ & 4 & 152 & 5 & $12 / 17 / 2015$ & 4 \\
\hline
\end{tabular}




\begin{tabular}{|c|c|c|c|c|c|c|c|c|}
\hline 2 & 169 & 5 & $10 / 3 / 2016$ & 4 & 159 & 5 & $11 / 14 / 2016$ & 4 \\
\hline 4 & 159 & 6 & & & & & & \\
\hline & & & & & & & & \\
\hline & & & & & & & & \\
\hline 4 & 107 & 6 & & & & & & \\
\hline & & & & & & & & \\
\hline & & & & & & & & \\
\hline 4 & 132 & 5 & $6 / 6 / 2016$ & 5 & 152 & 5 & $8 / 8 / 2016$ & 4 \\
\hline & & & & & & & & \\
\hline & & & & & & & & \\
\hline & & & & & & & & \\
\hline 4 & 104 & 5 & $11 / 16 / 2015$ & 999 & 999 & 9 & $12 / 9 / 2015$ & 4 \\
\hline & & & & & & & & \\
\hline & & & & & & & & \\
\hline & & & & & & & & \\
\hline & & & & & & & & \\
\hline & & & & & & & & \\
\hline 4 & 152 & 6 & & & & & & \\
\hline & & & & & & & & \\
\hline & & & & & & & & \\
\hline & & & & & & & & \\
\hline & & & & & & & & \\
\hline 4 & 163 & 7 & $4 / 15 / 2015$ & 999 & 999 & 8 & $6 / 1 / 2015$ & 3 \\
\hline 999 & 999 & 8 & $9 / 2 / 2015$ & 3 & 104 & 5 & $10 / 12 / 2015$ & 4 \\
\hline & & & & & & & & \\
\hline & & & & & & & & \\
\hline & & & & & & & & \\
\hline & & & & & & & & \\
\hline 4 & 132 & 5 & $2 / 20 / 2017$ & 4 & 152 & 5 & $4 / 19 / 2017$ & 4 \\
\hline & & & & & & & & \\
\hline & & & & & & & & \\
\hline & & & & & & & & \\
\hline & & & & & & & & \\
\hline & & & & & & & & \\
\hline & & & & & & & & \\
\hline & & & & & & & & \\
\hline & & & & & & & & \\
\hline & & & & & & & & \\
\hline & & & & & & & & \\
\hline & & & & & & & & \\
\hline & & & & & & & & \\
\hline & & & & & & & & \\
\hline & & & & & & & & \\
\hline & & & & & & & & \\
\hline & & & & & & & & \\
\hline & & & & & & & & \\
\hline
\end{tabular}




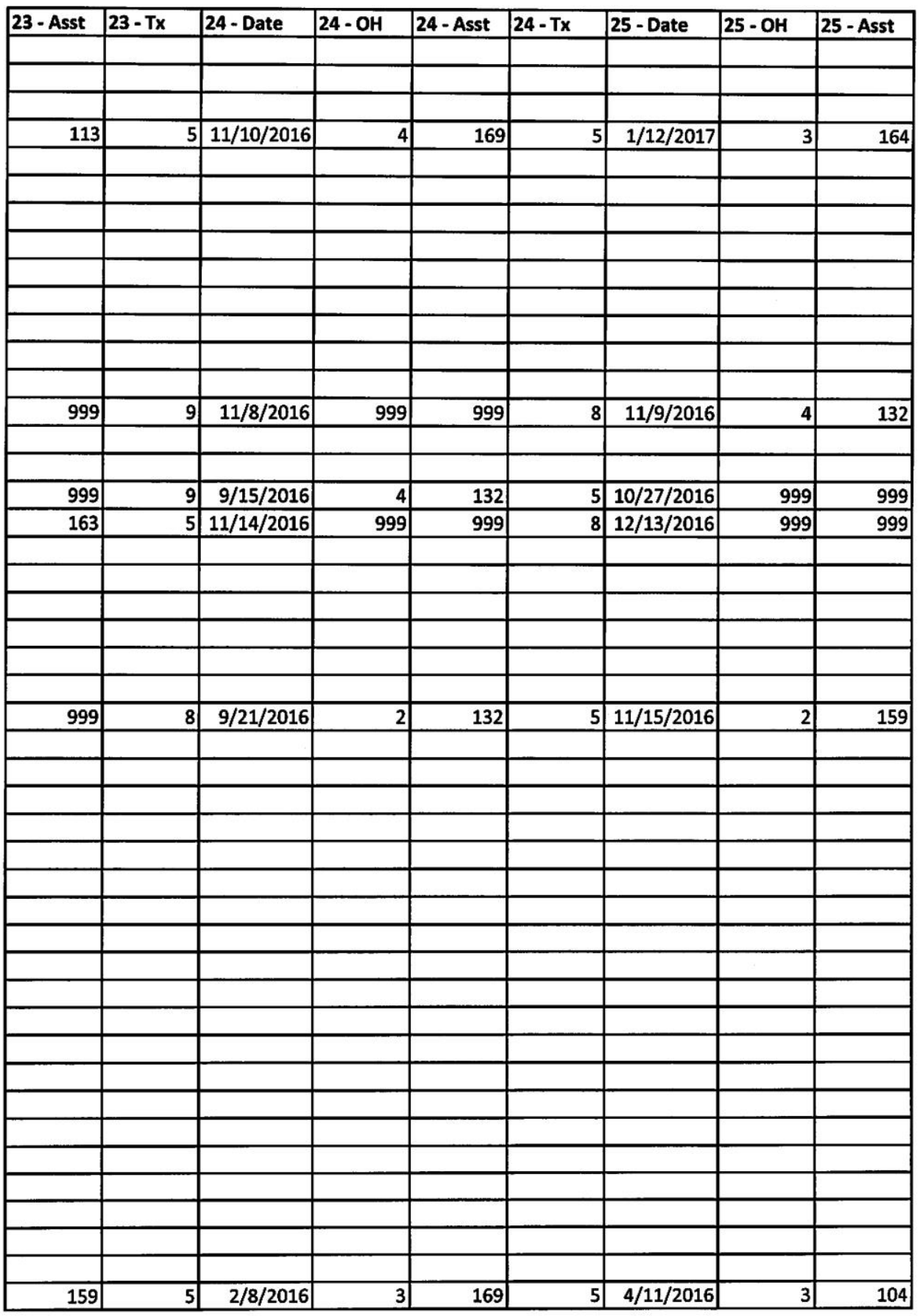




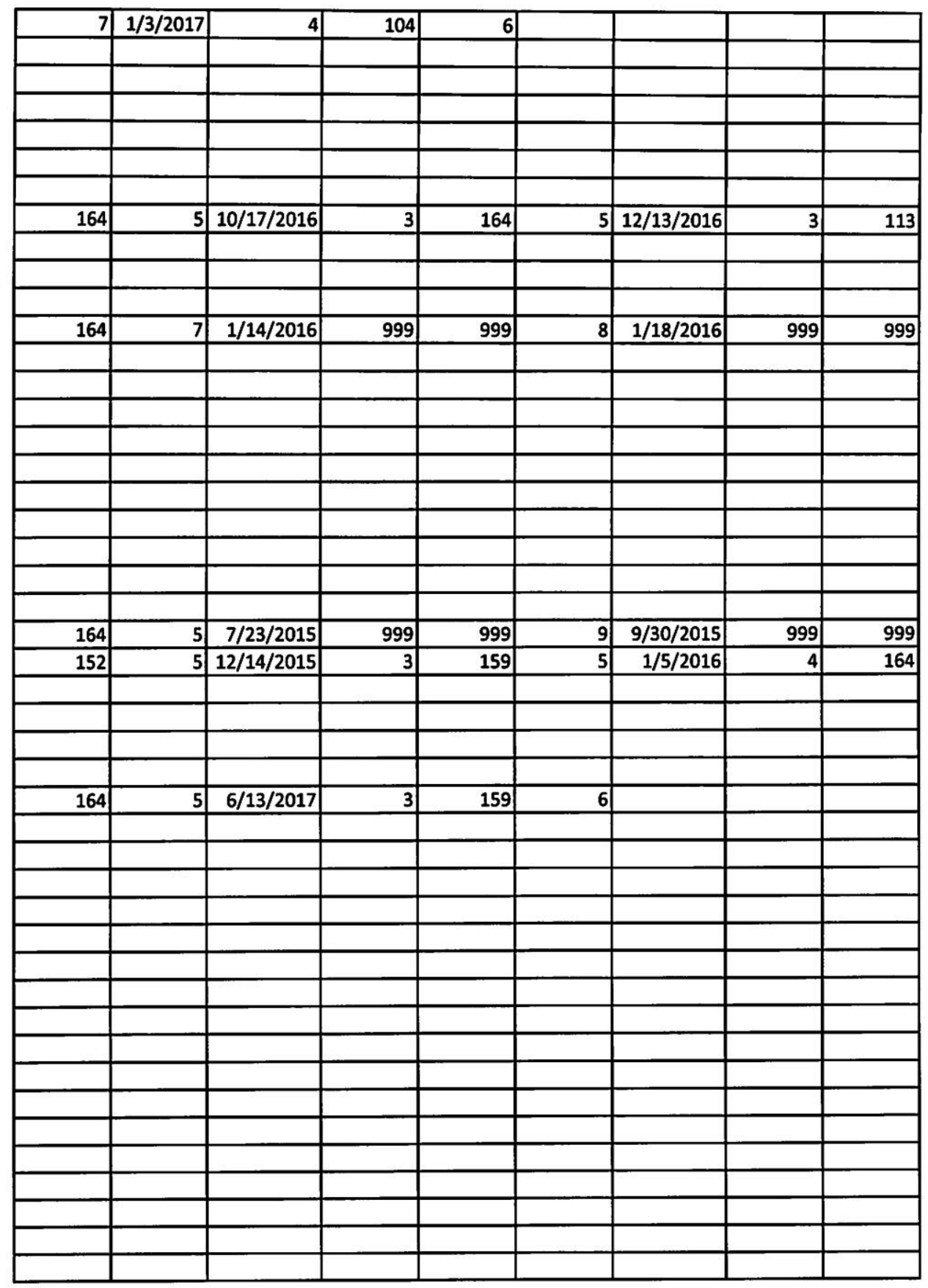




\begin{tabular}{|c|c|c|c|c|c|c|c|c|}
\hline $25-T x$ & 26-Date & $26-\mathrm{OH}$ & 26 - Asst & $26-T x$ & 27-Date & $27-\mathrm{OH}$ & 27 -Asst & $27-T x$ \\
\hline & & & & & & & & \\
\hline & & & & & & & & \\
\hline & & & & & & & & \\
\hline$\underline{6}$ & & & & & & & & \\
\hline & & & & & & & & \\
\hline & & & & & & & & \\
\hline & & & & & & & & \\
\hline & & & & & & & & \\
\hline & & & & & & & & \\
\hline & & & & & & & & \\
\hline & & & & & & & & \\
\hline & & & & & & & & \\
\hline & & & & & & & & \\
\hline 5 & $1 / 16 / 2017$ & 4 & 164 & 5 & $4 / 6 / 2017$ & 5 & 152 & $\underline{6}$ \\
\hline & & & & & & & & \\
\hline & & & & & & & & \\
\hline 9 & $11 / 10 / 2016$ & 5 & 159 & 5 & $12 / 15 / 2016$ & 5 & 152 & 5 \\
\hline 9 & $2 / 23 / 2017$ & 999 & 999 & 8 & $5 / 3 / 2017$ & 2 & 132 & 7 \\
\hline & & & & & & & & \\
\hline & & & & & & & & \\
\hline & & & & & & & & \\
\hline & & & & & & & & \\
\hline & & & & & & & & \\
\hline & & & & & & & & \\
\hline 5 & $2 / 6 / 2017$ & 1 & 104 & 5 & $4 / 24 / 2017$ & 2 & 132 & 5 \\
\hline & & & & & & & & \\
\hline & & & & & & & & \\
\hline & & & & & & & & \\
\hline & & & & & & & & \\
\hline & & & & & & & & \\
\hline & & & & & & & & \\
\hline & & & & & & & & \\
\hline & & & & & & & & \\
\hline & & & & & & & & \\
\hline & & & & & & & & \\
\hline & & & & & & & & \\
\hline & & & & & & & & \\
\hline & & & & & & & & \\
\hline & & & & & & & & \\
\hline & & & & & & & & \\
\hline & & & & & & & & \\
\hline & & & & & & & & \\
\hline & & & & & & & & \\
\hline & & & & & & & & \\
\hline & & & & & & & & \\
\hline 5 & $6 / 6 / 2016$ & 4 & 159 & 5 & $8 / 1 / 2016$ & 3 & 113 & 5 \\
\hline
\end{tabular}




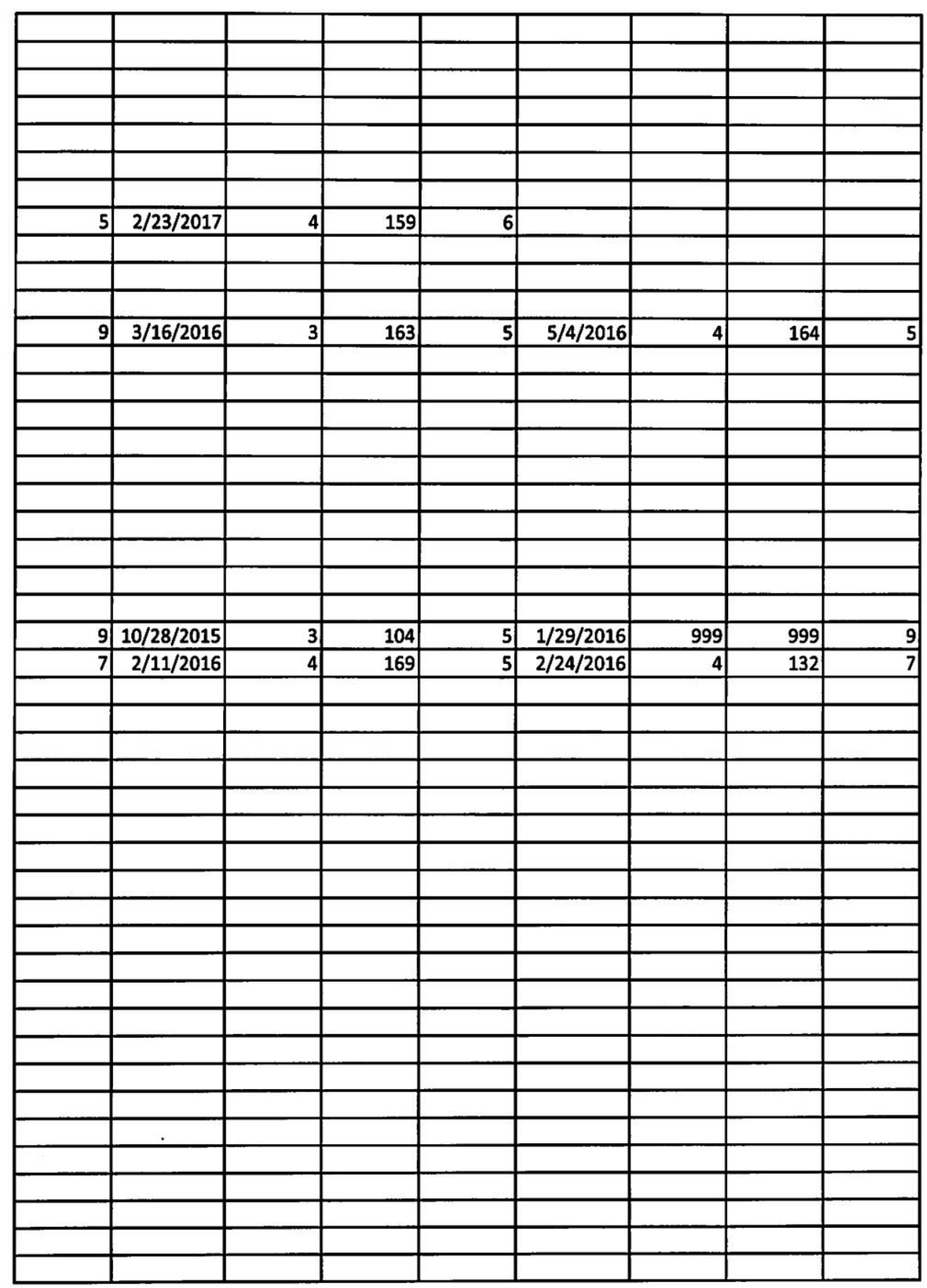




\begin{tabular}{|c|c|c|c|c|c|c|c|c|}
\hline 28 -Date & $28-\mathrm{OH}$ & 28 - Asst & $28-T x$ & 29-Date & $29 . \mathrm{OH}$ & $29-$ Asst & $29-T x$ & 30 -Date \\
\hline & & & & & & & & \\
\hline & & & & & & & & \\
\hline & & & & & & & & \\
\hline & & & & & & & & \\
\hline & & & & & & & & \\
\hline & & & & & & & & \\
\hline & & & & & & & & \\
\hline & & & & & & & & \\
\hline & & & & & & & & \\
\hline & & & & & & & & \\
\hline & & & & & & & & \\
\hline & & & & & & & & \\
\hline & & & & & & & & \\
\hline & & & & & & & & \\
\hline & & & & & & & $\longrightarrow$ & \\
\hline $2 / 16 / 2017$ & 4 & 152 & & \begin{tabular}{|l|}
$4 / 27 / 2017$ \\
\end{tabular} & 3 & 159 & 6 & \\
\hline & & & & & & & & \\
\hline & & & & & & & & \\
\hline & & & & & & 1 & & \\
\hline & & & & & & 1 & & \\
\hline & & & & & & & & \\
\hline & & & & & & & & \\
\hline $5 / 3 / 2017$ & 2 & 104 & $\underline{5}$ & $6 / 5 / 2017$ & 2 & 113 & 6 & \\
\hline & & & & & & & & \\
\hline & & & & & & $\perp$ & & \\
\hline & & & & & & & & \\
\hline & & & & & & & & \\
\hline & & & & & & & & \\
\hline & & & & & & & & \\
\hline & & & & & & & & \\
\hline & & & & & & & & \\
\hline & & & & & & & & \\
\hline & & & & & & & & \\
\hline & & & & & & & & \\
\hline & & & & & & & & \\
\hline & & & & & & & & \\
\hline & & & & & - & - & & \\
\hline & & & & & & & & \\
\hline & & & & & & & & \\
\hline & & & & & & & & \\
\hline 9/19/2016 & 4 & 159 & 5 & 9/21/2016 & 999 & 999 & 8 & $11 / 10 / 2016$ \\
\hline
\end{tabular}




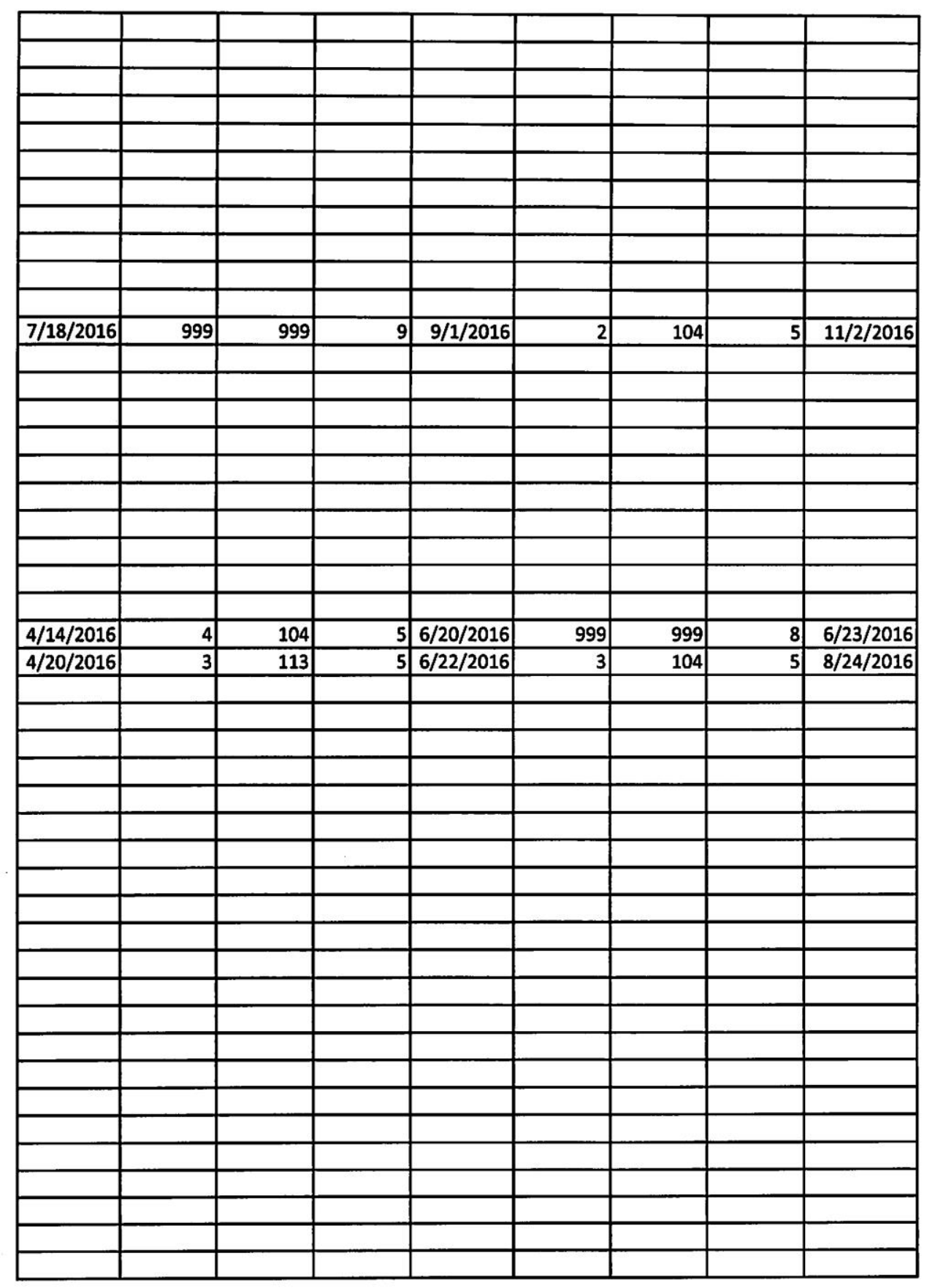




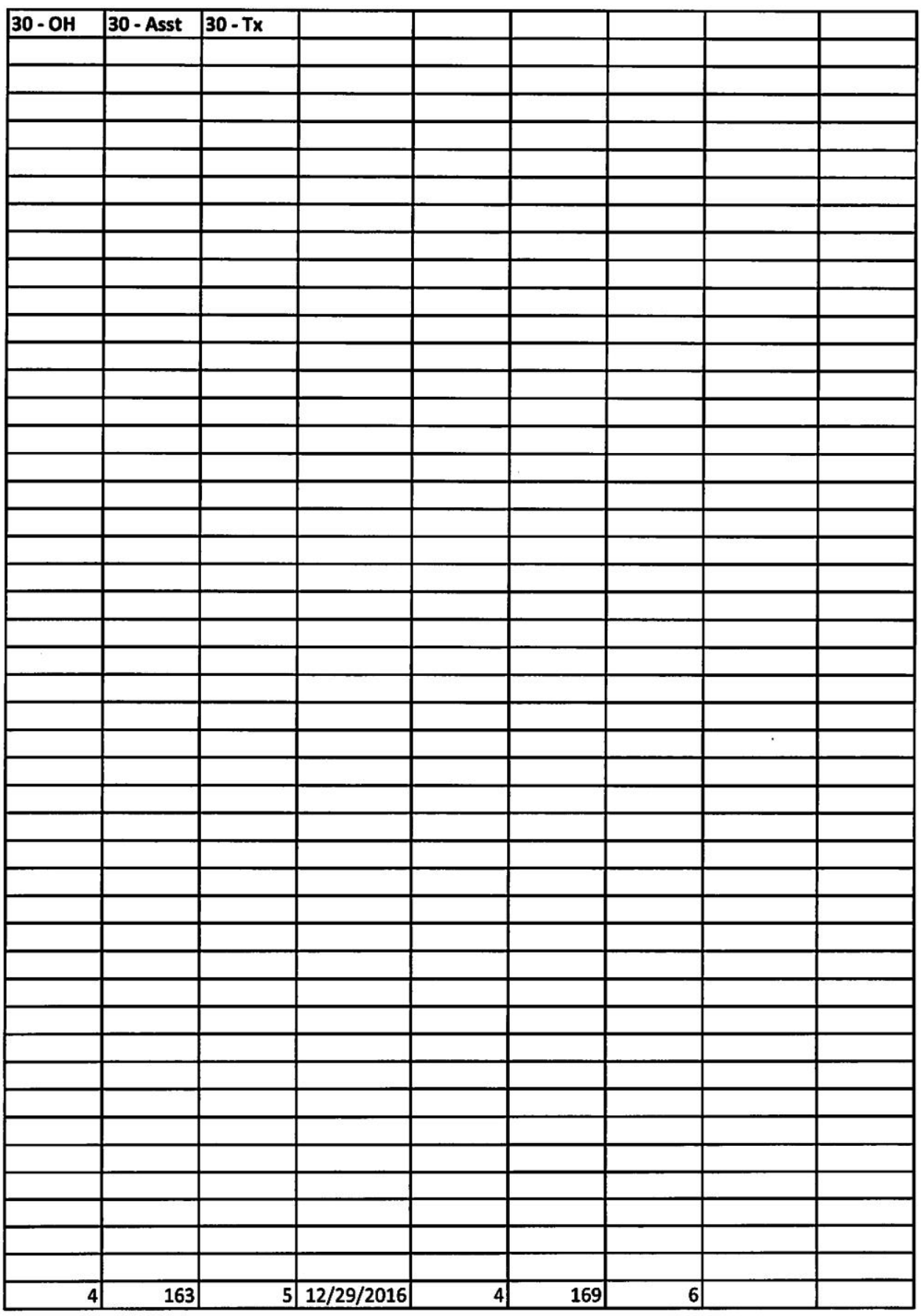




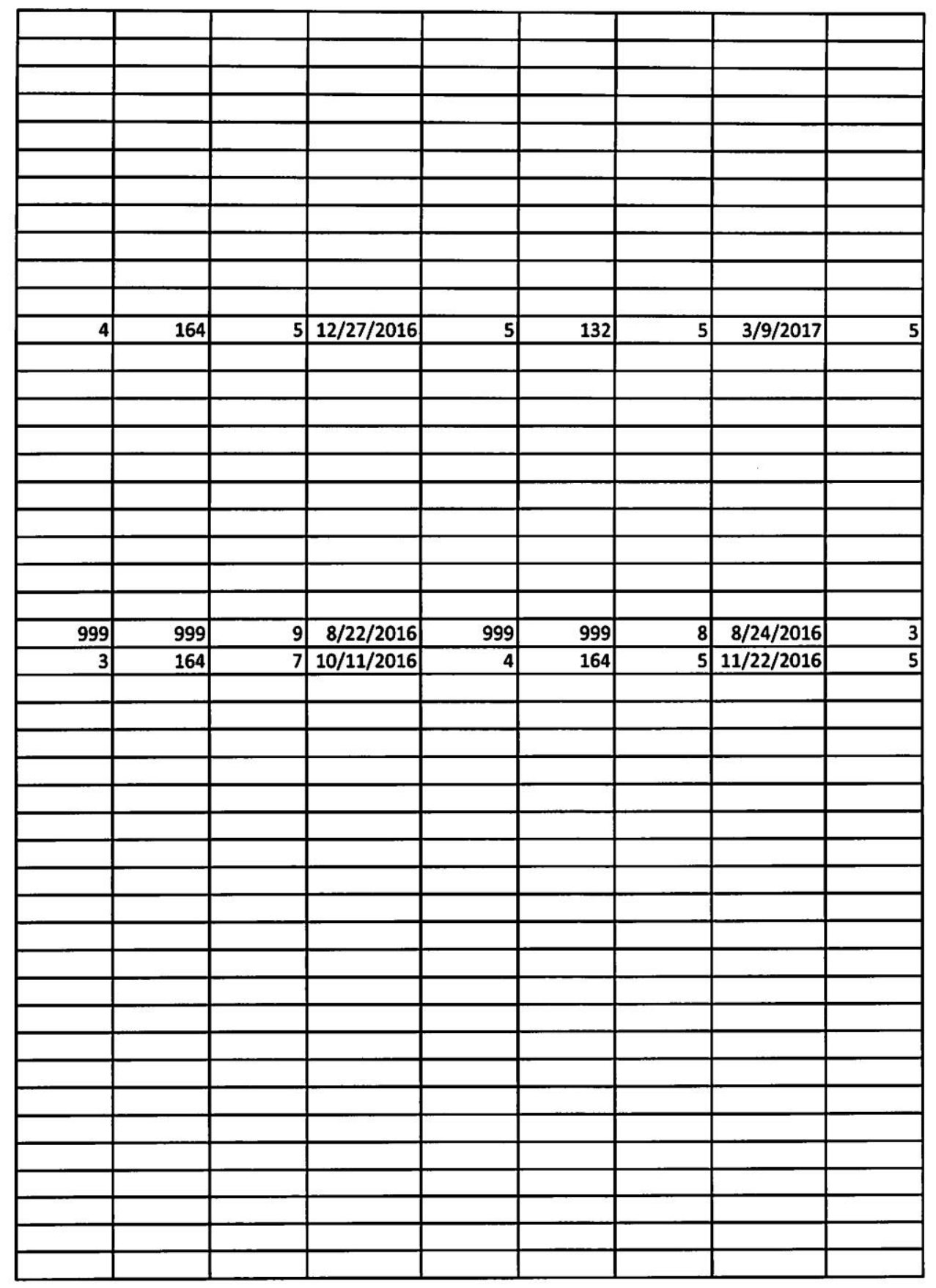




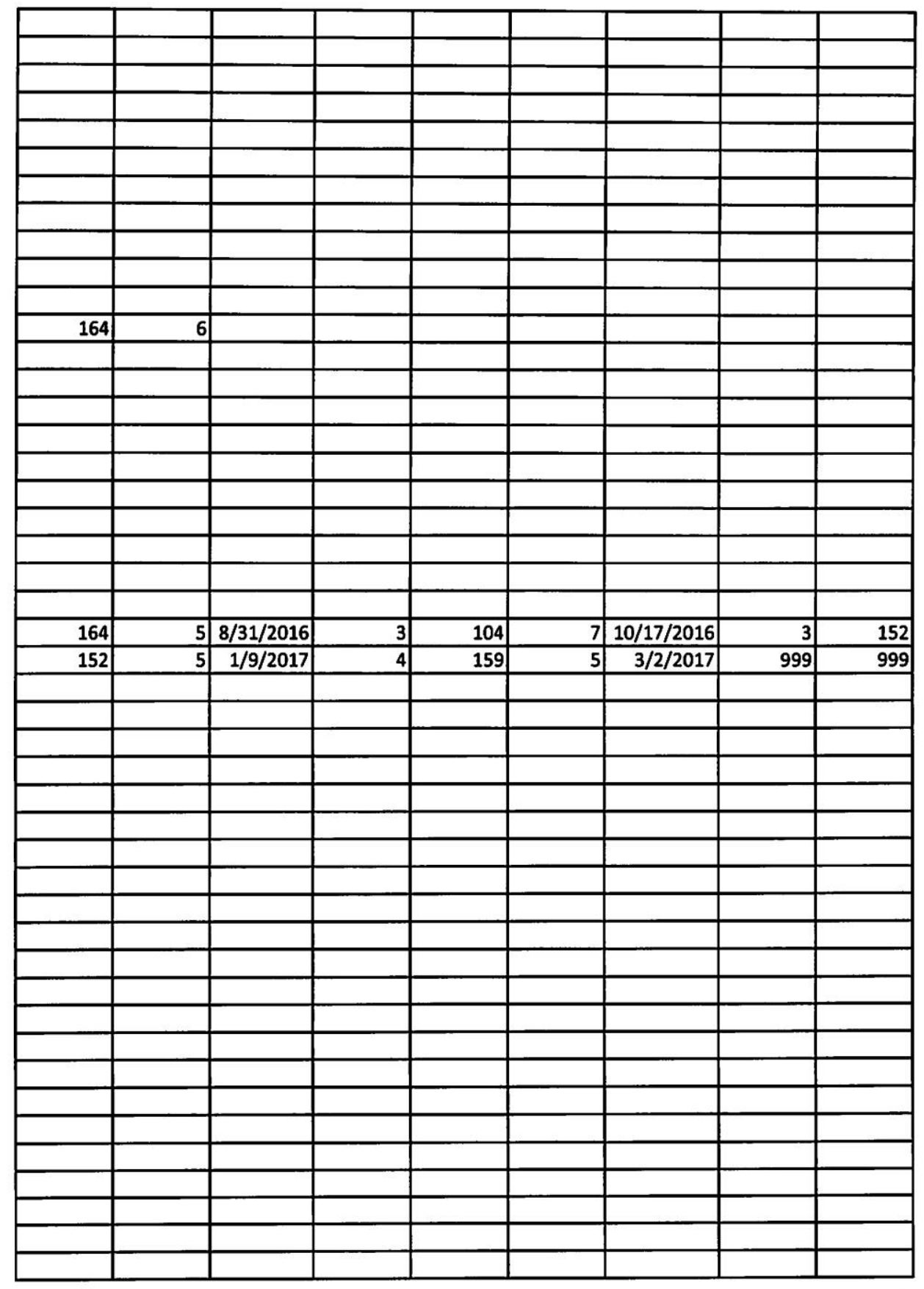




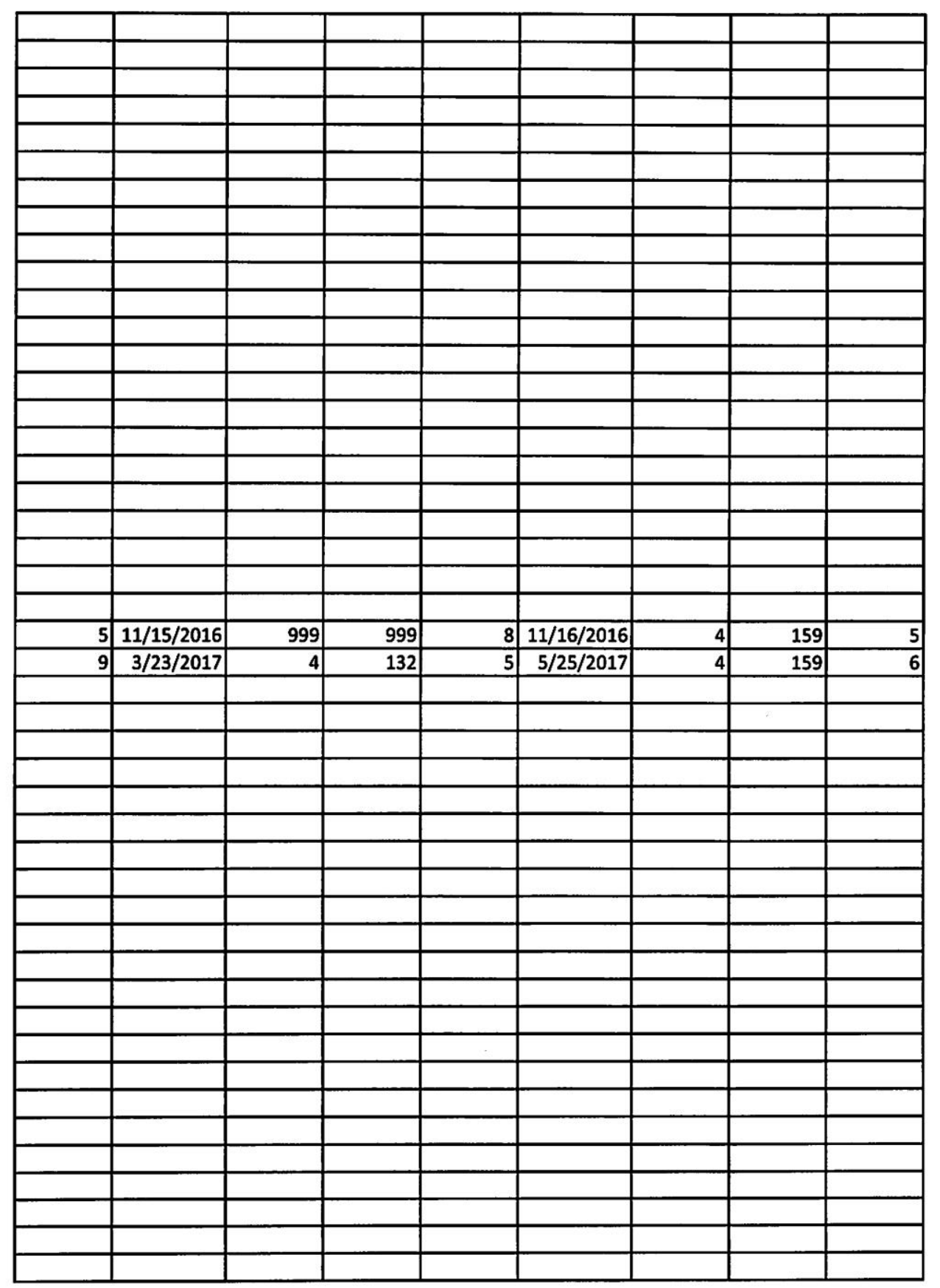




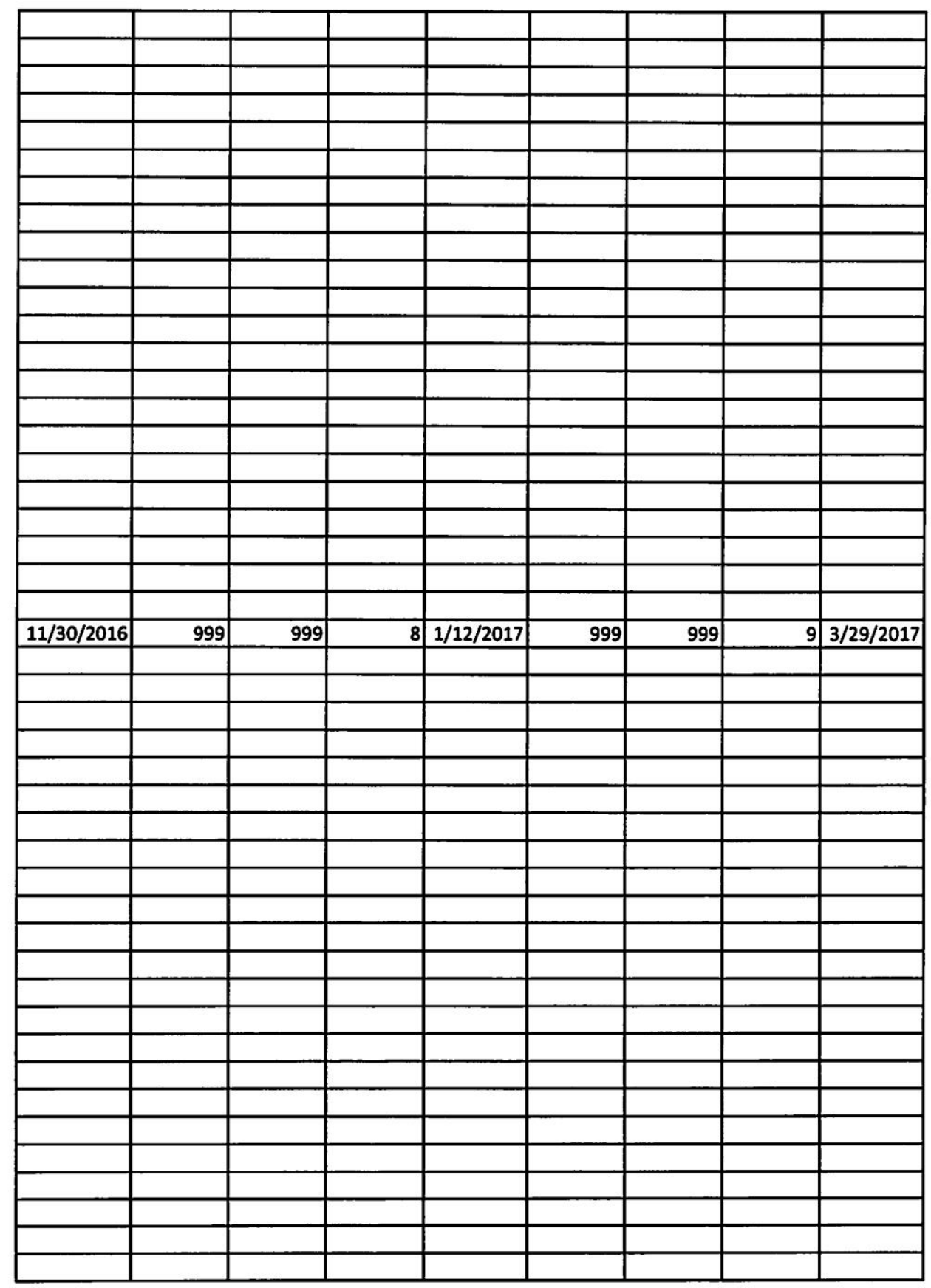




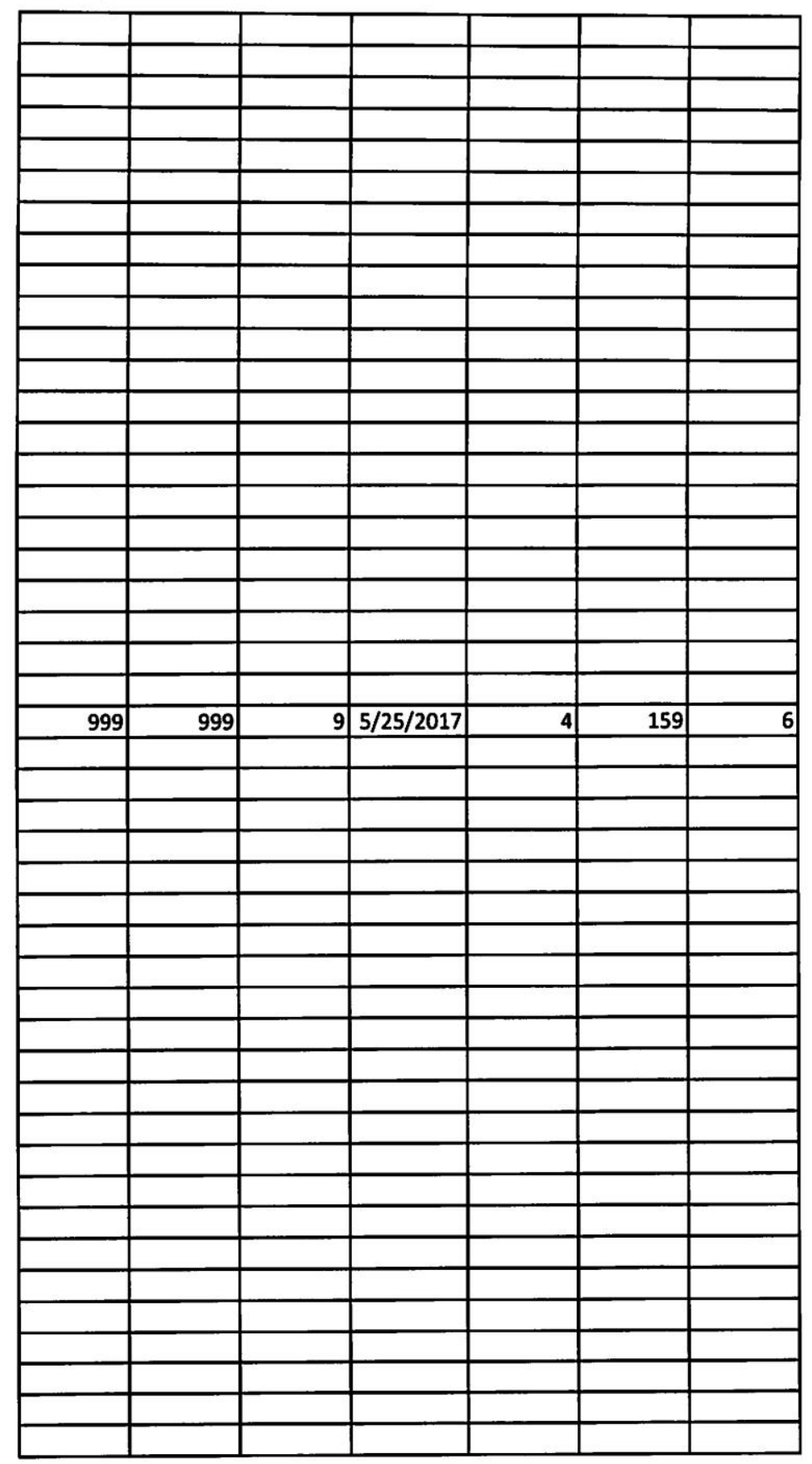

